CENTRO UNIVERSITÁRIO FEI

RODRIGO PASIANI COSTA

SIMULAÇÃO DE TEMPO DE VOLTA DE VEÍCULO FÓRMULA SAE COM MODELO QUASI-STEADY STATE

São Bernardo do Campo

2016 
RODRIGO PASIANI COSTA

\section{SIMULAÇÃO DE TEMPO DE VOLTA DE VEÍCULO FÓRMULA SAE COM MODELO QUASI-STEADY STATE}

Dissertação de Mestrado apresentada ao Centro Universitário FEI para obtenção do título de Mestre em Engenharia Mecânica. Orientado pelo Prof. Dr. Roberto Bortolussi.

São Bernardo do Campo 2016 
Pasiani Costa, Rodrigo.

SIMULAÇÃO DE TEMPO DE VOLTA DE VEÍCULO FÓRMULA SAE COM MODELO QUASI-STEADY STATE / Rodrigo Pasiani Costa São Bernardo do Campo, 2016.

122 p. : il

Dissertação - Centro Universitário FEI.

Orientador: Prof. Dr. Roberto Bortolussi

1. Simulação de tempo de volta. 2 . Modelo quasi-steady state. 3 . Fórmula SAE. I. Bortolussi, Roberto, orient. II Título.

Elaborada pelo sistema de geração automática de ficha catalográfica da FEI com os dados formecidos pelo(a) autor(a). 
Título do Trabalho: Simulação de tempo de volta de veículo fórmula SAE com modelo quasi-steady state

Área de Concentração: Sistemas da Mobilidade

Orientador: Prof. Dr. Roberto Bortolussi

Data da realização da defesa: 25/02/2016

ORIGINAL ASSINADA

Avaliação da Banca Examinadora:

São Bernardo do Campo,

\section{MEMBROS DA BANCA EXAMINADORA}

Prof. Dr. Roberto Bortolussi

Ass.:

Prof. Dr. Marko Ackermann

Ass.:

Dr. Claudio Gomes Fernandes

Ass.:

A Banca Julgadora acima-assinada atribuiu ao aluno o seguinte resultado:

APROVADO $\square$

REPROVADO $\square$

\section{YERSÃO FINALDADISSERTACÃO}

APROVO A VERSÃO FINAL DA DISSERTAÇ̃̃O EM QUE FORAM INCLUUIDAS AS RECOMENDACOÓES DA BANCA EXAMIINADORA
Aprovaçäo do Coordenador do Programa de Pós-graduaçăo

Prof. Dr. Rodrigo Magnabosco 
A minha família e namorada, que me apoiaram incondicionalmente, e aos meus amigos, que acreditaram em mim. 


\section{AGRADECIMENTOS}

Agradeço primeiramente ao meu orientador Professor Dr. Roberto Bortolussi, pela indicação do tema e pelo suporte ao longo de todo o desenvolvimento desta obra.

Não poderia deixar de agradecer a meus pais, Sr. Dorival e Sra. Maria Ildes, e à minha namorada Camila, que me apoiaram nesta jornada tão cansativa quanto prazerosa.

Sou grato também aos professores do Centro Universitário FEI, e aos colegas de trabalho da Mercedes-Benz do Brasil, especialmente a José Saraiva, Luís Ericsson e Daniel Luna. Não poderia omitir a ajuda de meu amigo Eng. Paulo Tonetto, pelo suporte e tempo concedidos.

Agradeço ainda a toda a equipe Fórmula FEI pelo suporte e atenção prestados.

Por último, agradeço a PROSUP/CAPES e ao Centro Universitário FEI, pois juntos me contemplaram com uma Bolsa Taxa, que seguramente foi de grande valia. 
"Para mim, é muito melhor compreender o universo como ele realmente é do que persistir no engano, por mais satisfatório e tranquilizador que possa parecer."

Carl Sagan 


\section{RESUMO}

Cada vez mais as equipes de competição têm recorrido a ferramentas computacionais para desenvolver seus veículos, visando redução de custos com protótipos e testes físicos, bem como tempo de desenvolvimento. O simulador de tempo de volta é uma das ferramentas utilizadas, indispensável em categorias de topo, como a Fórmula 1, Indy e Le Mans. Ele permite estimar o tempo de volta de um veículo em uma pista. O presente trabalho lançou mão de um simulador de tempo de volta do tipo quasi-steady state destinado à categoria Fórmula SAE para simular o protótipo RS8 do Centro Universitário FEI e validou o resultado com base em tempos de volta em competição. Uma vez validado o modelo, simulou-se o novo protótipo RS9 para prever seu desempenho. O objetivo é modelar os veículos RS8 e RS9, e as pistas da competição, de forma a comparar os desempenhos. Em trabalhos futuros, poderão ser simuladas diferentes configurações do veículo para analisar quais delas efetivamente reduzem o tempo de volta, direcionando e otimizando os testes físicos.

Foram criados dois modelos de veículo, com base em dados teóricos e empíricos fornecidos pela equipe Fórmula FEI. Por exemplo, a curva característica do motor foi levantada em dinamômetro, enquanto que os coeficientes aerodinâmicos foram determinados em simulação computacional de fluidodinâmica (CFD). Também foram gerados modelos de pistas de aceleração, skid-pad e autocross da etapa de Michigan de 2014 do circuito da Fórmula SAE.

O programa adotado, OptimumLap, é de código fechado. Não tendo acesso às equações do movimento, um código de MATLAB foi criado para validar o cálculo da aceleração partindo do repouso, permitindo determinar as equações empregadas pelo simulador de tempo de volta.

Determinadas as equações dinâmicas empregadas no programa OptimumLap, os resultados teóricos foram confrontados com os tempos das voltas da prova de Michigan 2014, para validação do modelo. Após a validação do modelo do veículo RS8, foram feitas as simulações das provas de Michigan 2014 com o novo protótipo RS9, finalizando o presente trabalho comparando os resultados e frisando as diferenças entre os dois veículos.

Palavras-chave: simulação de tempo de volta. Modelo quasi-steady state. Fórmula SAE. 


\begin{abstract}
Racing teams have increasingly adopted computational tools to develop their vehicles, in order to reduce costs with prototypes and physical tests, as well as development time. Lap time simulator (LTS) is one of the employed tools, indispensable in top categories, as Formula 1, Indy and Le Mans. It allows to estimate lap time for a given vehicle setup. Current work made use of a Formula SAE oriented lap time simulator that uses a quasi-steady state method to simulate RS8 prototype, from Centro Universitário FEI, and validate the result based on competition real laps. Once model is validated, new RS9 prototype was simulated in order to foresee its performance. The goal is to model vehicles and competition tracks in order to compare their performance. One may be able to simulate different vehicle configurations in future research, in order to define which vehicle setup is faster around the track, guiding and optimizing tests.

Two vehicle models were created, based on both theoretical and empiric data provided by Fórmula FEI racing team. For example, engine curves were raised through dynamometer tests, while aerodynamics data were determined through computer fluid dynamics simulations (CFD). Acceleration, skid-pad and autocross tracks from Michigan 2014 were generated.

The lap time simulator chosen was OptimumLap. Because the equations of motion were not available, a MATLAB code was created to validate acceleration calculation from standing start, allowing to determine the equations employed by the LTS.

Once equations of motion have been determined, theoretical results were compared to Michigan 2014 results, for model validation. After validation of the vehicle RS8 model, the simulation of Michigan 2014 with new RS9 prototype was done, finishing this work comparing the results and highlighting the differences between two vehicles.
\end{abstract}

Keywords: lap time simulation. Quasi-steady state model. Formula SAE. 


\section{LISTA DE FIGURAS}

Figura 1 - Protótipo RS8 de Fórmula SAE, ano 2015 ........................................................... 17

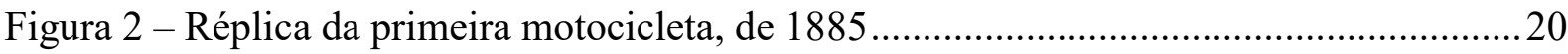

Figura 3 - Triciclo motorizado de Karl Benz, de 1886 ......................................................2 20

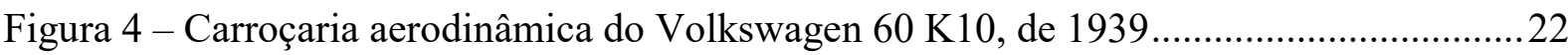

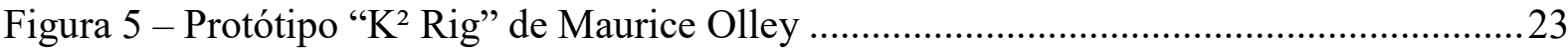

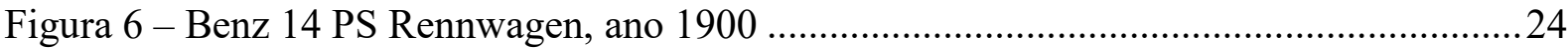

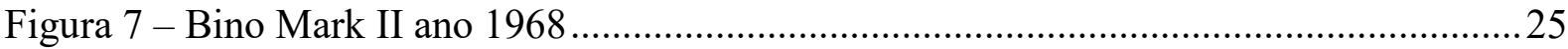

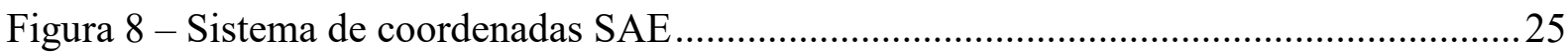

Figura 9 - Modelo de quarto de veículo com 2 graus de liberdade......................................... 31

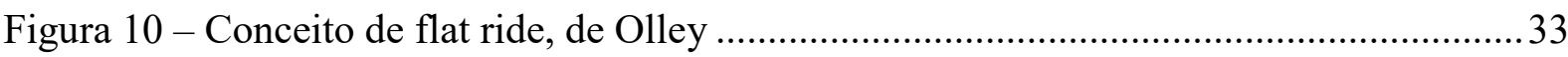

Figura 11 - Exemplos de efeito jacking em curva …......................................................... 34

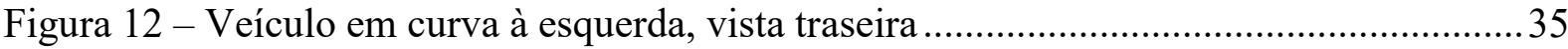

Figura 13 - Força lateral e ângulo de deriva de pneu.............................................................. 37

Figura 14 - Força lateral vs. força vertical de um pneu genérico ............................................37

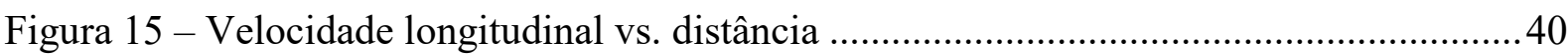

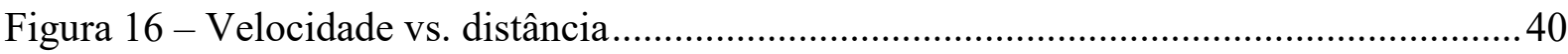

Figura 17 - Simplificação do modelo do veículo................................................................ 42

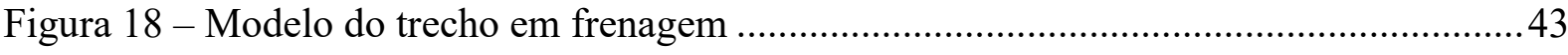

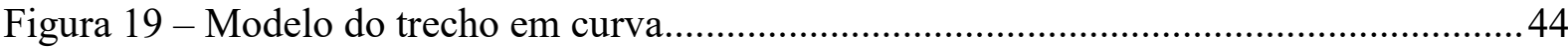

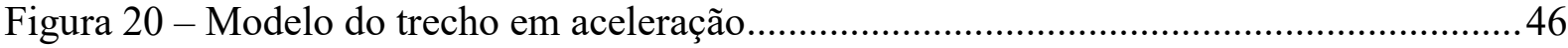

Figura 21 - Medição de força lateral em função da força vertical .......................................... 49

Figura 22 - Medição de força longitudinal em função da força vertical.................................. 50

Figura 23 - Variação da aderência do pneu ..............................................................................51

Figura 24 - Curva característica do motor Yamaha $449 \mathrm{~cm}^{3}$ modificado...............................52

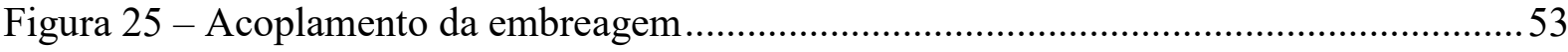

Figura 26 - Gráfico dente de serra da transmissão do RS8 ......................................................54

Figura 27 - Gráfico de força trativa por marcha do RS8 …...................................................54

Figura 28 - Gráfico de força trativa com resistências e limite de tração do RS8 ....................55

Figura 29 - Gráfico de força trativa com resistências e limite de tração do RS9 .....................58

Figura 30 - Representação gráfica da pista de aceleração de 75 m ........................................ 60

Figura 31 - Pista de skid-pad conforme regulamento ............................................................. 61 


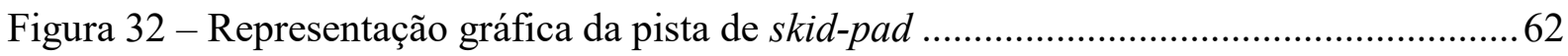

Figura 33 - Representação gráfica da pista de autocross de Michigan 2014 ........................... 63

Figura 34 - Curvas de torque e potência do motor no MATLAB...........................................66

Figura 35 - Força trativa e força resistiva em função da velocidade no MATLAB ................ 67

Figura 36 - Gráfico da velocidade em função do tempo, com escalonamento ........................67

Figura 37 - Gráfico da velocidade longitudinal em função da distância para prova de aceleração

Figura 38 - Gráfico da aceleração longitudinal em função da distância para prova de aceleração

Figura 39 - Gráfico do arrasto aerodinâmico em função da distância para prova de aceleração

Figura 40 - Gráfico da velocidade angular do motor em função do tempo para prova de aceleração .

Figura 41 - Gráfico de velocidade longitudinal em função da distância para prova de skid-pad 76

Figura 42 - Gráfico de downforce em função da distância para prova de skid-pad................. 77

Figura 43 - Gráfico de aceleração lateral em função da distância para prova de skid-pad...... 77

Figura 44 - Traçado de autocross com indicação de velocidade por cores para veículo RS9.79

Figura 45 - Gráfico de velocidade longitudinal em função da distância para prova de autocross 79

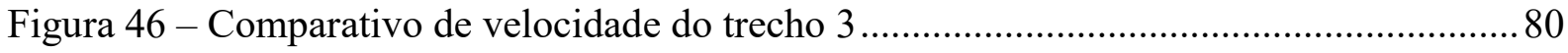

Figura 47 - Gráfico de velocidade longitudinal no trecho 3 (reta) ....................................... 81

Figura 48 - Gráfico de aceleração longitudinal no trecho 3 (reta) ........................................ 81

Figura 49 - Comparativo de velocidade do trecho 6 .......................................................... 82

Figura 50 - Gráfico de velocidade longitudinal no trecho 6 (reta) ....................................... 82

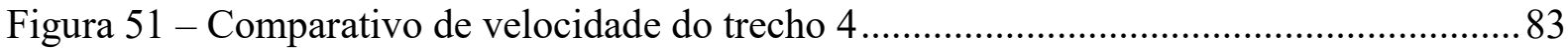

Figura 52 - Gráfico de velocidade longitudinal no trecho 4 (curva de baixa velocidade) ....... 84

Figura 53 - Gráfico de downforce no trecho 4 (curva de baixa velocidade)........................... 85

Figura 54 - Gráfico de aceleração lateral no trecho 4 (curva de baixa velocidade)................. 85

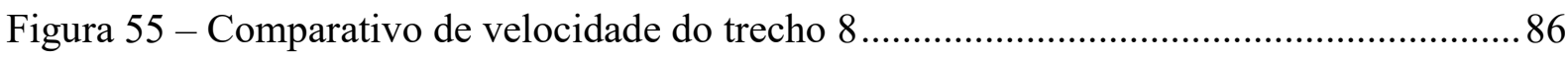

Figura 56 - Gráfico de downforce no trecho 8 (curva de média velocidade) ..........................87

Figura 57 - Gráfico de velocidade longitudinal no trecho 8 (curva de média velocidade)...... 88

Figura 58 - Gráfico de aceleração lateral no trecho 8 (curva de média velocidade) ................ 88

Figura 59 - Gráfico de aceleração lateral para toda a pista.................................................... 89 


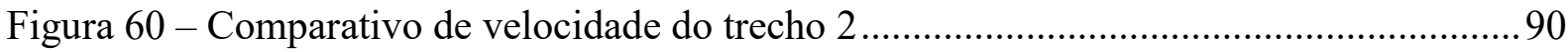

Figura 61 - Gráfico de velocidade no trecho 2 (sequência de curvas de baixa velocidade) ....90

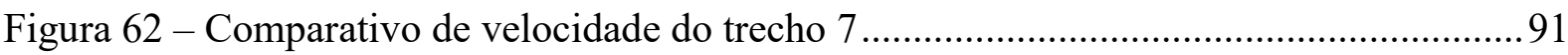

Figura 63 - Gráfico de velocidade no trecho 7 (sequência de curvas de baixa velocidade) ....92

Figura 64 - Gráfico de aceleração lateral no trecho 7 (sequência de curvas de baixa

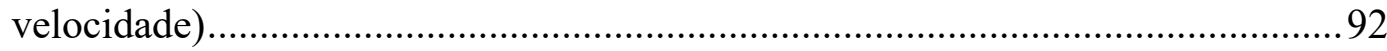

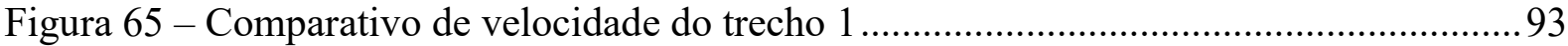

Figura 66 - Gráfico de velocidade no trecho 1 (sequência de curvas de média velocidade)...94

Figura 67 - Gráfico de aceleração lateral no trecho 1 (sequência de curvas de média velocidade)

Figura 68 - Comparativo de velocidade do trecho 5 95

Figura 69 - Gráfico de velocidade no trecho 5 (sequência de curvas de alta velocidade) ....... 96 Figura 70 - Gráfico de aceleração lateral no trecho 5 (sequência de curvas de alta velocidade)

Figura 71 - Gráfico de aceleração longitudinal no trecho 5 (sequência de curvas de alta velocidade) 98

Figura 72 - Gráfico de downforce no trecho 5 (sequência de curvas de alta velocidade) .......98

Figura 73 - Gráfico de arrasto aerodinâmico no trecho 5 (sequência de curvas de alta velocidade) 


\section{LISTA DE TABELAS}

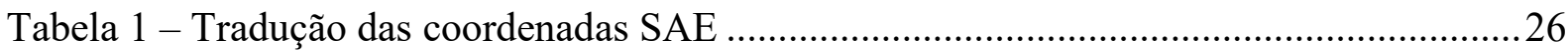

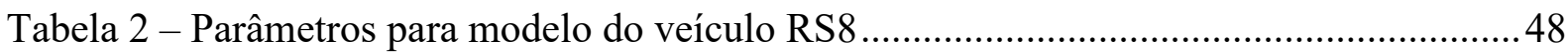

Tabela 3 - Geração de força lateral em função da força normal .............................................50

Tabela 4 - Geração de força longitudinal em função da força normal....................................51

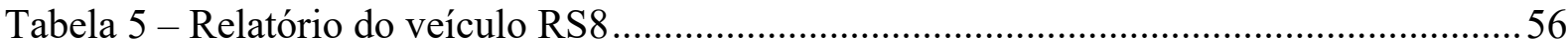

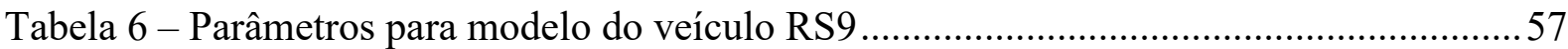

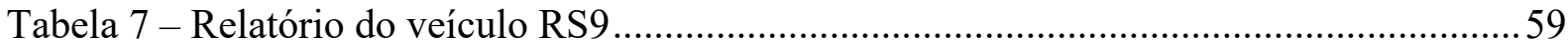

Tabela 8 - Parâmetros para modelo da pista de aceleração .....................................................60

Tabela 9 - Parâmetros para modelo da pista de skid-pad........................................................... 62

Tabela 10 - Métodos empregados na geração das equações do movimento de sistemas

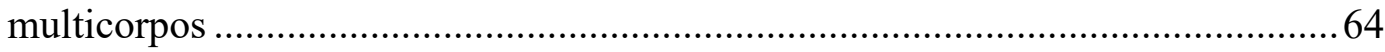

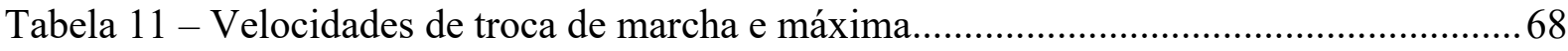

Tabela 12 - Velocidades máximas para diferentes forças resistivas ...................................... 68

Tabela 13 - Comparação dos tempos registrados na competição e simulados no OptimumLap

Tabela 14 - Comparação do desempenho geral dos veículos RS8 e RS9................................ 72

Tabela 15 - Resultado resumido da prova de aceleração ..................................................... 73

Tabela 16 - Resultado resumido da prova de skid-pad, uma volta ....................................... 76

Tabela 17 - Resultado resumido da prova de autocross, uma volta...................................... 78

Tabela 18 - Compilação dos tempos dos trechos estudados .................................................. 99

Tabela 19 - Comparação dos tempos de volta simulados para as provas de Michigan 2014102 


\section{LISTA DE SÍMBOLOS}

$\mathrm{A}_{\text {proj }}$ - área frontal projetada

$\mathrm{a}_{\mathrm{x}}$ - aceleração longitudinal

$\mathrm{a}_{\mathrm{y}}$ - aceleração lateral

$\mathrm{C}_{\mathrm{D}}$ - coeficiente de arrasto aerodinâmico

$\mathrm{C}_{\mathrm{L}}$ - coeficiente de sustentação aerodinâmica

$\mathrm{C} \alpha$ - rigidez de curva (cornering stiffness) do eixo, considerando cada pneu com metade da carga vertical

$\mathrm{D}_{\mathrm{A}}$ - força de resistência aerodinâmica

$\mathrm{f}_{\mathrm{r}}-$ coeficiente de resistência ao rolamento

$\mathrm{F}_{\mathrm{X}}$ - força longitudinal (de aceleração se positiva, de frenagem se negativa)

$\mathrm{F}_{\mathrm{y}}$ - força lateral

$\mathrm{F}_{\mathrm{yi}}$ - força lateral do pneu interno à curva

$\mathrm{F}_{\mathrm{yo}}$ - força lateral do pneu externo à curva

$\mathrm{F}_{\mathrm{zi}}$ - força vertical no pneu interno à curva

$\mathrm{F}_{\mathrm{zo}}$ - força vertical no pneu externo à curva

G; g - aceleração da gravidade

$\mathrm{h}_{1}$ - distância entre centro de gravidade da massa suspensa e eixo de rolagem

$\mathrm{h}_{\mathrm{CG}}$ - altura do centro de gravidade em relação ao solo

$\mathrm{h}_{\mathrm{r}}$ - altura do centro de rolagem em relação ao solo

$\mathrm{k}_{\mathrm{e}}-$ rigidez equivalente percebida pela massa suspensa

$\mathrm{k}_{\mathrm{en}}$ - rigidez equivalente percebida pela massa não suspensa

$\mathrm{k}_{\mathrm{p}}$ - rigidez vertical do pneu

$\mathrm{k}_{\mathrm{s}}$ - rigidez vertical equivalente da mola da suspensão

$\mathrm{K}_{\phi}$ - rigidez torcional de rolagem da suspensão

$\mathrm{K}_{\phi \mathrm{f}}$ - rigidez torcional de rolagem da suspensão dianteira

$\mathrm{K}_{\phi \mathrm{r}}-$ rigidez torcional de rolagem da suspensão traseira

$\mathrm{L}$ - distância entre eixos

$\mathrm{L}_{\mathrm{A}}$ - força de sustentação aerodinâmica

M - massa do veículo

$\mathrm{M}_{\mathrm{ap}}$ - massa aparente do veículo

$\mathrm{M}_{\mathrm{R}}$ - massa equivalente dos elementos rotativos

$\mathrm{m}_{\mathrm{s}}-$ massa suspensa 
$\mathrm{m}_{\mathrm{ns}}-$ massa não suspensa

$\mathrm{N}_{\mathrm{ef}}$ - relação de transmissão efetiva

$\mathrm{N}$ - força normal nos quatro pneus

$\mathrm{N}_{\mathrm{T}}$ - força normal no eixo trativo

$\mathrm{R}$ - raio da curva

$r_{d}-$ raio dinâmico dos pneus trativos

$\mathrm{R}_{\mathrm{r}}$ - força de resistência ao rolamento

$\mathrm{t}$ - bitola de pneus

$\mathrm{T}$ - tempo

$\mathrm{T}_{\mathrm{e}}$ - torque do motor

$\mathrm{v}_{\mathrm{x}}$ - velocidade longitudinal

$\mathrm{V}_{\mathrm{x}}$ - velocidade longitudinal relativa ao ar

$\mathrm{v}_{\mathrm{x} 0}-$ velocidade longitudinal no início do trecho

$\mathrm{V}_{\mathrm{XT}}$ - velocidade longitudinal no final do trecho

$\alpha$ - ângulo de deriva (slip angle)

$\delta$ - ângulo de esterçamento médio do eixo

$\Delta \mathrm{F}_{\mathrm{z}}$ - variação da força vertical em um pneu

$\Delta \mathrm{x}_{\mathrm{A}}$ - comprimento do trecho de aceleração

$\Delta \mathrm{x}_{\mathrm{B}}$ - comprimento do trecho de frenagem

$\Delta \mathrm{x}_{\mathrm{C}}-$ comprimento do trecho de curva

$\eta_{\mathrm{ef}}-$ rendimento efetivo do trem de força

$\theta$ - ângulo de rampa (positivo se aclive, negativo se declive)

$\mu_{\mathrm{x}}-$ coeficiente de atrito longitudinal pneu-pavimento

$\mu_{\mathrm{y}}$ - coeficiente de atrito transversal pneu-pavimento

$\rho$ - densidade do ar

$\phi$ - ângulo de rolagem da massa suspensa

$\omega_{\text {nns }}$ - frequência natural da massa não suspensa

$\omega_{\mathrm{ns}}-$ frequência natural da massa suspensa 


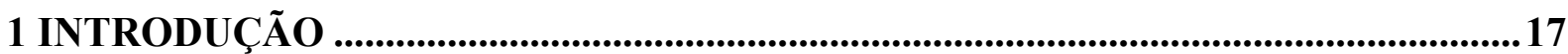

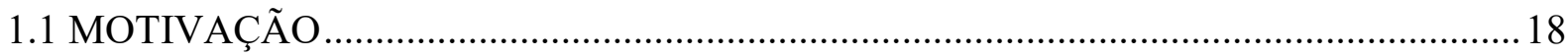

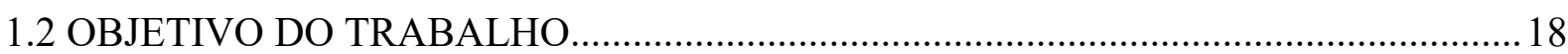

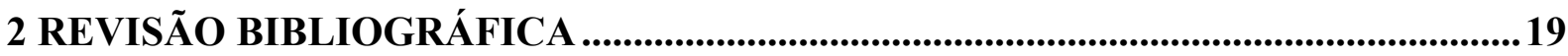

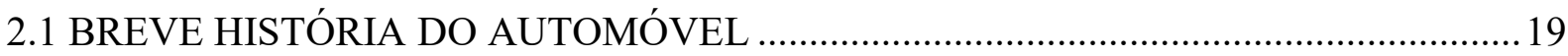

2.1.1 Origem .............................................................................................................................. 19

2.1.2 Popularização do automóvel...........................................................................................20

2.1.3 Implementação da aerodinâmica ....................................................................................21

2.1.4 Surgimento da dinâmica veicular ..................................................................................22

2.1.5 Evolução dos meios de produção..................................................................................23

2.1.6 O papel das competições .........................................................................................................24

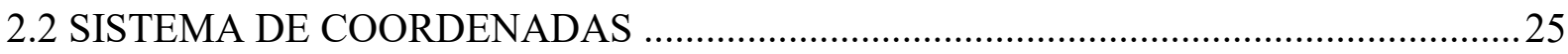

2.3 DINÂMICA LONGITUDINAL_................................................................................26

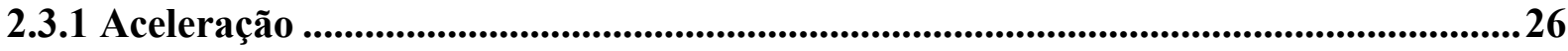

2.3.2 Frenagem .........................................................................................................................28

2.3.3 Resistência ao rolamento ..........................................................................................29

2.3.4 Arrasto e sustentação ..................................................................................................29

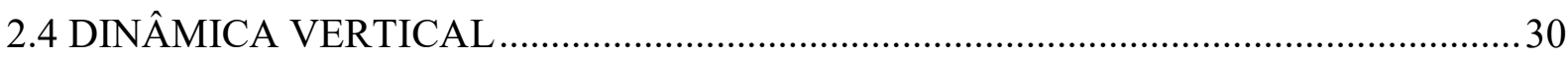

2.4.1 Massa suspensa .......................................................................................................31

2.4.2 Massa não suspensa .....................................................................................................32

2.4.3 Flat ride ..............................................................................................................................33

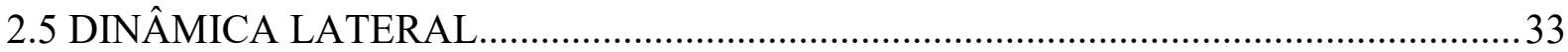

2.5.1 Centro de rolagem ................................................................................................................33

2.5.2 Ângulo de rolagem...............................................................................................................34

2.5.3 Ângulo de Ackerman ................................................................................................36

2.5.4 Ângulo de deriva dos pneus ...................................................................................36

2.5.5 Tendência direcional ................................................................................................................38

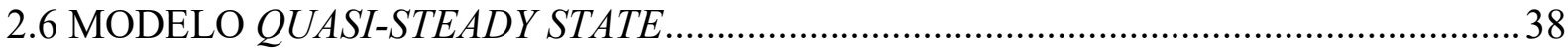

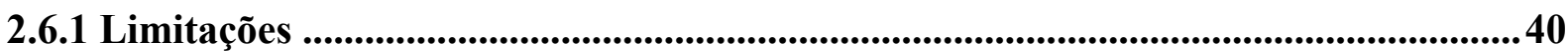

2.6.2 Modelo matemático do veículo ................................................................................42

2.6.3 Trecho de frenagem.......................................................................................................... 43

2.6.4 Trecho de curva ........................................................................................................................44 


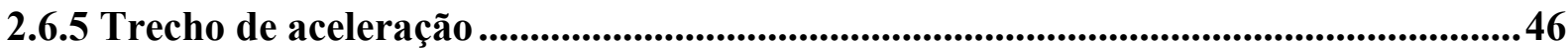

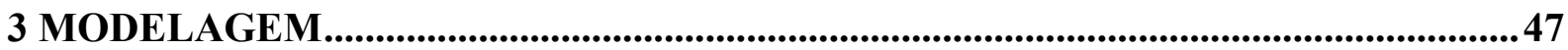

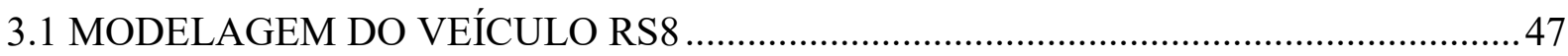

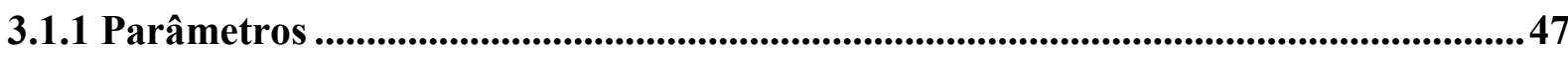

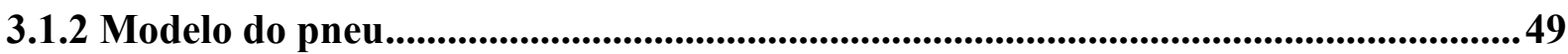

3.1.3 Curva do motor e acoplamento da embreagem .......................................................52

3.1.4 Escalonamento e força trativa ............................................................................................5

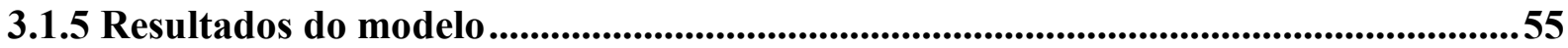

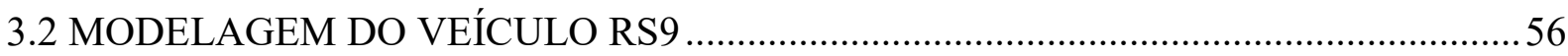

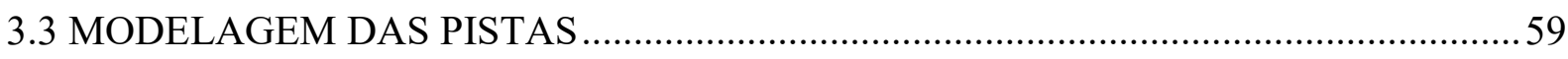

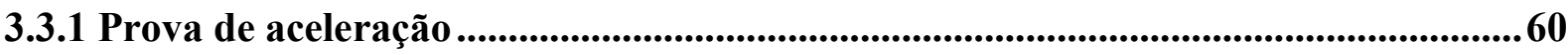

3.3.2 Prova de skid-pad ...............................................................................................................61

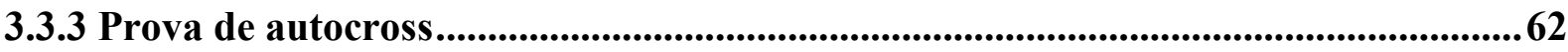

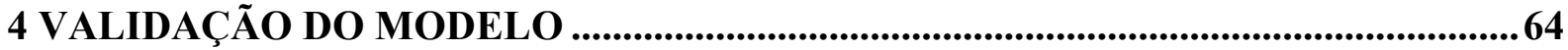

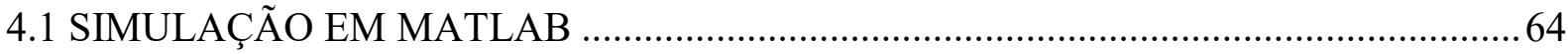

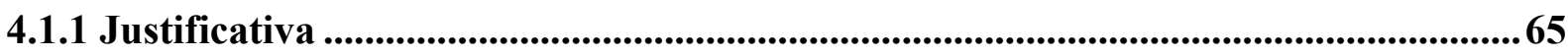

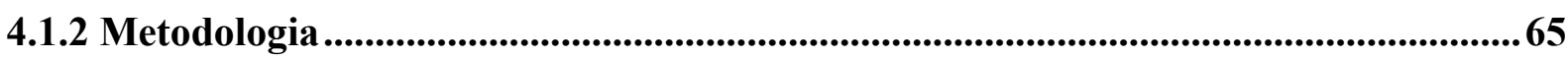

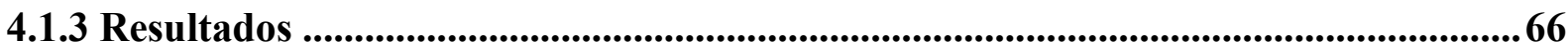

4.1.4 Conclusão .................................................................................................................................69

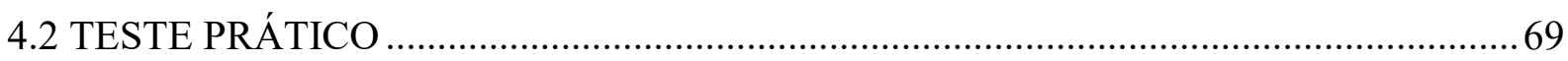

4.2.1 Justificativa ................................................................................................................................... 69

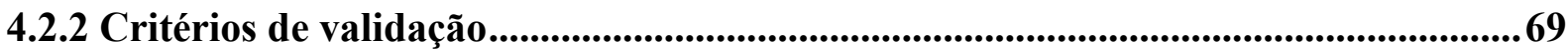

4.2.3 Simulação e análise dos resultados ...........................................................................70

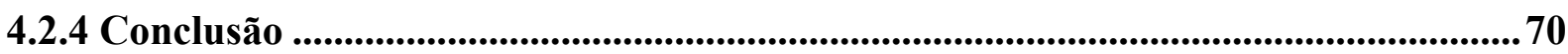

5 SIMULAÇÃO E ANÁLISE DOS RESULTADOS ....................................................... 72

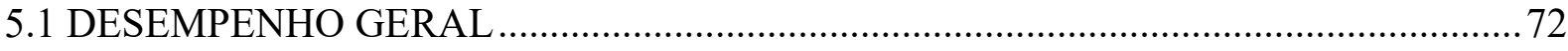

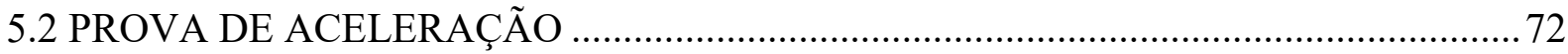

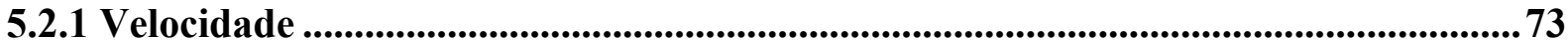

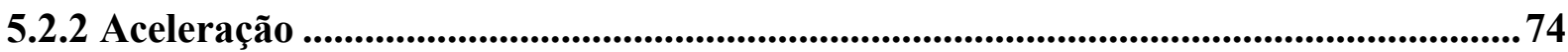

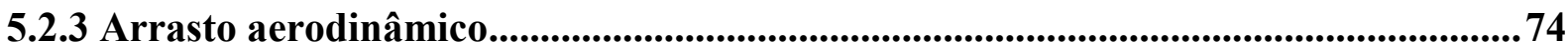

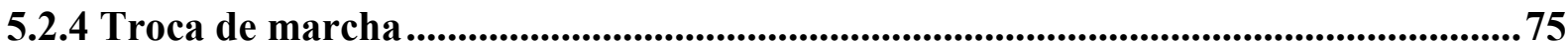

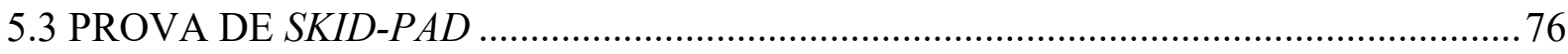

5.3.1 Velocidade ........................................................................................................................................... 76

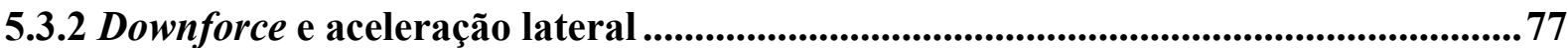




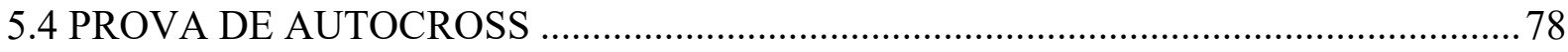

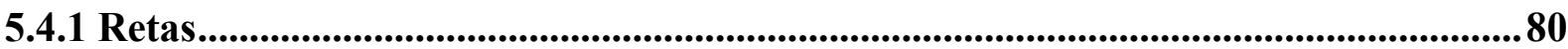

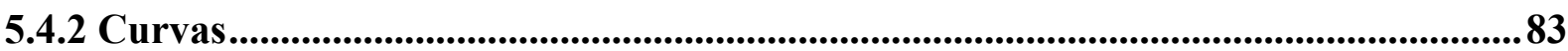

5.4.3 Sequências de curvas ........................................................................................................................89

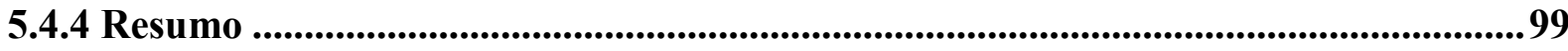

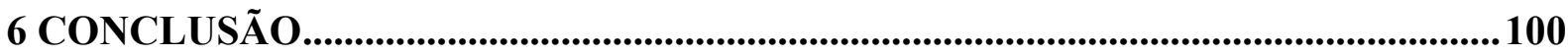

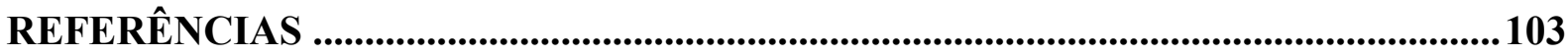

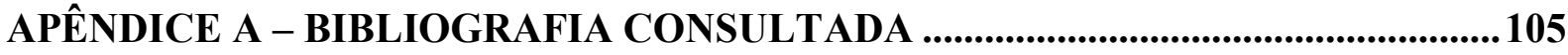

APÊNDICE B - CÓDIGO DA ACELERAÇÃO NO MATLAB ........................................ 108

APÊNDICE C - DADOS PARA MODELAGEM DO MOTOR ..................................115

APÊNDICE D - TABELA DE RESULTADOS DAS SIMULAÇÕES DO

OPTIMUMLAP.......................................................................................117

APÊNDICE E - PROPOSTAS PARA TRABALHOS FUTUROS ..................................121 


\section{INTRODUÇÃO}

A presente obra se baseou nos veículos de competição RS8 e RS9 categoria Fórmula SAE, desenvolvidos pelo Centro Universitário FEI, sendo o primeiro mostrado na figura 1 . O RS9 ainda está em construção, e sucederá o RS8.

A Fórmula SAE é uma competição entre universidades de engenharia em que os alunos projetam e constroem um veículo do tipo fórmula seguindo um regulamento estabelecido pela SAE (Society of Automotive Engineers). Na competição são avaliados diversos fatores, desde projeto até desempenho em pista. Essa competição existe há mais de vinte anos nos EUA e chegou ao Brasil em 2004 (FEI, [2015?]).

A equipe Fórmula FEI é atualmente oito vezes campeã brasileira e obteve o décimo lugar na classificação geral (entre 126 participantes) em sua última competição internacional, realizada em Michigan, nos Estados Unidos da América, no ano 2014 (SAE, 2015b).

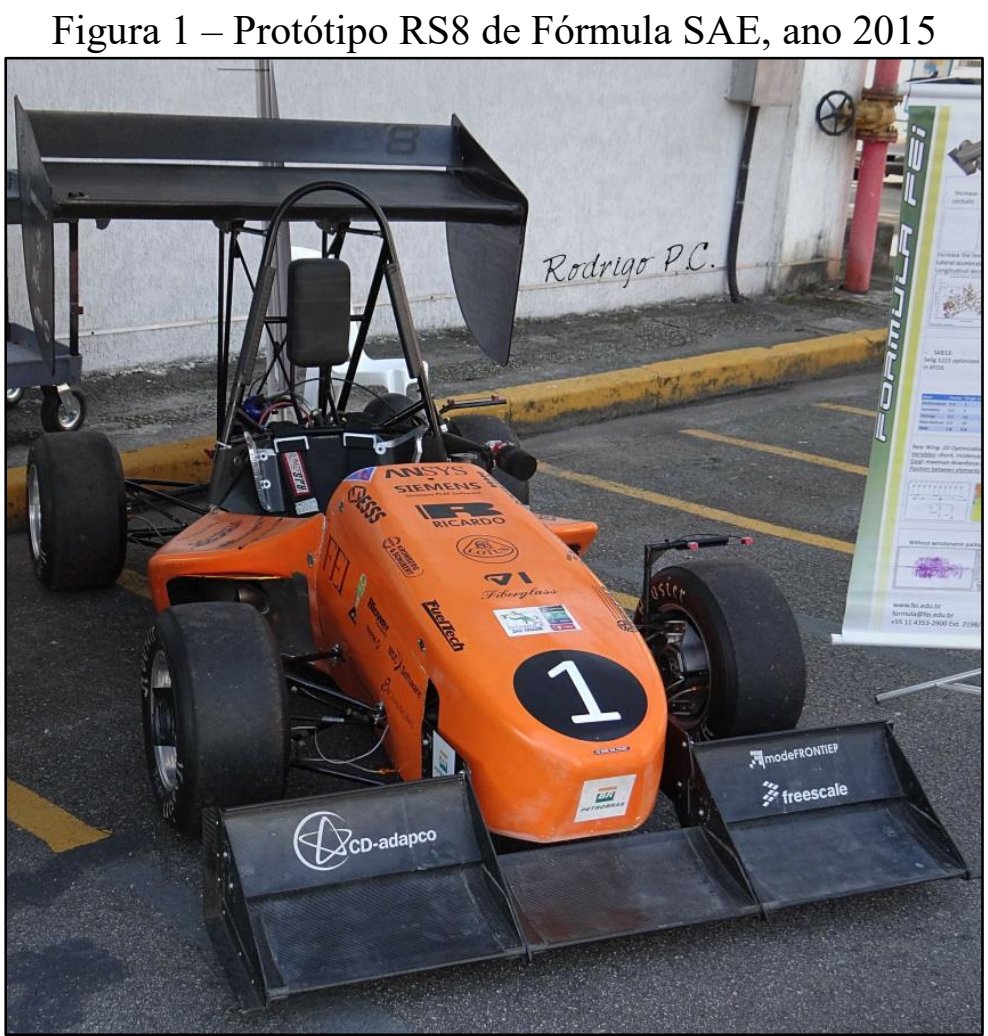

Fonte: autor

Durante o desenvolvimento de um novo veículo como o RS9, bem como no ajuste de um veículo para uma competição, a equipe, baseada em sua experiência, faz cálculos e testes de variadas configurações para subsistemas como trem de força, suspensão, pacotes aerodinâmicos e pneus, citando apenas alguns exemplos. 
A aquisição de dados durante os testes é fundamental para se atingir a exatidão desejada na simulação computacional do veículo. Dados da própria pista também são coletados, proporcionando simulações mais direcionadas e resultados orientados às reais necessidades do desenvolvimento.

As simulações numéricas vêm ganhando espaço tanto na indústria quanto na competição, uma vez que permitem reduzir e orientar os testes, minimizando o tempo e os dispêndios. Segundo Gillespie (2015), você pode testar um protótipo, mas se você tem um simulador, você pode testar qualquer coisa que imaginar (informação verbal). ${ }^{1}$

\subsection{MOTIVAÇÃO}

Visando melhores resultados a cada competição, foi proposto desenvolver um estudo com foco na previsão do comportamento do novo veículo, utilizando como ferramenta a simulação de tempo de volta com modelo quasi-steady state.

\subsection{OBJETIVO DO TRABALHO}

O objetivo do presente trabalho é comparar o desempenho do novo protótipo RS9 com o do RS8, empregado nas competições de 2014 e 2015 da Fórmula SAE a combustão. A alteração mais significativa foi a redução do aerofólio traseiro, por imposição do regulamento.

Espera-se poder simular tempo de volta em circuito com erro dentro da margem de 5\% para que, em projetos futuros, se possa prever o resultado de ajustes diversos na configuração do veículo. Além da alteração dos aerofólios, podemos citar como exemplo decidir entre um motor mais potente e mais pesado, ou outro menos potente, porém mais leve.

Com a utilização dessa ferramenta, economiza-se tempo e recursos no desenvolvimento e ajuste do veículo para uma competição, podendo-se determinar a melhor configuração dos subsistemas para cada circuito independentemente.

O programa utilizado foi o OptimumLap (OptimumG $\left.{ }^{\circledR}\right)$, cujos criadores atestam um erro de até $10 \%$ no tempo de volta, afirmando que um erro dentro da margem de $5 \%$ não é incomum (OPTIMUMG, [2015?b]). A empresa atua no desenvolvimento de programas e consultoria nas competições American LeMans, IndyCar Series e NASCAR, entre outras. Alguns clientes na indústria são Ferrari, Daimler, Porsche Motorsport e Pagani Automobili, entre outros ao redor do mundo (OPTIMUMG, [2015?a]).

\footnotetext{
${ }^{1}$ Informação verbal concedida por Thomas D. Gillespie, no dia 07 de agosto de 2015 em palestra.
} 


\section{REVISÃO BIBLIOGRÁFICA}

Este capítulo trata brevemente da história do automóvel, destacando os adventos mais relevantes, para melhor compreensão desta obra. Em seguida, aborda os fundamentos da dinâmica veicular e, finalmente, introduz o leitor à simulação com modelo quasi-steady state.

\subsection{BREVE HISTÓRIA DO AUTOMÓVEL}

O universo do automobilismo sempre teve relação direta com a indústria. Esses dois segmentos, quando não são dependentes um do outro, possuem, no mínimo, uma cooperação mútua de desenvolvimento e avanços tecnológicos. Um estudo da história nos permite entender melhor os veículos de que dispomos hoje, seja nas vias públicas, seja nos autódromos.

\subsubsection{Origem}

As locomotivas a vapor surgiram na Inglaterra no início do século XIX, e pouco mais de meio século depois surgiram nas ruas os primeiros automóveis a vapor. No final daquele século, as locomotivas a vapor deram lugar às locomotivas movidas a óleo ou parafina. Já os automóveis a vapor perduraram até o início do século XX, alguns anos após a invenção do carro com motor de combustão interna. Aqueles eram mais silenciosos e de funcionamento mais suave, mas possuíam o inconveniente da partida ser muito demorada, e exigir frequentes reabastecimentos de água (HAPPIAN-SMITH, 2002).

Na década de 1870, o alemão Dr. Nikolaus A. Otto patenteou e produziu o primeiro motor de combustão interna a gás, usado em plantas para mover máquinas. Em 1885, seus conterrâneos Gottlieb Daimler e Wilhelm Maybach adaptaram o motor para funcionar com um combustível derivado do petróleo, que era pulverizado na câmara de combustão. A ignição era dada não por vela, mas por um tubo aquecido, e foi um dos maiores desafios do projeto. O motor de Daimler e Maybach era pequeno e veloz o suficiente para equipar uma bicicleta de madeira adaptada, que seria a primeira motocicleta da história (HAPPIANSMITH, 2002). Uma réplica se encontra no Mercedes-Benz Museum, em Stuttgart, Alemanha, aqui vista na figura 2. 
Figura 2 - Réplica da primeira motocicleta, de 1885

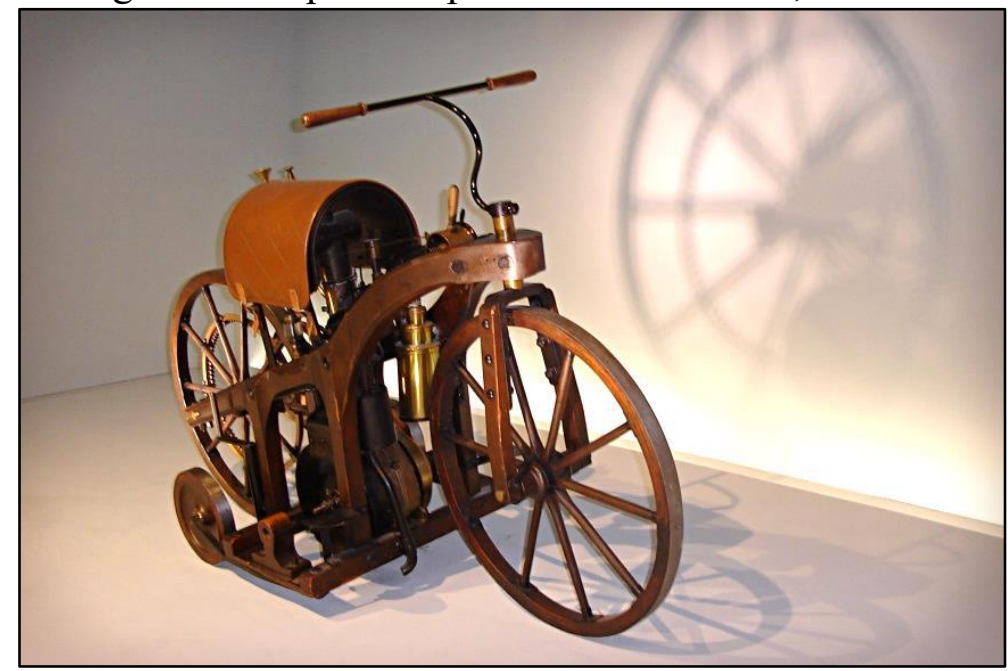

Fonte: autor

No ano seguinte, a dupla de engenheiros que havia inventado a motocicleta apresentou o primeiro automóvel com motor de combustão interna, uma adaptação de uma pequena carruagem. Também em 1886, outro alemão - Karl Benz - criou um triciclo motorizado em paralelo com o automóvel de Daimler (HAPPIAN-SMITH, 2002). Uma réplica do triciclo também está exposta no Mercedes-Benz Museum, em Stuttgart, aqui mostrado na figura 3. Mais tarde, os pioneiros Daimler e Benz se uniriam para fundar a marca Mercedes-Benz.

Figura 3 - Triciclo motorizado de Karl Benz, de 1886

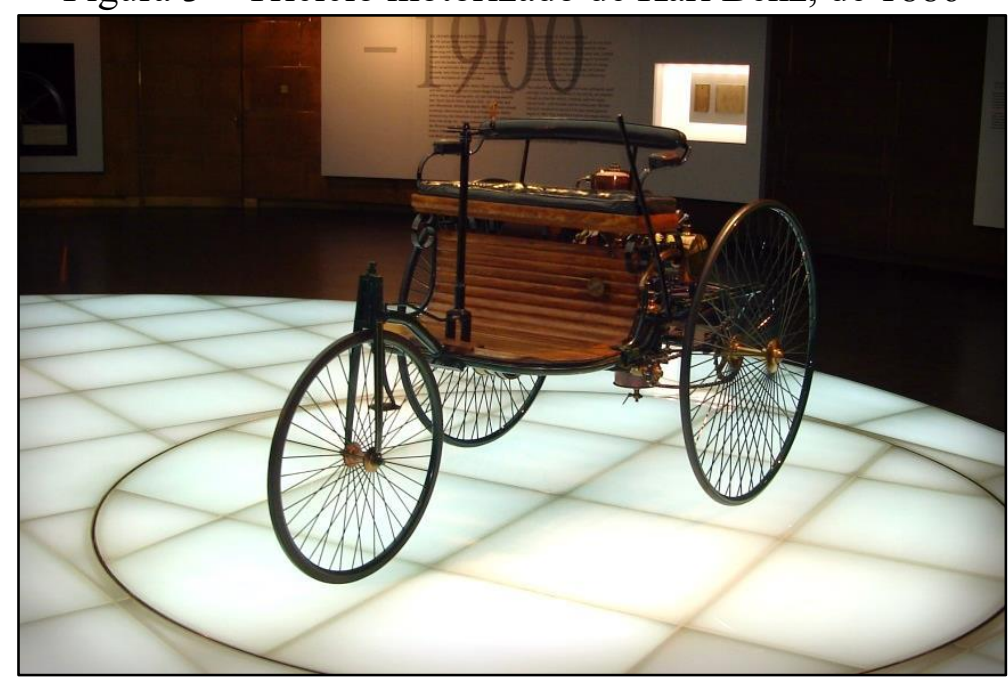

Fonte: autor

\subsubsection{Popularização do automóvel}

Os primeiros veículos eram produzidos artesanalmente, a exemplo das carruagens. Uma carroçaria de madeira era adicionada ao chassi, conforme encomenda do cliente. Foi o americano Henry Ford quem, em 1909, produziu em série o popular Modelo T. Em Detroit, a 
Ford também inovou inaugurando a linha de produção móvel, onde os veículos se moviam em vez dos trabalhadores. A produção em massa reduziu drasticamente o preço do automóvel, expandindo seu mercado consumidor, que agora não se restringia aos mais afortunados (HAPPIAN-SMITH, 2002).

Na Europa, o francês André Citroën importou os métodos de produção em massa de Henry Ford, e investiu fortemente em propaganda, chegando a iluminar a Torre Eiffel com o nome Citroën e seu $\operatorname{logo}$ - os dois dentes da engrenagem que havia criado (SANDLER, 2011).

Foi Ferdinand Porsche, entretanto, a pedido de Adolf Hitler, que projetou o carro popular europeu de maior sucesso pela confiabilidade, por atingir velocidade de cruzeiro superior a $100 \mathrm{~km} / \mathrm{h}$, transportar quatro ocupantes (segundo Hitler, os filhos não poderiam ser separados dos pais durante as viagens) e ter preço acessível, apesar de ter ficado acima do teto inicial de mil Marcos (SANDLER, 2011).

O Volkswagen KdF (Fusca) não era um carro revolucionário, como divulgava a propaganda da época, mas apresentava soluções bem sucedidas em veículos maiores, como o chassi de túnel central, motor traseiro, refrigeração a ar, molas tipo barras de torção e carroçaria aerodinâmica. O que Porsche fez foi unir essas tecnologias de maneira eficaz e relativamente barata. Sua produção se iniciou em 1938, mas foi somente no pós-guerra que o “carro popular” alemão foi produzido em grande escala (SANDLER, 2011).

\subsubsection{Implementação da aerodinâmica}

Desde o fim da década de 1890 se aplicam conceitos de aerodinâmica em veículos, inclusive o para-brisa inclinado. Mas foi só na década de 1930 que os veículos aerodinâmicos se difundiram, quando a Alemanha construiu autoestradas de grande velocidade, as Autobahn. Veículos mais aerodinâmicos poderiam, finalmente, promover o transporte individual de alta velocidade (HAPPIAN-SMITH, 2002).

Pode-se dizer que o Volkswagen $60 \mathrm{~K} 10$, de Ferdinand Porsche, foi um marco no desenvolvimento de automóveis aerodinâmicos. Apresentado ao público em 1939, no Rali do Eixo, era baseado no Volkswagen $\mathrm{KdF}$, de quem herdou chassi e suspensão. A carroçaria era de alumínio para reduzir a massa, e as rodas eram cobertas para reduzir o arrasto. Graças à aerodinâmica avançada para a época, alcançava $140 \mathrm{~km} / \mathrm{h}$ com um motor quatro cilindros de $1.086 \mathrm{~cm}^{3}$ e apenas $40 \mathrm{cv}$ (SANDLER, 2011). Uma carroçaria reconstruída se encontra no Porsche Museum, no distrito de Zuffenhausen em Stuttgart, e aqui pode ser vista na figura 4. 
Figura 4 - Carroçaria aerodinâmica do Volkswagen 60 K10, de 1939

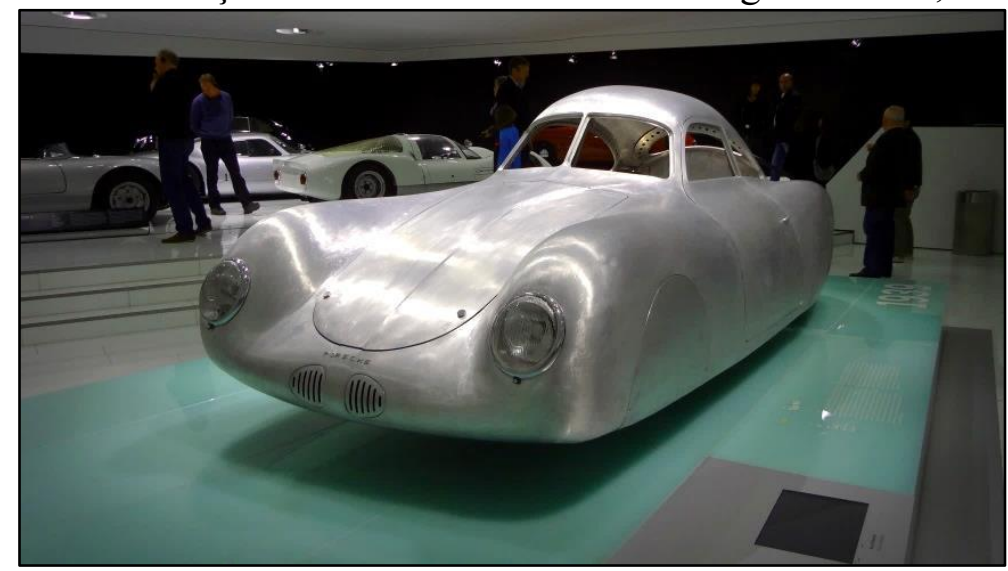

Fonte: autor

\subsubsection{Surgimento da dinâmica veicular}

Maurice Olley, nascido na Inglaterra em 1889, trabalhou como projetista na Rolls Royce, primeiramente na Inglaterra, depois nos Estados Unidos. Com a crise de Wall Street de 1929, a Rolls Royce fechou as portas na América do Norte, deixando-o então desempregado. No ano seguinte, foi contratado como engenheiro de chassi pela Cadillac, do grupo General Motors, com a missão de melhorar a dirigibilidade e o conforto dos automóveis da marca (MILLIKEN, 2000).

Os trabalhos de Olley, desenvolvidos no Departamento de Engenharia Mecânica da General Motors entre os anos de 1930 e 1957, foram pioneiros no estudo da dinâmica veicular pela maneira abordada. Apesar de Olley ter se baseado em trabalhos teóricos de Rowel e Guest, sua abordagem foi essencialmente prática, realizando testes em protótipos no Campo de Provas da General Motors (MILLIKEN, 2000).

Seu protótipo mais famoso é o "K² Rig", de 1932, ilustrado na figura 5. Tratava-se de um Cadillac adaptado, que contava com massas removíveis adicionadas à frente do balanço dianteiro e atrás do balanço traseiro. Adicionando ou removendo massas, podia-se ajustar o centro de gravidade longitudinal e o ponto de acoplamento das suspensões, para estudo da arfagem, também conhecida como pitch (MILLIKEN, 2000). 
Figura 5 - Protótipo “K² Rig” de Maurice Olley

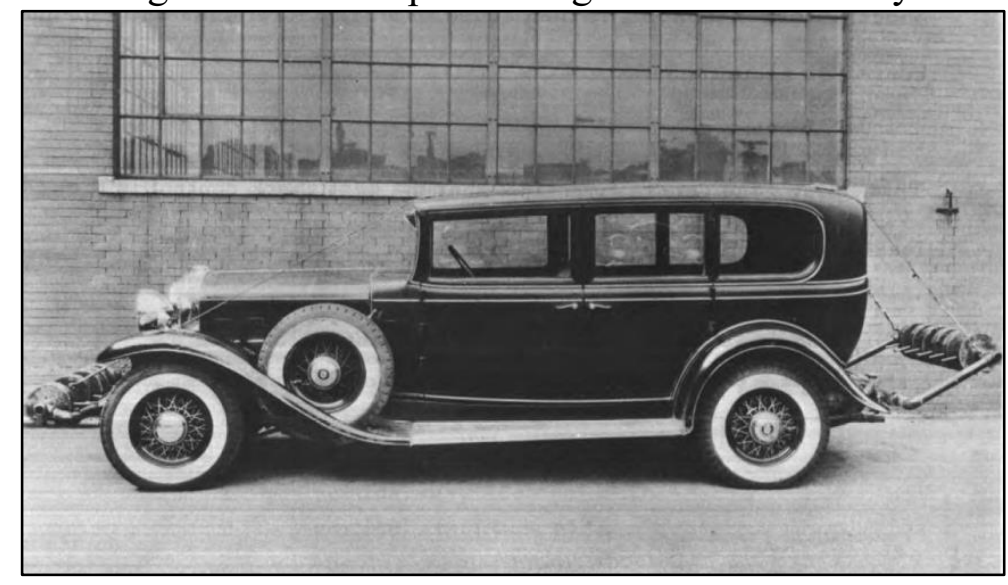

Fonte: Milliken, 2000, p. 12

Com esse e outros protótipos, Olley e seu time desenvolveram os conceitos de flat ride (minimizar arfagem), sub e sobresterçamento, entre outros de grande importância para a melhora da segurança e do conforto dos automóveis, inclusive a introdução da suspensão dianteira independente em automóveis de passeio em 1933 (MILLIKEN, 2000). Alguns conceitos são brevemente explanados nos itens 2.3 e 2.4 .

\subsubsection{Evolução dos meios de produção}

A produção em série, iniciada por H. Ford e amplamente adotada pela indústria, causou o descontentamento dos funcionários, que passaram a realizar tarefas repetitivas e que exigiam pouca habilidade. O desconforto dos funcionários, somado a uma filosofia das montadoras de não priorizar a qualidade dos veículos, levou a produtos de baixa confiabilidade e de acabamento ruim (HAPPIAN-SMITH, 2002).

Nos anos de 1960, a japonesa Toyota ganhava mercado nos Estados Unidos e no continente europeu. Surgia um novo método produtivo, baseado em automação e disciplina. Os funcionários trabalhavam em equipes, e a produção era mais flexível, sendo que as máquinas podiam alternar as tarefas rapidamente (HAPPIAN-SMITH, 2002).

A filosofia também mudou, já que a qualidade do produto era prioridade, e buscava-se minimizar o retrabalho. As relações com os fornecedores de componentes eram mais cooperativas, permitindo reduzir o tempo de desenvolvimento e de produção, e aumentar a variedade de produtos. Esse processo foi intitulado "lean production" (HAPPIAN-SMITH, 2002). 


\subsubsection{O papel das competições}

Tão logo surgiu o automóvel, surgiram as competições. Na figura 6, vê-se um veículo alemão de competição do ano 1900, com potência de $14 \mathrm{cv}$ e velocidade máxima de $65 \mathrm{~km} / \mathrm{h}$. Seu arrefecimento era feito com um sistema aberto, por evaporação, com um trocador de calor tubular na parte traseira do chassi.

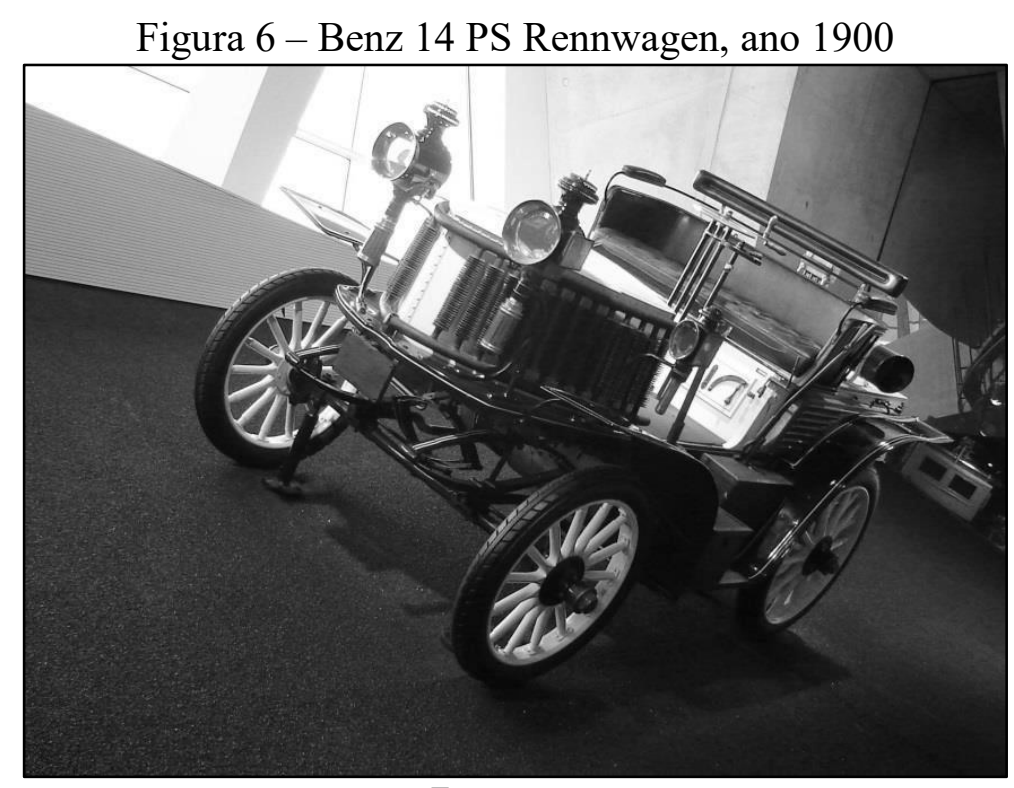

Fonte: autor

Ora pela busca de uma volta mais rápida, ora forçadas pelo regulamento, as equipes desenvolvem novas tecnologias, como sistemas de arrefecimento, sobrealimentação, freios, pneus, chassi, entre muitos outros campos. Atualmente tem-se focado em eficiência energética, com a redução do bloco do motor e emprego do turbocompressor, propulsão híbrida e recuperação de energia [como na Fórmula 1]. A maioria dessas tecnologias é transferida aos veículos de passeio, beneficiando o usuário comum com veículos mais leves, eficientes e seguros (HAPPIAN-SMITH, 2002).

Além das inovações, a durabilidade dos veículos é posta à prova em competições, onde os elevados esforços e temperaturas criam o ambiente ideal para testar novos componentes. As competições servem como verdadeiros laboratórios para as montadoras, que se utilizam delas para desenvolverem seus produtos. Como exemplo, tem-se o Bino Mark II, de 1968 (figura 7). Esse modelo, utilizado pela Ford em competições no Brasil, foi conduzido pelos pilotos Luiz Pereira Bueno e José Carlos Pace e venceu o "IV 1000 Quilômetros de Brasília" naquele mesmo ano. Os protótipos Willys Mark I e Bino Mark II, construídos pela 
Bino Samdaco, serviram para o teste de componentes mecânicos do projeto EME, futuro Ford Corcel, originalmente um projeto Renault (BINO, [2015?]).

Figura 7 - Bino Mark II ano 1968

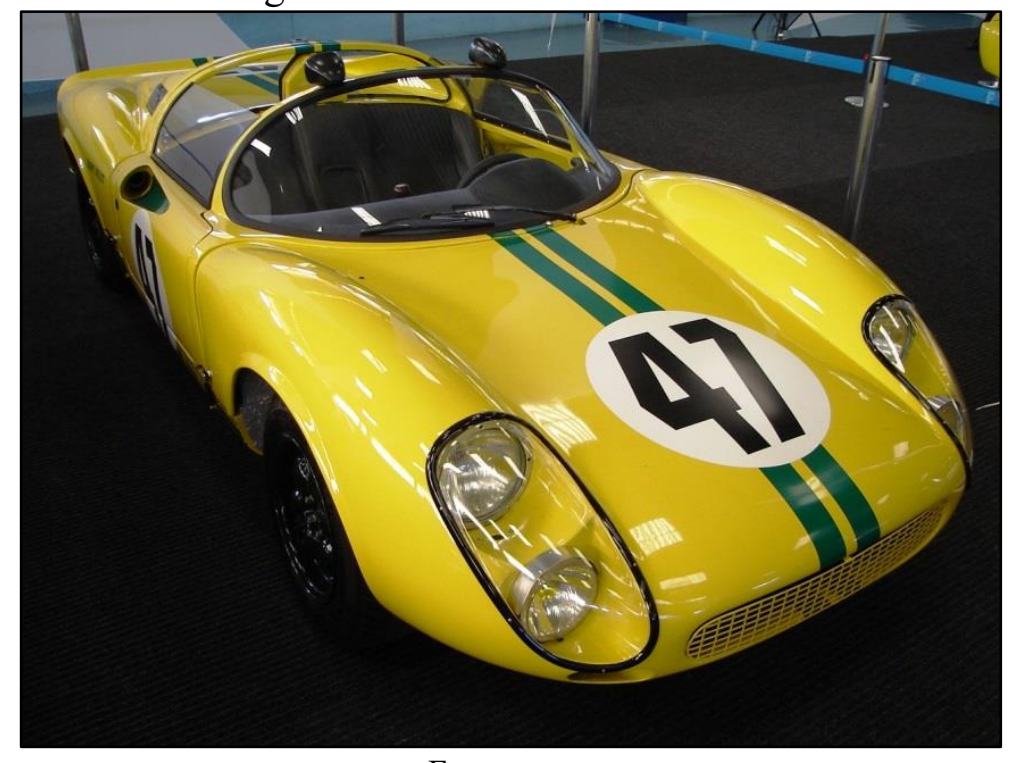

Fonte: autor

\subsection{SISTEMA DE COORDENADAS}

O sistema de coordenadas de referência da Sociedade de Engenharia da Mobilidade (SAE), adotado no presente estudo, está representado na figura 8.

Figura 8 - Sistema de coordenadas SAE

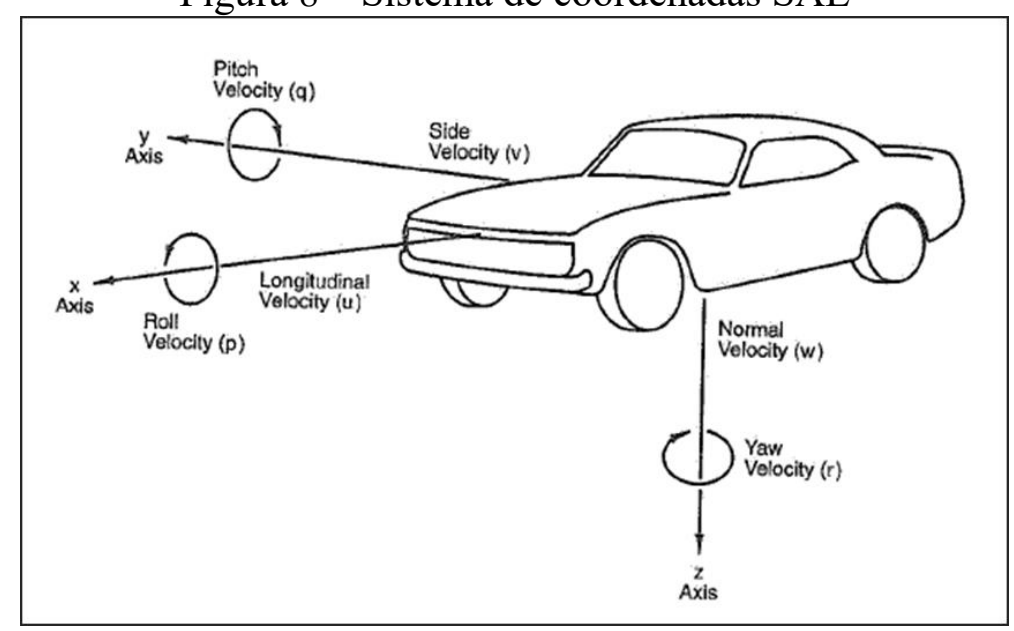

Fonte: Milliken, 1995, p. 116

Uma tradução livre dos parâmetros em inglês da figura 8, proposta pelo autor, encontra-se na tabela 1 . 
Tabela 1 - Tradução das coordenadas SAE

\begin{tabular}{c|l|l}
\hline Eixo & \multicolumn{1}{|c}{ Denotação SAE } & \multicolumn{1}{|c}{ Tradução (do autor) } \\
\hline $\mathbf{x}$ & Longitudinal Velocity & Velocidade Longitudinal \\
$\mathbf{x}$ & Roll Velocity & Velocidade de Rolagem \\
$\mathbf{y}$ & Side Velocity & Velocidade Lateral \\
$\mathbf{y}$ & Pitch Velocity & Velocidade de Arfagem \\
$\mathbf{z}$ & Normal Velocity & Velocidade Normal ou Vertical \\
$\mathbf{z}$ & Yaw Velocity & Velocidade de Guinada \\
\hline \multicolumn{2}{|c}{ Fonte: autor }
\end{tabular}

\subsection{DINÂMICA LONGITUDINAL}

A dinâmica longitudinal descreve o movimento do veículo ao longo de seu eixo $\mathrm{x}$, podendo ser dividida em aceleração e frenagem.

\subsubsection{Aceleração}

A aceleração pode ser limitada pela potência disponível ou pela aderência dos pneus (GILLESPIE, 1992). A potência fornecida pelo motor chega às rodas trativas após passar pela transmissão e relação final (final drive). Uma vez que a eficiência do trem de força é menor que $100 \%$, a potência disponível nas rodas é menor que a potência gerada pelo motor.

Admitindo-se que as rodas não escorreguem, e desprezando-se as forças resistivas, a aceleração do veículo pode ser determinada pela Segunda Lei de Newton, aqui representada pela equação 1 (GILLESPIE, 1992).

$$
M_{a p} \cdot a_{x}=F_{x}
$$

onde:

$$
\begin{aligned}
& \mathrm{M}_{\mathrm{ap}} \text { - massa aparente do veículo; } \\
& \mathrm{a}_{\mathrm{x}} \text { - aceleração longitudinal; } \\
& \mathrm{F}_{\mathrm{x}} \text { - força longitudinal. }
\end{aligned}
$$

A massa aparente do veículo é o resultado da soma da inércia rotativa do trem de força e das rodas e a massa do veículo, conforme equação 2. Isso porque os elementos rotativos armazenam energia durante a aceleração (GILLESPIE, 1992).

$$
M_{a p}=M+M_{R}
$$


onde:

M - massa do veículo;

$M_{R}$ - massa equivalente dos elementos rotativos.

A força longitudinal que acelera o veículo é aquela disponível no contato pneu-solo, representada pela equação 3 (GILLESPIE, 1992).

$$
F_{x}=\frac{T_{e} \cdot N_{e f} \cdot \eta_{e f}}{r_{d}}
$$

onde:

$\mathrm{T}_{\mathrm{e}}$ - torque do motor;

$\mathrm{N}_{\mathrm{ef}}$ - relação de transmissão efetiva;

$\eta_{\text {ef }}$ - rendimento efetivo do trem de força;

$r_{d}-$ raio dinâmico dos pneus trativos.

Considerando as forças resistivas, como de rolamento, aerodinâmica e rampa, tem-se a equação 4 (GILLESPIE, 1992).

$M_{a p} \cdot a_{x}=F_{x}-R_{r}-D_{A}-(M \cdot g \cdot \sin (\theta))$

onde:

$\mathrm{R}_{\mathrm{r}}$ - força de resistência ao rolamento;

$\mathrm{D}_{\mathrm{A}}$ - força de resistência aerodinâmica;

$\mathrm{g}$ - aceleração da gravidade;

$\theta$ - ângulo de rampa.

A aceleração longitudinal de um veículo pode ser determinada, portanto, conhecendose sua massa, inércia do trem de força e das rodas e as forças resistivas que nele atuam. Entretanto, acima de certa força trativa, o atrito entre os pneus trativos e o pavimento limita a aceleração, como prevê a equação 5 (GILLESPIE, 1992).

$F_{x}=\mu_{x} \cdot N_{T}$

onde: 
$\mu_{\mathrm{x}}$ - coeficiente de atrito longitudinal pneu-pavimento;

$\mathrm{N}_{\mathrm{T}}$ - força normal no eixo trativo.

Em altas velocidades, o fator limitante deve ser a potência do motor, enquanto que em baixas velocidades normalmente é o coeficiente de atrito, também conhecido como aderência (GILLESPIE, 1992).

\subsubsection{Frenagem}

Analogamente à aceleração longitudinal, a dinâmica da frenagem pode ser equacionada pela Segunda Lei de Newton, como na equação 6 (GILLESPIE, 1992).

$$
M_{a p} \cdot a_{x}=-\left(M_{a p} \cdot d_{x}\right)=-F_{x}-R_{r}-D_{A}-(M \cdot g \cdot \sin (\theta))
$$

onde:

$$
\begin{aligned}
& \mathrm{d}_{\mathrm{x}}-\text { desaceleração longitudinal; } \\
& \mathrm{F}_{\mathrm{x}}-\text { força longitudinal. }
\end{aligned}
$$

Mais uma vez, analogamente à aceleração longitudinal, a aderência pode ser um fator limitante da desaceleração, com a vantagem de que as quatro rodas aplicam forças longitudinais ao solo, como na equação 7 (GILLESPIE, 1992).

$$
F_{x}=\mu_{x} . N
$$

onde:

$\mathrm{N}$ - força normal nos quatro pneus.

Para uma pista plana horizontal, a força normal no veículo pode ser calculada conforme equação 8 .

$$
N=(M \cdot g)-L_{A}
$$

onde:

$\mathrm{L}_{\mathrm{A}}$ - força de sustentação aerodinâmica (item 2.3.4). 
É importante ressaltar que as forças resistivas favorecem a desaceleração. Alguns veículos de alto desempenho utilizam freios aerodinâmicos auxiliares para aumentar o arrasto e reduzir a distância de parada.

\subsubsection{Resistência ao rolamento}

A resistência ao rolamento é a força que se opõe ao rolamento dos pneus. Em baixas velocidades, é a principal resistência ao movimento, sendo superada pela resistência aerodinâmica aproximadamente acima de $80 \mathrm{~km} / \mathrm{h}$ [em carro de passeio] (GILLESPIE, 1992).

Gillespie (1992) afirma que não é necessário calcular a resistência de cada um dos pneus para uma primeira estimativa de desempenho. Pode-se simplesmente considerar o veículo como um todo, aplicando a equação 9.

$R_{r}=f_{r} \cdot M \cdot g$

onde:

$\mathrm{f}_{\mathrm{r}}-$ coeficiente de resistência ao rolamento.

Segundo Gillespie (1992), essa resistência é causada por diversos fatores, como deflexão dos flancos laterais e da banda de rodagem, atrito da banda com o pavimento, deflexão do próprio pavimento, escorregamento entre pneu e pavimento, circulação do ar dentro do pneu etc.

Múltiplos fatores influem na resistência ao rolamento. $\mathrm{O}$ aumento da temperatura, da pressão de inflação dos pneus e da rigidez do pavimento reduz a resistência ao rolamento. Já o aumento da velocidade, do ângulo de deriva e da carga vertical incrementa a força resistiva. Dada a complexidade dos pneus, seja pela composição, seja pela geometria, a maioria dos dados como resistência ao rolamento e capacidade de geração de força é obtida empiricamente (GILLESPIE, 1992).

\subsubsection{Arrasto e sustentação}

$\mathrm{O}$ ar fluindo em torno do veículo gera a resistência aerodinâmica, ou arrasto aerodinâmico (drag), que se opõe ao movimento. Parte do arrasto é causada pela diferença de pressão entre as porções anterior e posterior do veículo, parte pelo atrito do ar com a superfície, parte pela circulação de ar no compartimento do motor, caixas de roda e interior do veículo, entre outros fatores (GILLESPIE, 1992). 
A equação 10 representa a resistência aerodinâmica. Seus coeficientes podem ser determinados por simulação computacional (Computer Fluid Dynamics - CFD) ou por medição em túnel de vento, seja em modelo de escala reduzida, seja em protótipo (GILLESPIE, 1992).

$D_{A}=0,5 \rho \cdot v_{x}^{\prime 2} \cdot C_{D} \cdot A_{p r o j}$

onde:

$\mathrm{D}_{\mathrm{A}}$ - força de resistência aerodinâmica;

$\rho$ - densidade do ar;

$\mathrm{V}_{\mathrm{X}}^{\prime}$ - velocidade longitudinal relativa ao ar;

$\mathrm{C}_{\mathrm{D}}$ - coeficiente de arrasto;

$\mathrm{A}_{\text {proj }}$ - área frontal projetada.

A sustentação, resultado da diferença de pressão entre a parte de cima e de baixo do veículo, reduz a força normal dos pneus, prejudicando sua capacidade de gerar força. A sustentação negativa, comum em veículos de competição, muitas vezes gerada com auxílio de aerofólios e defletores, também é conhecida por downforce, ou força vertical para baixo. Nesse caso, há um incremento na capacidade dos pneus gerarem força, melhorando o desempenho em curvas e frenagem (GILLESPIE, 1992).

Conforme Gillespie (1992), a força de sustentação pode ser estimada conforme a equação 11 , análoga à equação 10 do arrasto.

$$
L_{A}=0,5 \rho \cdot v_{x}^{\prime 2} \cdot C_{L} \cdot A_{p r o j}
$$

onde:

$\mathrm{L}_{\mathrm{A}}$ - força de sustentação;

$\mathrm{C}_{\mathrm{L}}$ - coeficiente de sustentação.

\subsection{DINÂMICA VERTICAL}

De forma simplificada, o estudo das vibrações pode ser dividido em duas faixas de frequência. O intervalo compreendido entre zero e $25 \mathrm{~Hz}$ está abaixo do limite da audição, e é denominado ride. Já a faixa audível, entre 25 e $20.000 \mathrm{~Hz}$, é denominada ruído (GILLESPIE, 1992). 
As vibrações podem ser provocadas pelo perfil da pista em função da velocidade do veículo, pela vibração do motor e transmissão, pelo desbalanceamento das rodas e das partes girantes, pela aerodinâmica etc, e são um dos critérios mais importantes na avaliação do conforto dos ocupantes (GILLESPIE, 1992).

\subsubsection{Massa suspensa}

Segundo Gillespie (1992, p. 7, tradução do autor), o veículo “[...] pode ser representado como uma massa concentrada no centro de gravidade (C.G.) com apropriadas propriedades de massa e momento de inércia. [...] Para a análise de ride, normalmente é necessário tratar as rodas como massas concentradas separadamente. Nesse caso, a massa concentrada representando a carroçaria é a 'massa suspensa', e as rodas são denominadas 'massas não suspensas'.”

É função da suspensão isolar a massa suspensa e, consequentemente, seus ocupantes das vibrações excitadas pelo pavimento, minimizando as acelerações e deslocamentos. Para o estudo das frequências naturais, pode-se adotar o modelo de quarto de veículo, ilustrado na figura 9, composto por massas (m), molas (k) e amortecedores (c).

Figura 9 - Modelo de quarto de veículo com 2 graus de liberdade

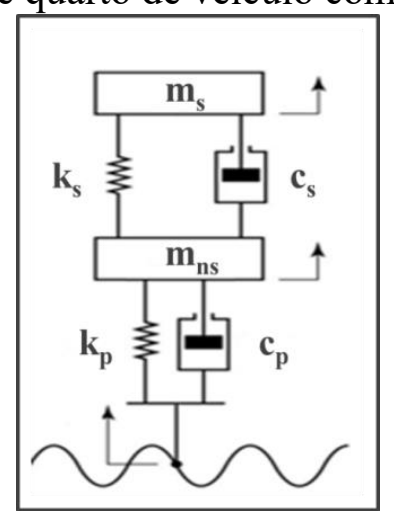

Fonte: autor "adaptado de" Silva, 2014, p. 31

Apesar do modelo de quarto de veículo possuir dois graus de liberdade (GdL), pode-se calcular aproximadamente a frequência natural de cada massa, uma vez que se espera que tenham frequências naturais muito distintas.

Em veículos de passeio, a primeira frequência de ressonância do sistema, relativa à massa suspensa, ocorre entre 1,0 e $1,5 \mathrm{~Hz}$, enquanto que a segunda, relativa à massa não suspensa, é de aproximadamente $10 \mathrm{~Hz}$. Veículos de competição têm o conforto sacrificado em prol do desempenho, empregando suspensões mais rígidas, que proporcionam frequências naturais de até $2,5 \mathrm{~Hz}$ para a massa suspensa (GILLESPIE, 1992). 
Gillespie (1992) adota o nome de ride rate para a rigidez vertical equivalente percebida pela massa suspensa. A mola da suspensão e o pneu podem ser associados em série, pois estão sob a ação da mesma força vertical, como na equação 12.

$$
k_{e}=\frac{k_{s} \cdot k_{p}}{k_{s}+k_{p}}
$$

onde:

$\mathrm{k}_{\mathrm{e}}$ - rigidez equivalente percebida pela massa suspensa;

$\mathrm{k}_{\mathrm{s}}$ - rigidez equivalente vertical da mola da suspensão;

$\mathrm{k}_{\mathrm{p}}$ - rigidez vertical do pneu.

A frequência natural da massa suspensa é calculada pela equação 13 (GILLESPIE, 1992).

$\omega_{n s}=\sqrt{\frac{k_{e}}{m_{s}}}$

onde:

$\omega_{\mathrm{ns}}-$ frequência natural da massa suspensa;

$\mathrm{m}_{\mathrm{s}}-$ massa suspensa.

\subsubsection{Massa não suspensa}

A dinâmica vertical da massa não suspensa está relacionada à segurança, pois os pneus precisam se manter em contato com o solo, gerando força suficiente para o controle do veículo. Durante o projeto da suspensão, busca-se minimizar a variação da força de contato do pneu com o solo.

Gillespie (1992) recomenda que as molas equivalentes (pneus e suspensão) sejam associadas em paralelo para calcular a rigidez equivalente da massa não suspensa, pois sofrem aproximadamente o mesmo deslocamento vertical, como na equação 14 .

$$
k_{\text {en }}=k_{s}+k_{p}
$$

onde:

$\mathrm{k}_{\mathrm{en}}$ - rigidez equivalente da massa não suspensa. 
A frequência natural da massa não suspensa é calculada como na equação 15 (GILLESPIE, 1992).

$\omega_{n n s}=\sqrt{\frac{k_{e n}}{m_{n s}}}$

onde:

$$
\begin{aligned}
& \omega_{\mathrm{nns}} \text { - frequência natural da massa não suspensa; } \\
& \mathrm{m}_{\mathrm{ns}}-\text { massa não suspensa. }
\end{aligned}
$$

\subsubsection{Flat ride}

A combinação de arfagem e oscilação vertical é amplamente conhecida como pitch and bounce, e foi originalmente estudada por Olley, com seu protótipo $\mathrm{K}^{2}$ Rig. Ele concluiu que o movimento de arfagem causa mais desconforto, e criou o conceito de flat ride, ilustrado na figura 10 (MILLIKEN, 2000).

Para melhorar o conforto, recomenda-se que a frequência natural da massa suspensa no eixo traseiro seja entre dez e vinte por cento mais alta que no dianteiro, minimizando a arfagem (REIMPELL, 2001).

Figura 10 - Conceito de flat ride, de Olley

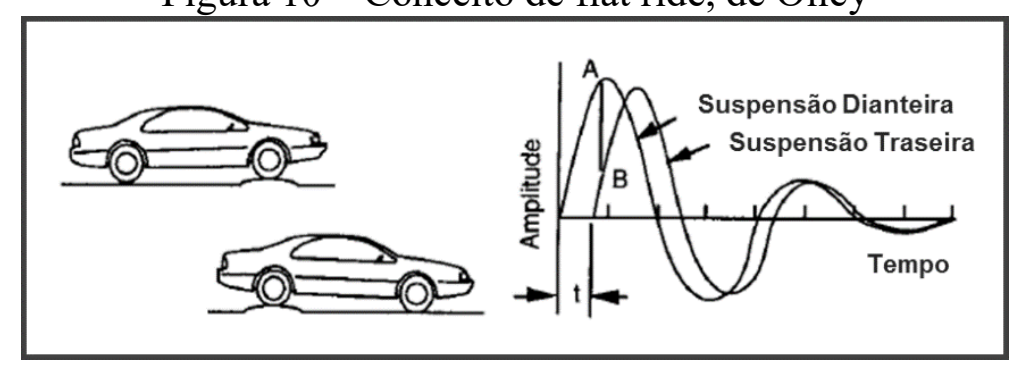

Fonte: autor "adaptado de" Gillespie, 1992, p. 177

\subsection{DINÂMICA LATERAL}

A dinâmica lateral explica o comportamento do veículo sob aceleração lateral. A capacidade do veículo de contornar curvas depende, por exemplo, de características da suspensão, altura do centro de gravidade e da bitola de pneus (GILLESPIE, 1992).

\subsubsection{Centro de rolagem}

Segundo Gillespie (1992, p. 212, tradução do autor), centro de rolagem (roll center) é “o ponto onde as forças laterais são transferidas do eixo para a massa suspensa [...] e é o ponto onde o eixo rola quando submetido a um momento de rolagem puro." 
Ainda segundo Gillespie (1992, p. 213, tradução do autor), o eixo de rolagem, ou roll axis, é "a linha conectando os centros de rolagem das suspensões dianteira e traseira." Submetida a forças laterais, a massa suspensa do veículo rola em torno do eixo de rolagem.

Um centro de rolagem alto reduz o momento de rolagem, propiciando ângulo de rolagem relativamente pequeno em curva. Em contrapartida, provoca maior deflexão lateral da roda durante a compressão da suspensão (bump), e o efeito jacking, ou seja, a elevação da carroçaria em curvas, como ilustrado na figura 11. Já um centro de rolagem baixo reduz o efeito jacking e provoca menor deflexão lateral das rodas, mas permite maior ângulo de rolagem do chassi (COSTIN, 1965).

Figura 11 - Exemplos de efeito jacking em curva

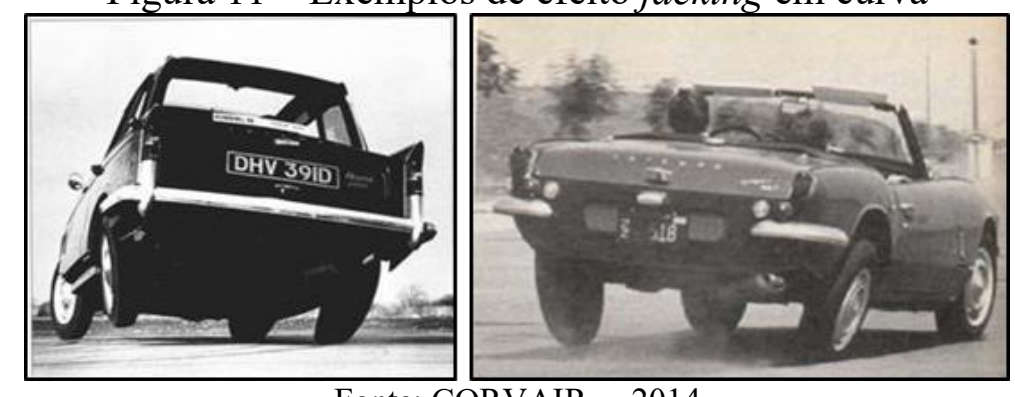

Fonte: CORVAIR..., 2014

Costin (1965) e Fenton (1999) orientam posicionar o centro de rolagem de modo que sua altura varie pouco com o trabalho da suspensão, para manter a transferência de peso relativamente constante em diferentes condições de operação.

Gillespie (2015) orienta posicionar o centro de rolagem baixo para evitar solavancos laterais [lateral shake] quando o veículo é submetido a torção (informação verbal). ${ }^{2}$

\subsection{2 Ângulo de rolagem}

O ângulo de inclinação lateral da carroçaria em relação ao solo é chamado ângulo de rolagem, e é determinado pelo momento de rolagem e pela rigidez torcional da suspensão (negligenciando a deflexão dos pneus). A rolagem da carroçaria é consequência da aceleração lateral atuando no centro de gravidade da massa suspensa.

Segundo Gillespie (1992, p. 211, tradução do autor), "todas as suspensões são equivalentes a duas molas", como na figura 12.

\footnotetext{
${ }^{2}$ Informação verbal concedida por Thomas D. Gillespie, no dia 07 de agosto de 2015 em palestra.
} 
Figura 12 - Veículo em curva à esquerda, vista traseira

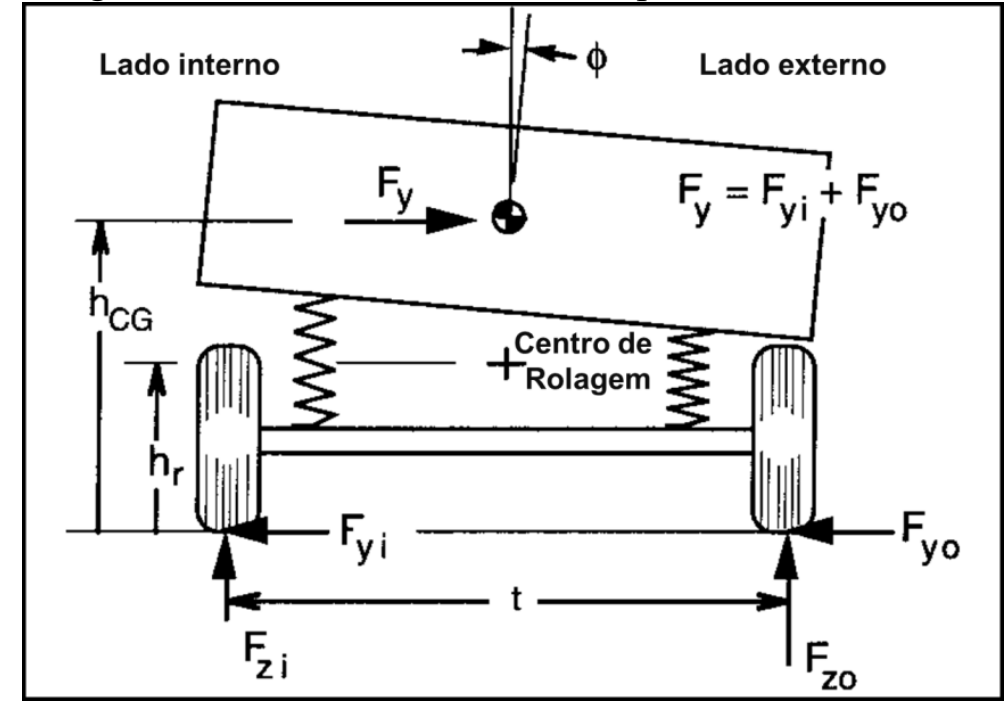

Fonte: autor "adaptado de" Gillespie, 1992, p. 211

Ainda segundo Gillespie (1992), a rigidez torcional de rolagem da suspensão pode ser determinada conforme a equação 16 .

$K_{\phi}=0,5 K_{s} \cdot t^{2}$

onde:

$\mathrm{K}_{\phi}-$ rigidez torcional de rolagem da suspensão;

$\mathrm{t}-$ bitola de pneus.

Para pequenos ângulos, a rolagem pode ser determinada pela equação 17 (GILLESPIE, 1992).

$\phi=\frac{M \cdot h_{1}\left(v_{x}^{2} / R\right)}{K_{\phi f}+K_{\phi r}-\left(M \cdot g \cdot h_{1}\right)}$

onde:

$\mathrm{h}_{1}$ - distância entre centro de gravidade da massa suspensa e eixo de rolagem;

$\mathrm{K}_{\phi \mathrm{f}}$ - rigidez torcional de rolagem da suspensão dianteira;

$\mathrm{K}_{\phi r}-$ rigidez torcional de rolagem da suspensão traseira.

A transferência lateral de carga, responsável pela perda da capacidade de curva (item 2.5.4), é calculada conforme a equação 18 (GILLESPIE, 1992). 
$F_{z o}-F_{z i}=2 F_{y}\left(h_{r} / t\right)+2 K_{\phi}(\phi / t)=2 \Delta F_{z}$

onde:

$\mathrm{F}_{\mathrm{zo}}$ - força vertical no pneu externo à curva;

$\mathrm{F}_{\mathrm{zi}}$ - força vertical no pneu interno à curva;

$\mathrm{F}_{\mathrm{y}}$ - força lateral;

$\mathrm{h}_{\mathrm{r}}-$ altura do centro de rolagem;

$\Delta \mathrm{F}_{\mathrm{z}}$ - variação da força vertical em um pneu.

\subsection{3 Ângulo de Ackerman}

Segundo Gillespie (1992), para curvas em baixa velocidade e para pequenos ângulos de esterçamento, o esterçamento médio do eixo dianteiro é dado pela equação 19.

$$
\delta=L / R
$$

onde:

$\delta$ - ângulo de esterçamento médio do eixo;

L - distância entre eixos;

$\mathrm{R}$ - raio da curva.

Nessa situação de baixa velocidade longitudinal, o ângulo de deriva dos pneus pode ser desprezado (GILLESPIE, 1992).

\subsection{4 Ângulo de deriva dos pneus}

Ângulo de deriva ou slip angle é o ângulo formado entre a direção de movimento da roda e a direção para a qual esta aponta, como indicado na figura 13.

Um pneu é elástico. Uma força aplicada a ele em qualquer direção irá distorcer a forma básica do pneu. Uma força de curva no pneu distorcê-lo-á no ponto de contato com a pista. Essa distorção lateral faz o carro seguir uma trajetória com um ângulo em relação à direção para a qual a roda está apontando. Esse ângulo é denominado ângulo de deriva e dá ao condutor um sentimento de como o carro está se comportando na curva (Puhn, 1976, p. 10, tradução do autor). 
A força lateral é a resistência do pneu à força de curva, e aquela não existiria sem a distorção do pneu e o consequente ângulo de deriva, ou slip angle (PUHN, 1976).

Figura 13 - Força lateral e ângulo de deriva de pneu

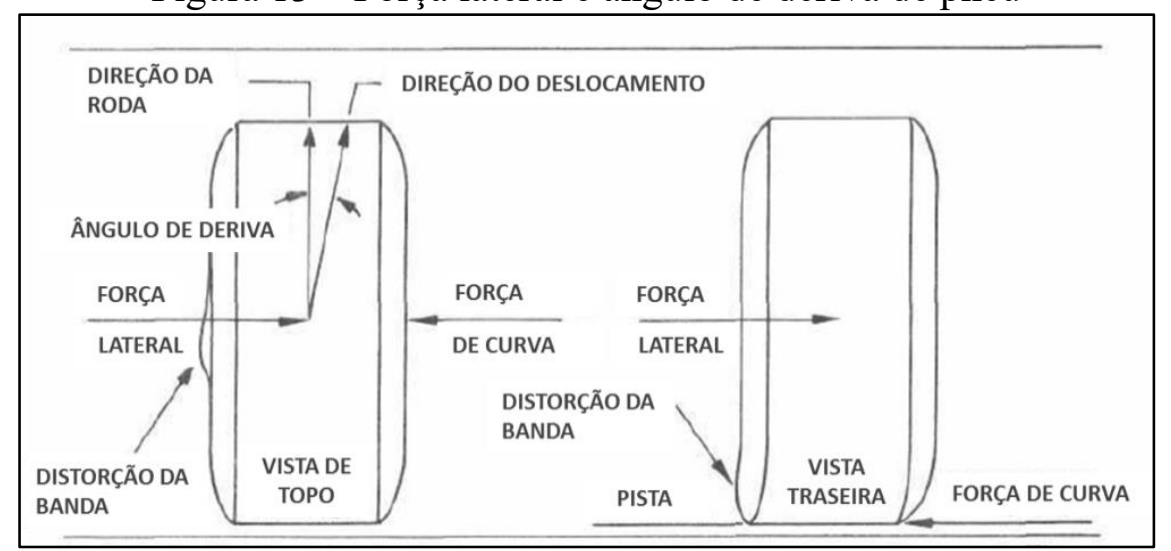

Fonte: autor "adaptado de" Puhn, 1976, p. 10

Na figura 14 é apresentado um gráfico genérico de geração de força lateral de um pneu em função da sua carga vertical, para um ângulo de deriva de 5 graus.

Figura 14 - Força lateral vs. força vertical de um pneu genérico

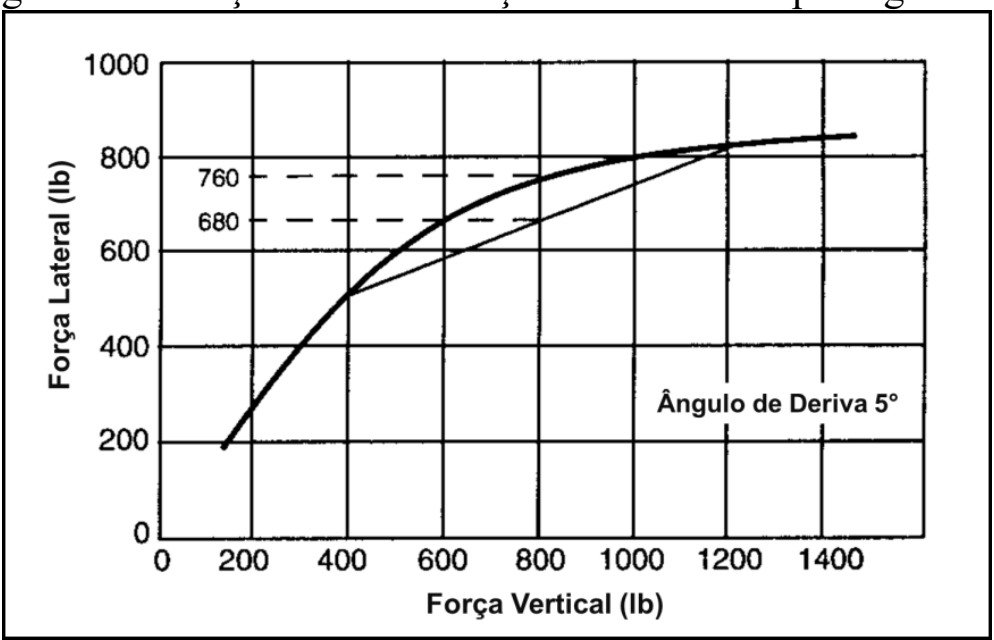

Fonte: autor "adaptado de" Gillespie, 1992, p. 210

A força lateral depende da força vertical, mas a não linearidade dessa relação faz com que a transferência lateral [e longitudinal] de carga seja prejudicial à capacidade de curva, obrigando os pneus a assumirem maiores ângulos de deriva. Para uma abordagem inicial, desprezando-se o efeito da transferência lateral de carga, a força lateral desenvolvida por um eixo é dada pela equação 20 (GILLESPIE, 1992).

$F_{y}=C_{\alpha} . \alpha$ 
onde:

$\mathrm{C}_{\alpha}$ - rigidez de curva (cornering stiffness) do eixo, considerando cada pneu com metade da carga vertical;

$\alpha$ - ângulo de deriva (slip angle).

\subsubsection{Tendência direcional}

O conceito de tendência direcional, criado por Olley, define se um veículo possui tendência subesterçante ou sobresterçante, e se aplica em curvas de alta velocidade, quando o ângulo de deriva dos pneus não pode ser desprezado. Segundo a definição original de Olley, no caso dos pneus dianteiros apresentarem maiores ângulos de deriva que os traseiros, o veículo é denominado subesterçante. Caso contrário, o veículo é sobresterçante (GILLESPIE, 1992).

Para um veículo subesterçante, em uma trajetória curva de raio constante, o ângulo de esterçamento aumenta com a velocidade. Esse comportamento, além de intuitivo, é mais seguro, pois o eixo dianteiro atinge o limite de aderência primeiro, e o veículo sai pela tangente em linha reta, permitindo que o condutor reduza a velocidade e retome o controle do veículo. Esta velocidade limite é chamada velocidade característica. Mesmo no caso de uma colisão, esta é frontal, e a zona de deformação dianteira dissipa parte da energia do impacto. De acordo com Milliken (2000, p. 139, tradução do autor), "quase todos os carros de passageiros convencionais são moderada ou fortemente subesterçantes."

Veículos de competição, ao contrário, são muitas vezes sobresterçantes. Essa condição permite maiores velocidades nas curvas, apesar do risco de rodopio em caso de perda de aderência do eixo traseiro, tornando mais difícil a recuperação da estabilidade. A velocidade na qual ocorre a instabilidade é chamada velocidade crítica. Acima de tal velocidade, o veículo se torna instável, mesmo trafegando em linha reta.

\subsection{MODELO QUASI-STEADY STATE}

De acordo com Siegler (2002, p. 17, tradução do autor), "todos esses pacotes [de simulação de tempo de volta], com poucas exceções, usam uma abordagem de simulação quasi-static", ou seja, quasi-steady state. O programa empregado, OptimumLap, calcula o tempo de volta pelo modelo quasi-steady state, pormenorizado neste item 2.6. Esse programa foi escolhido por ter sido desenvolvido especificamente para a categoria Fórmula SAE, exigir pouco poder de processamento computacional, possuir modelos de traçados e veículos reais 
em seu banco de dados e ser gratuito. Ainda que a empresa desenvolvedora do programa seja renomada no meio automobilístico, simulações em MATLAB e comparações com voltas reais foram feitas para comprovar sua assertividade.

Alguns programas de simulação de tempo de volta comercialmente disponíveis que se utilizam de modelo quasi-steady state são RaceWare (Vehicle Dynamics Performance Ltd), Dynamic Response (Pressplay Ltd), LTS (Milliken Research Associates), PiSim (Pi Corporation) e RaceSim (DATAS). A maioria dos programas não comerciais desenvolvidos por universidades para simulação de tempo de volta também adotam o modelo quasi-steady state, como os desenvolvidos na Universidade de Michigan (EUA) e na Universidade de Brescia (Itália) (SIEGLER, 2002).

O método steady state, ou estado estacionário, ou ainda regime permanente, abordado no livro de Gillespie (1992), considera o veículo em movimento uniforme, ou seja, dotado de velocidade longitudinal constante. A introdução da frenagem e da aceleração caracteriza o método como quasi-steady state. Segundo OptimumG ([2015?d]], p. 66, tradução do autor), "o programa pode ser classificado como quasi-steady state por permitir que o veículo acelere em curva até atingir sua máxima velocidade de curva. Analogamente, ao veículo também é permitido frear em curva."

Pode-se calcular tempo de volta representando o veículo como um ponto material em um modelo quasi-steady state. A pista é dividida em segmentos retos e curvos, e calcula-se a velocidade máxima possível em cada trecho. Trata-se de um cálculo matemático simplificado, mas suficientemente preciso para uma abordagem inicial, calculando a volta ideal e permitindo analisar a influência de determinados parâmetros (OPTIMUMG, [2015?d]).

Esse método calcula a velocidade de contorno e saída de curva, e a velocidade em retas. A representação gráfica dessas velocidades pode ser vista na figura 15. Em mais detalhes, o programa calcula a velocidade máxima atingida no trecho de reta, durante a aceleração longitudinal. Determina-se, então, a máxima velocidade no trecho em curva. Em seguida, calcula-se a desaceleração longitudinal retrocedendo da curva até que a velocidade se iguale à velocidade em aceleração. Determina-se, assim, o ponto de entrada de curva, representado pelo cruzamento das linhas azul (aceleração) e vermelha (frenagem) na figura 15. Na prática, esse é o ponto onde o piloto inicia a frenagem. 
Figura 15 - Velocidade longitudinal vs. distância

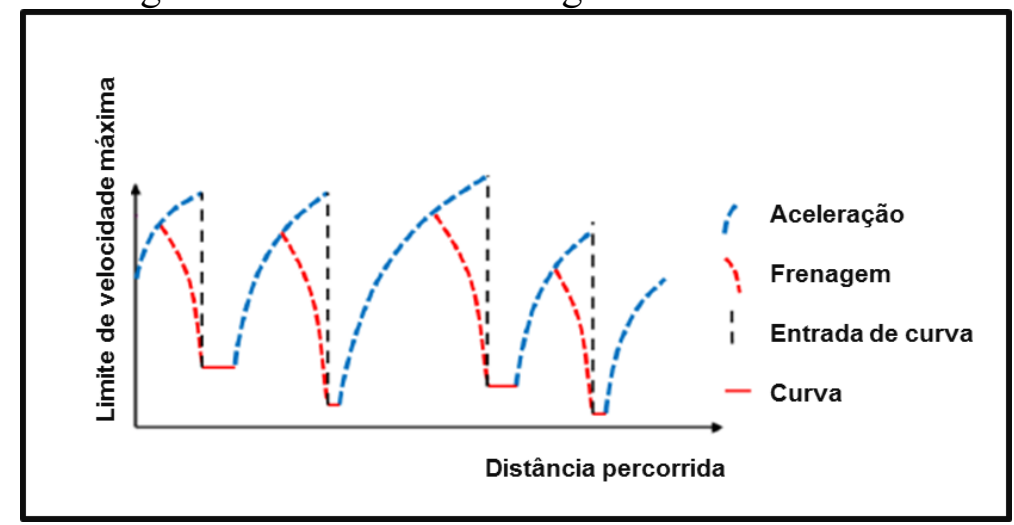

Fonte: autor "adaptado de" OptimumG, [2015?d], p. 5

A combinação desses resultados é feita de modo que não haja descontinuidade, como ilustrado no gráfico da figura 16. Caso contrário, haveria degraus na velocidade entre trechos adjacentes, não condizentes com a realidade (OPTIMUMG, [2015?d]). Esses degraus são representados na figura 15 pela linha preta vertical. Esse degrau é desconsiderado para o cálculo do tempo de volta, pois a linha azul (aceleração) é interrompida na intersecção com a linha vermelha (frenagem), definindo o ponto de início de frenagem.

Figura 16 - Velocidade vs. distância

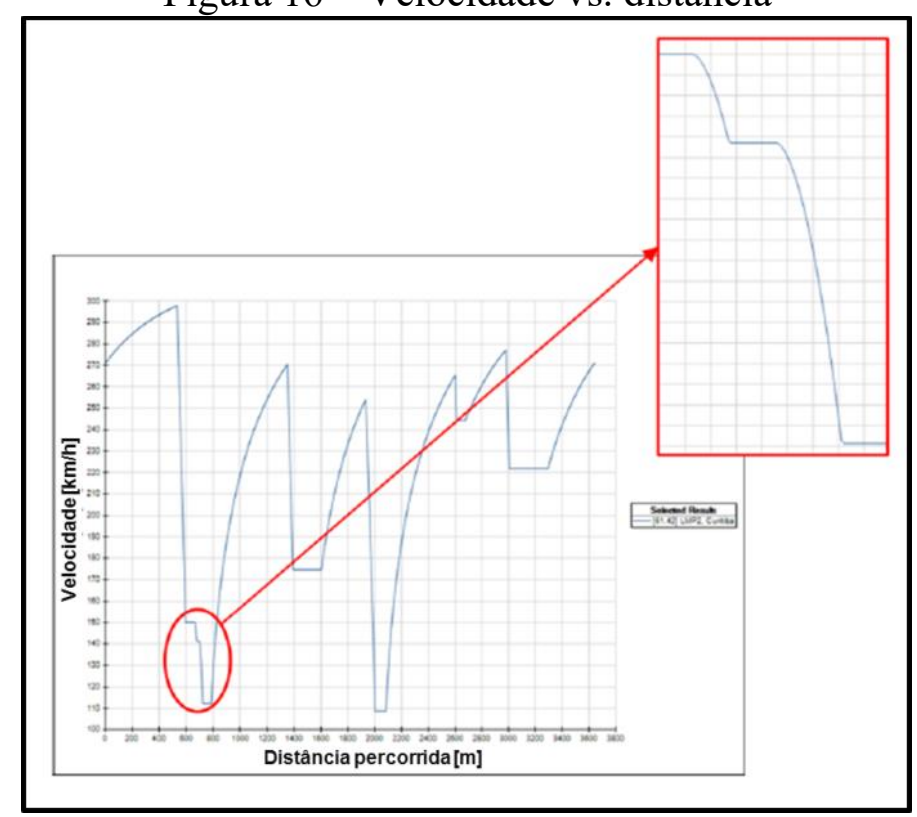

Fonte: autor "adaptado de" OptimumG, [2015?d], p. 5 Nota: Detalhe da transição suave entre segmentos

\subsubsection{Limitações}

Para qualquer simulação, é importante conhecer as limitações do modelo matemático. Este representa a realidade dentro de certas condições, numa determinada faixa de tolerância. 
Conforme destacado por OptimumG ([2015?d]), como o método adotado considera o veículo um ponto material, sem dimensões como bitola e distância entre eixos, não é considerada a transferência de peso, acarretando nas seguintes implicações:

a) nenhum efeito da suspensão;

b) nenhum efeito de inércia;

c) não ocorre transferência de carga entre os pneus.

O fato de não utilizar um modelo complexo de pneu traz as seguintes consequências:

a) desprezado efeito de cambagem;

b) desprezado ângulo de deriva e atraso de resposta;

c) desconsideradas influências da pressão e temperatura;

d) força lateral constante (embora haja fator que corrija tal parâmetro para influência da sustentação aerodinâmica).

O modelo também não considera a guinada, resultando na não capacidade de simular comportamento sub ou sobresterçante.

O traçado modelado possui largura desprezível. Não é modelada, portanto, a linha mais rápida adotada pelo piloto. Beckman ([2002?]) propõe um método matemático para determinação da linha mais rápida, ou racing line. Cambiaghi et al (1996) desenvolveram um programa computacional para determinação da linha mais rápida.

Não é modelada a superelevação da pista, portanto não há variação da capacidade de curva devido à decomposição das forças peso e inercial centrífuga.

Não há estados transitórios, desprezando a inércia e o efeito dos amortecedores.

A influência do momento de inércia em manobra de guinada (yaw) para traçados de autocross é irrelevante segundo trabalho de Casanova, Sharp e Symonds (2000).

Também é desconsiderada incidência de ventos e variação da pressão atmosférica.

Por fim, não é modelado o piloto, cujas principais consequências são:

a) nenhum atraso de resposta, ou seja, tempo de reação nulo;

b) troca de marcha na rotação ideal.

Apesar de todas as limitações, a empresa OptimumG ([2015?b]), desenvolvedora do programa empregado nesta pesquisa, afirma que os resultados ficam normalmente dentro de 
uma margem de dez por cento do tempo medido, e não raramente dentro de uma margem de cinco por cento.

\subsubsection{Modelo matemático do veículo}

Para o cálculo de tempo de volta pelo método quasi-steady state, o programa OptimumLap adota um modelo simplificado, com as devidas penalizações enumeradas no item 2.6.1.

Algumas equações que regem o movimento são descritas no manual do programa, as demais foram encontradas com auxílio do programa MATLAB. O trabalho está registrado no item 4 - VALIDAÇÃO DO MODELO.

O modelo matemático do veículo compreende as forças longitudinais de tração e frenagem, força lateral (de curva), força de arrasto aerodinâmico e de sustentação, conforme esquematizado na figura 17. Ainda pode-se adicionar a resistência ao rolamento dos pneus.

Figura 17 - Simplificação do modelo do veículo

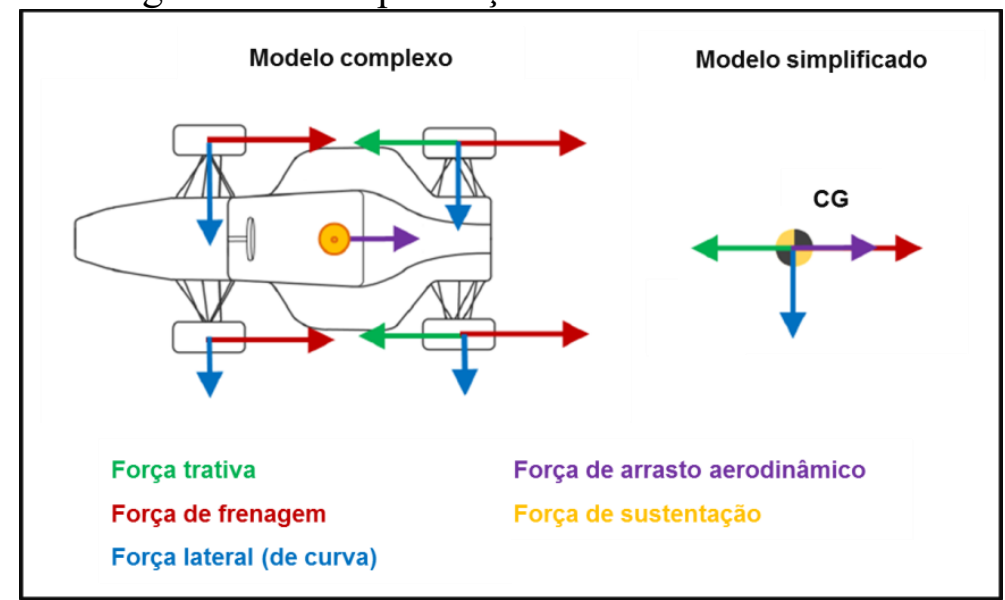

Fonte: autor "adaptado de" OptimumG, [2015?d], p. 62

O programa OptimumLap calcula a resistência ao rolamento como na equação 21.

$R_{r}=f_{r} . N$

A equação 21 inclui a influência da força de sustentação, resultando em valor diferente daquele empregado na equação 9, recomendada por Gillespie (1992). Vale lembrar que a força de sustentação negativa, ou downforce, apesar de incrementar a resistência ao rolamento, aumenta a capacidade de geração de forças longitudinal e lateral dos pneus, o que normalmente justifica seu emprego por meio de aerofólios. 


\subsubsection{Trecho de frenagem}

Pode-se ver na figura 18 o modelo do veículo em frenagem (trechos “B”). A seta verde indica o sentido de marcha. As forças de resistência ao rolamento e de sustentação não estão representadas para simplificar visualização.

Figura 18 - Modelo do trecho em frenagem

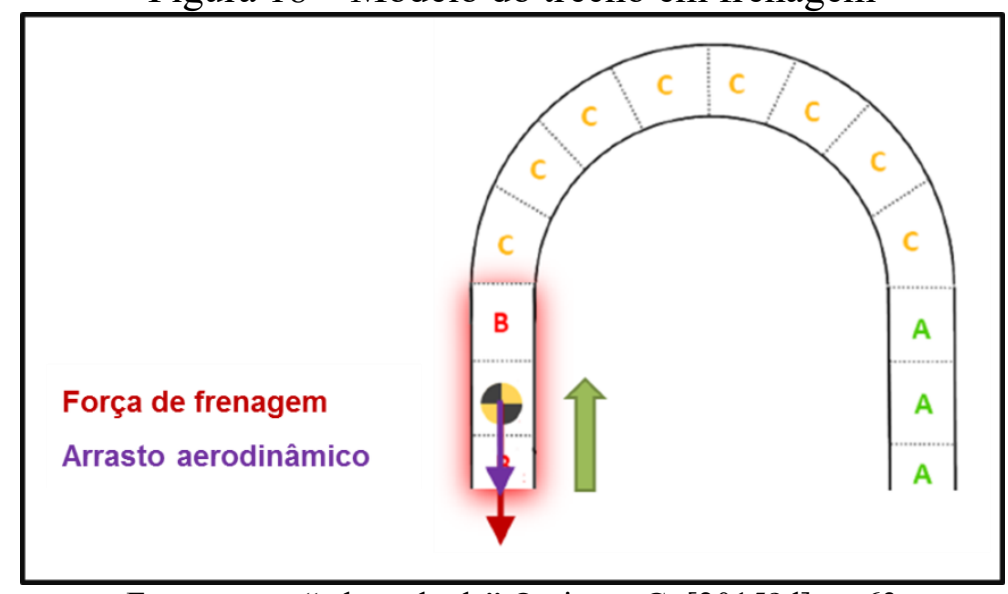

Fonte: autor "adaptado de" OptimumG, [2015?d], p. 63

As equações da frenagem são aquelas do item 2.3.2. O programa OptimumLap despreza a inércia rotativa das partes girantes, logo a massa equivalente é igual à massa do veículo. Resolvendo a Segunda Lei de Newton para a aceleração, tem-se a equação 22.

$a_{x}=\frac{-\left(F_{x}+R_{r}+D_{A}\right)}{M}$

Notar que na equação 22 não foi incluído ângulo de rampa. Foi considerada pista plana, conforme mencionado no item 3.3.

O programa adotado considera que, na frenagem, o veículo está em movimento uniformemente acelerado, logo a velocidade longitudinal no final do segmento de frenagem pode ser determinada pela equação 23 .

$v_{x T}=a_{x} . T+v_{x 0}$

onde:

$\mathrm{V}_{\mathrm{xT}}$ - velocidade longitudinal no final do trecho;

$\mathrm{T}$ - tempo;

$\mathrm{v}_{\mathrm{x} 0}-$ velocidade longitudinal no início do trecho. 
Segundo Beckman ([2002?]), entretanto, os freios não dissipam energia com uma taxa constante. A eficiência do processo de frenagem, ou seja, dissipação de energia, depende da interação entre o material de atrito e o disco ou tambor. Essa interação varia em função da temperatura. A eficiência aumenta com o aumento da temperatura até certo ponto, quando ocorre o fade térmico, ou seja, ebulição do fluido de freio. As bolhas no circuito de freio, compressíveis, absorvem praticamente toda a energia que deveria ser transferida para os freios de roda, e o veículo perde sua capacidade de frenagem. Além do fade, também há a não linearidade da força de arrasto, função do quadrado da velocidade relativa ao ar.

O tempo para percorrer o segmento é estimado pelo programa com base na velocidade inicial do trecho, como na equação 24 .

$T=\frac{\Delta x_{B}}{v_{x 0}}$

onde:

$\Delta \mathrm{x}_{\mathrm{B}}-$ comprimento do trecho de frenagem.

\subsubsection{Trecho de curva}

Os trechos de curva são representados pela letra "C" na figura 19.

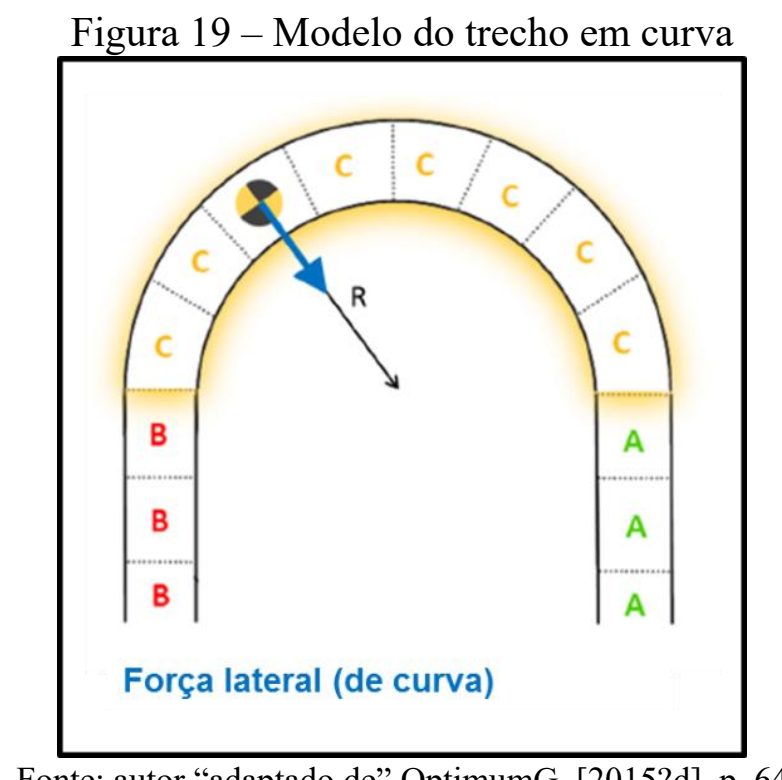

Fonte: autor "adaptado de" OptimumG, [2015?d], p. 64

A força lateral máxima suportada em curva pode ser determinada pela equação 25 .

$$
F_{y}=N \cdot \mu_{y}
$$


onde:

$\mu_{\mathrm{y}}-$ coeficiente de atrito lateral pneu-pavimento.

Esse coeficiente de atrito lateral pode ser medido em um banco de provas específico, mas não deve ser aplicado ao modelo do veículo, uma vez que incorreria no erro da não consideração da transferência de carga, como detalhado no item 2.6.1. Como o modelo aqui adotado não inclui as transferências de carga lateral e longitudinal, testes de skid-pad podem ser utilizados para determinar a capacidade de curva do veículo, contornando essa limitação do modelo.

Segundo Rill (2009, p. 159, tradução do autor), "quando um veículo contorna uma curva com uma aceleração lateral $\mathrm{a}_{\mathrm{y}}$, forças [inerciais] centrífugas são aplicadas às massas."

A aceleração lateral para o veículo modelado como ponto material é igual à centrípeta (equação 26).

$a_{y}=v_{x 0}^{2} / R$

onde:

$\mathrm{a}_{\mathrm{y}}$ - aceleração lateral.

As curvas de um traçado comumente possuem raio variável. Nesse caso, o programa adota raio constante para cada segmento, não necessariamente sendo iguais os raios de segmentos consecutivos.

Da Segunda Lei de Newton, tem-se a equação 27.

$F_{y}=M \cdot a_{y}$

Combinando as equações 26 e 27 e resolvendo para a velocidade, chega-se à equação 28.

$v_{x 0}=\sqrt{\frac{F_{y} \cdot R}{M}}$

Substituindo-se a equação 25 na equação 28, tem-se a equação 29 .

$v_{x 0}=\sqrt{\frac{N \cdot \mu_{y} \cdot R}{M}}$ 
A equação 30 calcula o tempo para percorrer o trecho de curva, assim como o trecho de frenagem, com base na velocidade inicial.

$T=\frac{\Delta x_{C}}{v_{x 0}}$

onde:

$\Delta \mathrm{x}_{\mathrm{C}}-$ comprimento do trecho de curva.

\subsubsection{Trecho de aceleração}

Na figura 20 se encontra o modelo do veículo em aceleração (trechos “A”). A seta verde indica o sentido de marcha. As forças de resistência ao rolamento e de sustentação não estão representadas.

Figura 20 - Modelo do trecho em aceleração

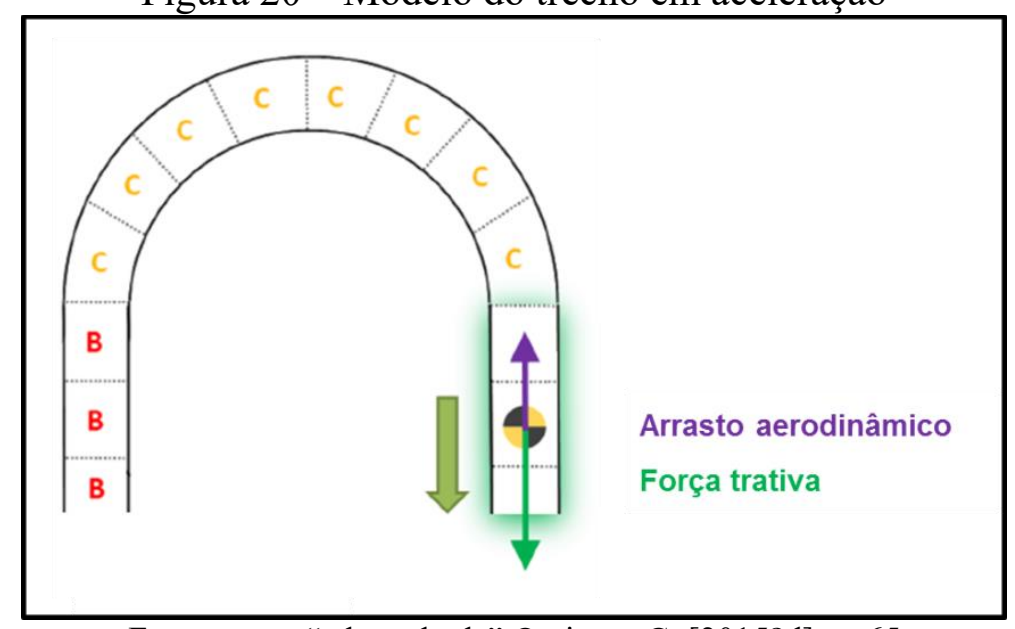

Fonte: autor "adaptado de" OptimumG, [2015?d], p. 65

As equações da aceleração são aquelas do item 2.3.1. O programa utilizado não inclui a inércia das partes girantes, portanto a massa equivalente é a própria massa do veículo. Resolvendo a Segunda Lei de Newton para a aceleração, tem-se a equação 31.

$a_{x}=\frac{F_{R}-R_{r}-D_{A}}{M}$

Analogamente ao cálculo da frenagem (item 2.6.3), não se aplicou o ângulo de rampa.

Considerando que na aceleração o veículo está em movimento uniformemente acelerado, como uma simplificação, a velocidade no final do trecho de aceleração também pode ser determinada pela equação 23. Da mesma forma, a equação 24 serve para determinar o tempo para percorrer o trecho de aceleração. 


\section{MODELAGEM}

Este capítulo apresenta os parâmetros e instruções para recriação dos modelos empregados na simulação, tanto dos veículos quanto das pistas, e como algumas limitações do programa OptimumLap podem ser contornadas.

\subsection{MODELAGEM DO VEÍCULO RS8}

A modelagem do protótipo RS8 foi feita com base nos dados fornecidos pela equipe Fórmula FEI, do Centro Universitário FEI, além de dados coletados em pista, com algumas adaptações exigidas pelo programa.

Optou-se por utilizar a densidade do ar no nível do mar e empregar um fator de correção (scaling factor) para diferentes altitudes.

\subsubsection{Parâmetros}

A tabela 2 contém os dados a serem inseridos na criação do modelo do veículo. A tabela completa de torque em função da rotação do motor está no Apêndice C.

Nota-se que, apesar da unidade J.kg-1 adotada para a densidade energética do combustível, este é selecionado de uma lista. Sua escolha determina o consumo de combustível por volta. O veículo RS8 utiliza, efetivamente, etanol E100, não disponível na lista do programa. Optou-se pelo combustível de poder calorífico mais próximo, E85. Essa divergência não influencia o tempo de volta, apenas o consumo energético. 
Tabela 2 - Parâmetros para modelo do veículo RS8

\begin{tabular}{|c|c|c|c|}
\hline Parâmetro OptimumLap & Parâmetro traduzido & Preencher com & Unidade \\
\hline GENERAL DATA & Dados Gerais & & \\
\hline Vehicle Type & Tipo de Veículo & FSAE & [ ] \\
\hline Mass & Massa & 255 & {$[\mathrm{~kg}]$} \\
\hline Driven Type & Tração & $2 \mathrm{WD}$ & [ ] \\
\hline AERO DATA & Aerodinâmica & Drag-Lift & [ ] \\
\hline Drag Coefficient & Coeficiente de Arrasto & 2,240 & [ ] \\
\hline Downforce Coefficient & Coeficiente de Downforce & 3,016 & [ ] \\
\hline Front Area & Área Frontal Projetada & 1,134 & {$\left[\mathrm{~m}^{2}\right]$} \\
\hline Air Density & Densidade do Ar & 1,226 & {$\left[\mathrm{~kg} / \mathrm{m}^{3}\right]$} \\
\hline TIRE DATA & Dados dos Pneus & & \\
\hline Tire Radius & Raio Dinâmico do Pneu & 0,226 & [m] \\
\hline Rolling Resistance & $\begin{array}{l}\text { Coeficiente de Resistência } \\
\text { ao Rolamento }\end{array}$ & 0,015 & [ ] \\
\hline Longitudinal Friction & $\begin{array}{l}\text { Limite de Aderência } \\
\text { Longitudinal }\end{array}$ & 1,750 & [ ] \\
\hline $\begin{array}{l}\text { Longitudinal Load } \\
\text { Sensitivity }\end{array}$ & $\begin{array}{l}\text { Sensibilidade Longitudinal à } \\
\text { Carga }\end{array}$ & 0,006 & {$\left[\mathrm{kgf}^{1}\right]$} \\
\hline Lateral Friction & Limite de Aderência Lateral & 1,750 & [ ] \\
\hline Lateral Load Sensitivity & $\begin{array}{l}\text { Sensibilidade Lateral à } \\
\text { Carga }\end{array}$ & 0,006 & {$\left[\operatorname{kgf}^{1}\right]$} \\
\hline ENGINE DATA & Dados do Motor & & \\
\hline Engine Speed & $\begin{array}{l}\text { Velocidade Angular do } \\
\text { Motor }\end{array}$ & 802 a 10300 & {$\left[\mathrm{~min}^{-1}\right]$} \\
\hline Engine Torque & Torque do Motor & 3,84 a 4,93 & [kgf.m] \\
\hline Thermal Efficiency & Eficiência Térmica & 30,000 & {$[\%]$} \\
\hline Fuel Energy Density & $\begin{array}{l}\text { Densidade Energética do } \\
\text { Combustível }\end{array}$ & E85 & {$[\mathrm{J} / \mathrm{kg}]$} \\
\hline TRANSMISSION DATA & Dados da Transmissão & & \\
\hline Transmission Type & Tipo de Transmissão & Sequential Gearbox & [ ] \\
\hline Gear 1 & Relação da Marcha 1 & 2,4160 & [ ] \\
\hline Gear 2 & Relação da Marcha 2 & 1,7330 & [ ] \\
\hline Gear 3 & Relação da Marcha 3 & 1,3120 & [ ] \\
\hline Gear 4 & Relação da Marcha 4 & 1,0500 & [ ] \\
\hline Gear 5 & Relação da Marcha 5 & 0,8400 & [ ] \\
\hline Final Drive Ratio & Relação Final & 7,850 & [ ] \\
\hline Drive Efficiency & Eficiência da Transmissão & 91 & [\%] \\
\hline SCALING FACTORS & Fatores de Correção & & \\
\hline Power Factor & Fator de Potência & 100 & {$[\%]$} \\
\hline Aero Factor & Fator de Aerodinâmica & 90 & [\%] \\
\hline Grip Factor & Fator de Aderência & 100 & [\%] \\
\hline
\end{tabular}




\subsubsection{Modelo do pneu}

Os quatro pneus empregados no veículo são modelo Hoosier LC0 18" x 7" x 10" montados em rodas de largura 6 polegadas na dianteira e 7 polegadas na traseira.

O modelo do pneu foi criado com base no trabalho de Lotto (2014). A única grande diferença entre o veículo estudado por ele e os da presente obra são os aerofólios dianteiro e traseiro, não presentes naquela época. Logo, os dados dos pneus podem ser aproveitados. Os dados foram coletados em um banco de provas específico para pneus, por meio de um consórcio ao qual aderiram várias universidades participantes da competição Fórmula SAE.

A figura 21 contém os pontos referentes à geração de força lateral em função da força normal. Os pontos vermelhos representam a máxima capacidade de geração de força lateral do pneu para diferentes cargas verticais, permitindo determinar a sensibilidade do pneu à variação de força normal.

Figura 21 - Medição de força lateral em função da força vertical

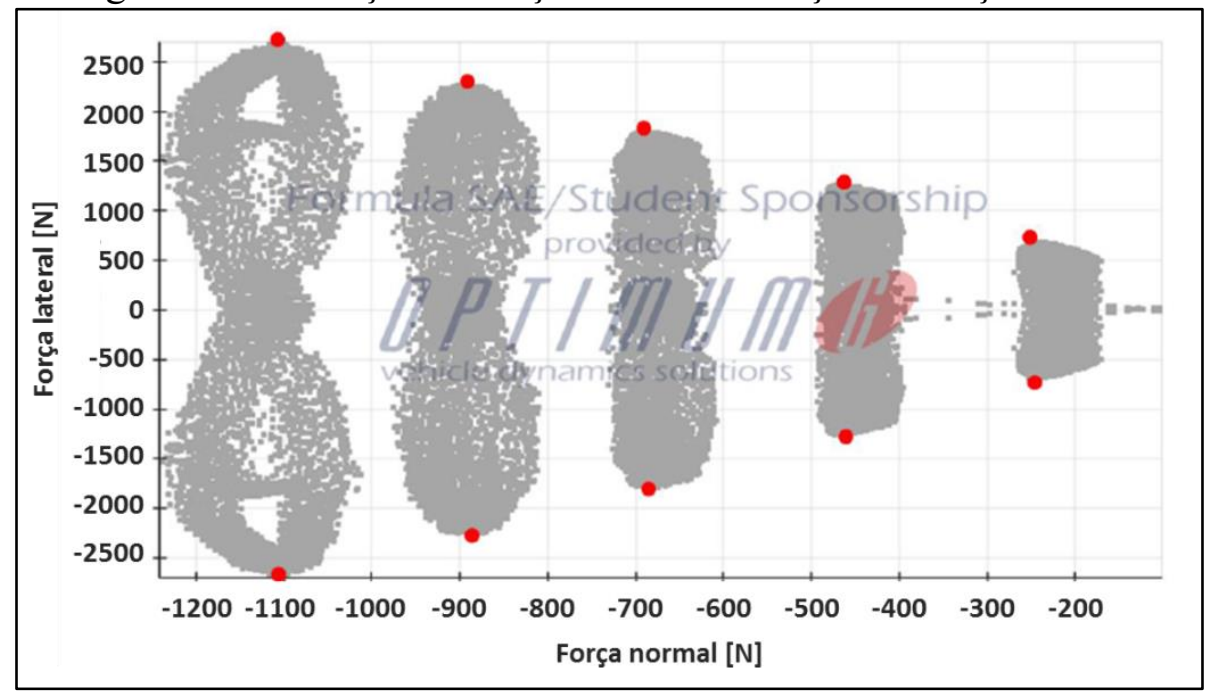

Fonte: autor "adaptado de" Lotto, 2014, p. 64

Nota: teste em bancada

A sensibilidade à variação da força normal indica quanto se perde do coeficiente de atrito pelo incremento de $1 \mathrm{kgf}$ de carga vertical. O programa utiliza esse dado para corrigir a geração de força dos pneus em função da força de sustentação.

O coeficiente de atrito lateral máximo obtido no teste de pneu em bancada não deve ser confundido com o máximo coeficiente de atrito que se encontra nos testes com veículo em pista, uma vez que há influência do pavimento, da transferência de carga e dos sistemas de suspensão e direção. Um fator de correção pode ser aplicado, reduzindo esse valor e adequando a capacidade de curva do veículo. 
Os resultados da análise se encontram na tabela 3.

Tabela 3 - Geração de força lateral em função da força normal

\begin{tabular}{c|c|c|c|c}
\hline $\begin{array}{c}\text { Força } \\
\text { Normal [N] }\end{array}$ & $\begin{array}{c}\text { Força } \\
\text { Lateral [N] }\end{array}$ & $\begin{array}{c}\text { Coef. de Atrito } \\
\text { Lateral [ ] }\end{array}$ & $\begin{array}{c}\text { Força } \\
\text { Normal [kgf] }\end{array}$ & $\begin{array}{c}\text { Sensibilidade à } \\
\text { Carga [kgf }^{\mathbf{1}} \text { ] }\end{array}$ \\
\hline 250 & 730 & 2,920 & 25,48 & (referência) \\
460 & 1280 & 2,783 & 46,89 & 0,006 \\
690 & 1800 & 2,609 & 70,34 & 0,007 \\
890 & 2300 & 2,584 & 90,72 & 0,005 \\
1120 & 2710 & 2,420 & 114,17 & 0,006 \\
\hline \multicolumn{4}{c}{ Fonte: autor } \\
\multicolumn{4}{c}{ Nota: teste em bancada }
\end{tabular}

Observando os dados da tabela 3, conclui-se que o pneu tem sua capacidade de geração de força lateral reduzida em 0,006 por quilograma-força acrescido em sua carga vertical. Isso implica numa redução do coeficiente de atrito com o aumento da carga, uma vez que a força de sustentação negativa aumenta a força normal gerada entre pneu e solo.

Analogamente, foi feito estudo para a geração de força longitudinal, como visto na figura 22. Um fator de correção também deve ser utilizado para o coeficiente de atrito longitudinal.

Figura 22 - Medição de força longitudinal em função da força vertical

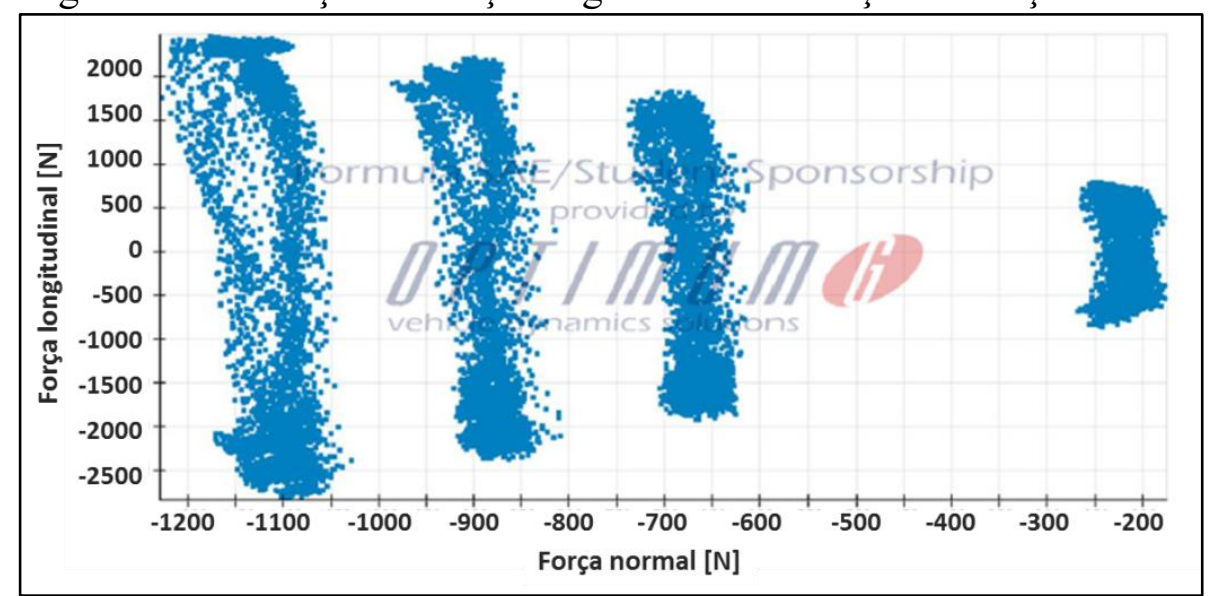

Fonte: Lotto, 2014, p. 68

Nota: teste em bancada 
A tabela 4 apresenta os resultados da geração de força longitudinal.

Tabela 4 - Geração de força longitudinal em função da força normal

\begin{tabular}{c|c|c|c|c}
\hline $\begin{array}{c}\text { Força } \\
\text { Normal [N] }\end{array}$ & $\begin{array}{c}\text { Força } \\
\text { Longit. [N] }\end{array}$ & $\begin{array}{c}\text { Coef. de Atrito } \\
\text { Longit. [ ] }\end{array}$ & $\begin{array}{c}\text { Força } \\
\text { Normal [kgf] }\end{array}$ & $\begin{array}{c}\text { Sensibilidade à } \\
\text { Carga [kgf }^{\mathbf{1}} \text { ] }\end{array}$ \\
\hline 250 & 860 & 3,440 & 25,48 & (referência) \\
675 & 1890 & 2,800 & 68,81 & 0,015 \\
880 & 2320 & 2,636 & 89,70 & 0,013 \\
1100 & 2640 & 2,400 & 112,13 & 0,012 \\
\hline \multicolumn{4}{c}{ Fonte: autor } \\
\multicolumn{4}{c}{ Nota: teste em bancada }
\end{tabular}

Nota-se uma maior diminuição do coeficiente de atrito longitudinal em função do aumento da força normal se comparada à geração de força lateral. O programa, entretanto, permite um valor máximo de 0,006 para essa entrada, que foi adotado.

A figura 23 exibe um gráfico da máxima capacidade de geração de força do pneu em função da força normal. Os diferentes coeficientes de sensibilidade à variação da força normal são evidentes pela inclinação das retas. A curva traço-ponto azul, com maior inclinação, indica maior variação do coeficiente de atrito longitudinal em função da carga vertical em relação ao coeficiente de atrito lateral (curva tracejada vermelha).

Figura 23 - Variação da aderência do pneu

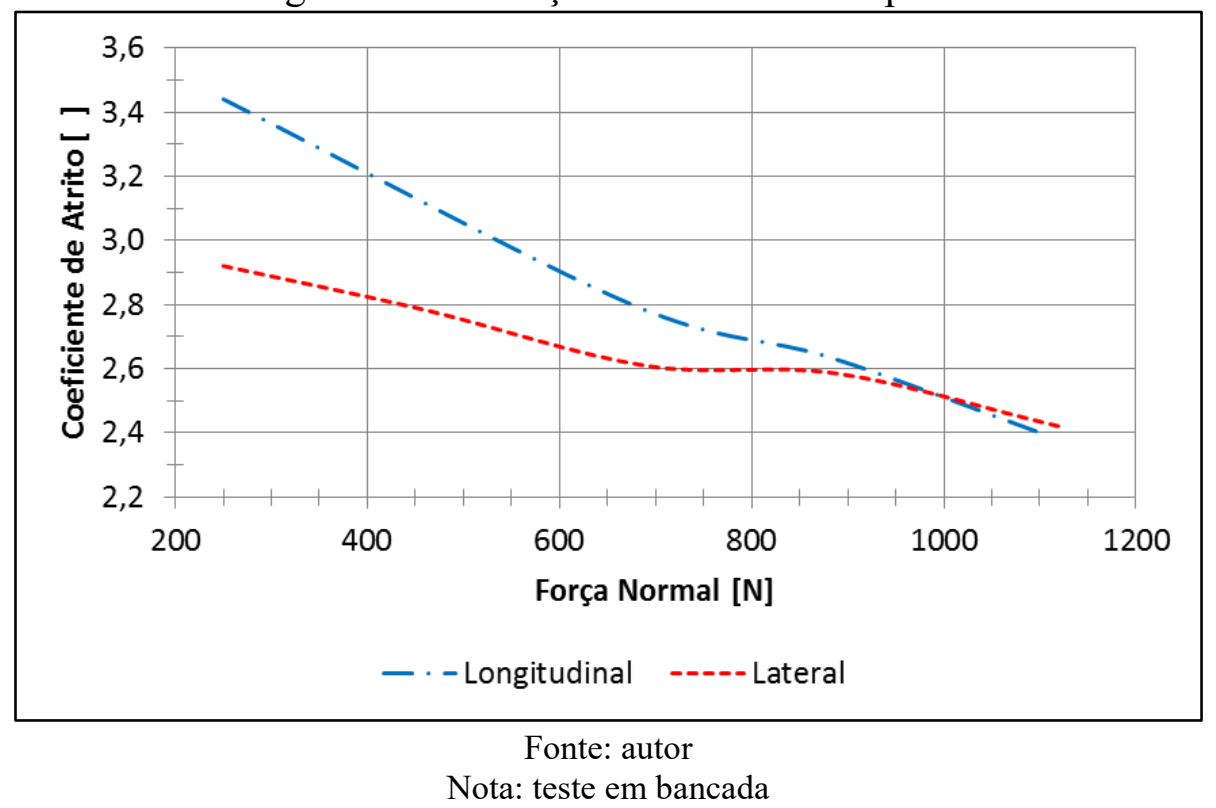

A entrada de dados no programa deve ser feita com o coeficiente de atrito para a carga estática, minimizando, dessa forma, os erros, especialmente para a direção longitudinal, onde o elevado índice não pode ser inserido por limitações do programa. 
A divergência entre a capacidade de geração de força longitudinal do veículo real e do veículo simulado não deve ocasionar problemas, uma vez que o limite de tração é determinante até segunda marcha, a uma velocidade aproximada de $53 \mathrm{~km} / \mathrm{h}$ (figura 28). Em altas velocidades, onde a divergência é maior pelo aumento da força vertical aerodinâmica, o limite de aderência longitudinal passa a ser irrelevante. O limite de tração é determinado pela potência disponível nas rodas trativas, pela força normal no eixo trativo e pela aderência longitudinal dos pneus desse mesmo eixo.

\subsubsection{Curva do motor e acoplamento da embreagem}

O motor empregado no veículo é um quatro tempos de deslocamento $449 \mathrm{~cm}^{3}$, monocilíndrico de cinco válvulas, originário da motocicleta de competição fora de estrada Yamaha WR450, com adaptações dos coletores de admissão e exaustão, por exigência do regulamento da competição Fórmula SAE (LOTTO, 2014). Suas curvas de torque e potência estão representadas na figura 24. O combustível utilizado é etanol E100.

Figura 24 - Curva característica do motor Yamaha $449 \mathrm{~cm}^{3}$ modificado

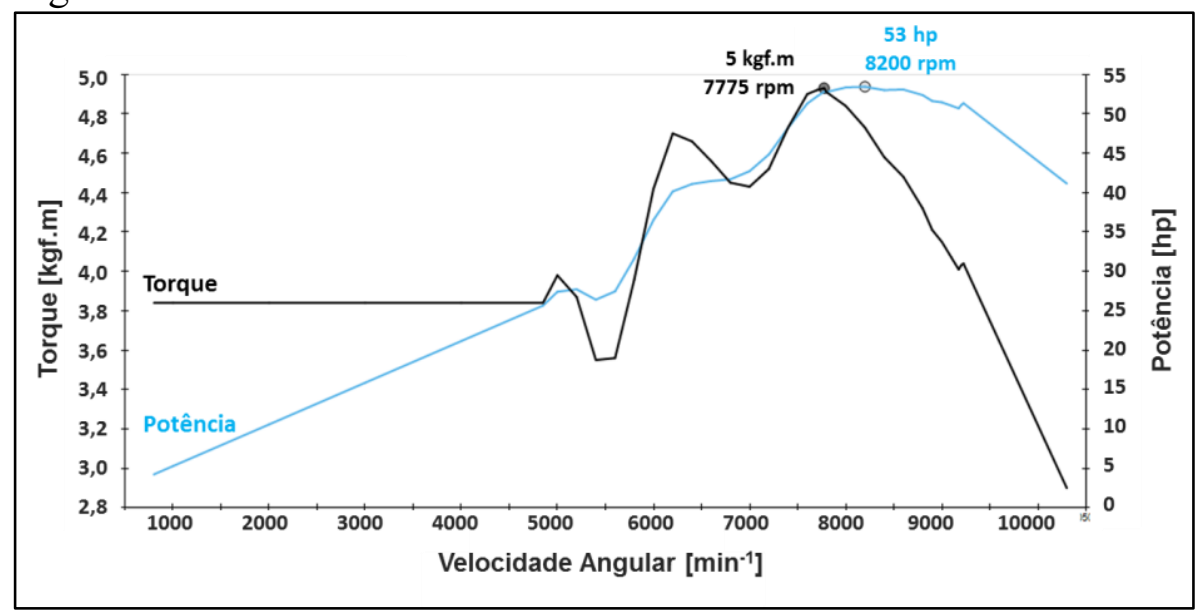

Fonte: autor

Por limitações do programa, a menor velocidade de partida é $1 \mathrm{~m} / \mathrm{s}$, ou seja, 3,6 km/h. Para que o veículo não parta acima dessa velocidade, é necessário incluir a velocidade angular do motor correspondente em primeira marcha. Nesse caso, são $802 \mathrm{rpm}$. Incluir rotações abaixo de 802 rpm geraria erro no relatório do veículo, acarretando em tempos artificialmente altos para aceleração. Iniciar com rotações mais altas, ao contrário, faria com que o veículo partisse com velocidade inicial alta, o que indica que o programa não extrapola a curva de torque do motor nem simula o acoplamento da embreagem. Não se deve inserir $0 \mathrm{rpm}$, pois isso causa um erro e todo o modelo do veículo é perdido. 
Como o código do programa não calcula a modulação da embreagem, essa deficiência pode ser contornada ajustando o torque do motor na faixa de rotações da modulação.

A figura 25 ilustra o acoplamento da embreagem de um veículo de passeio qualquer. No início da modulação da embreagem, a transmissão se encontra em baixa rotação, enquanto o motor desenvolve uma rotação mais alta. Durante a equalização das rotações, ocorre a desaceleração dos componentes do motor, que provoca um pico de torque na transmissão. Esse fenômeno também não é considerado pelo OptimumLap, que despreza tanto a modulação da embreagem quanto as inércias rotativas.

Figura 25 - Acoplamento da embreagem

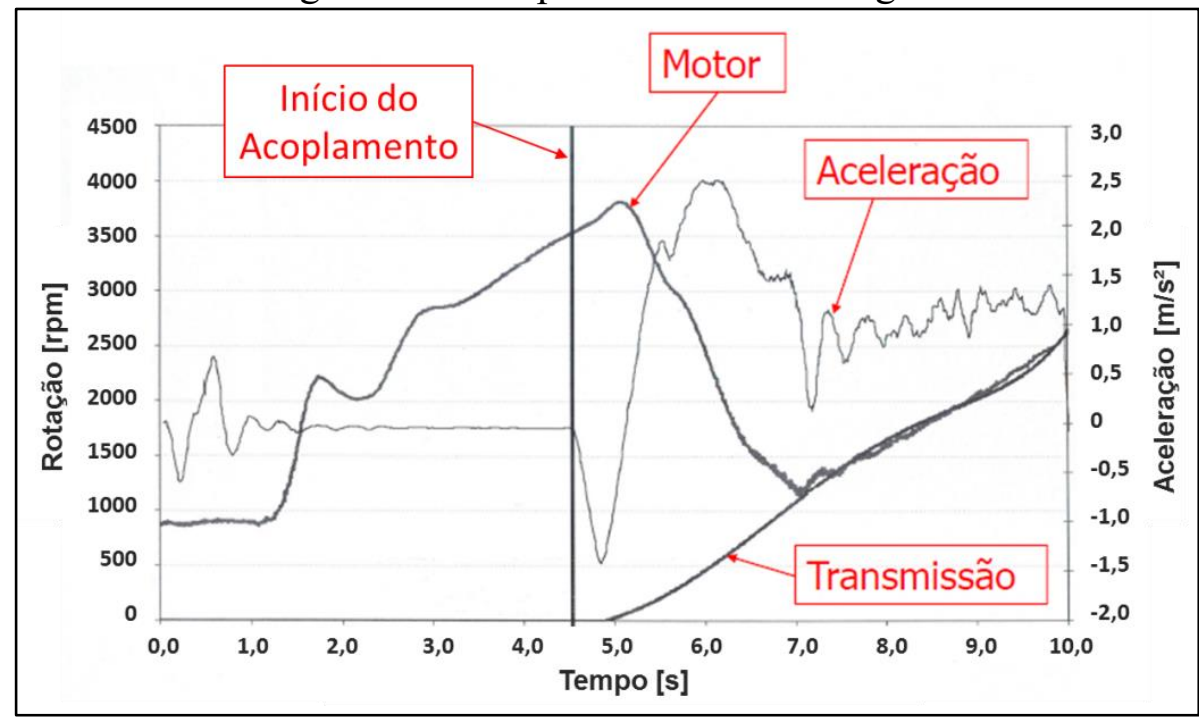

Fonte: autor "adaptado de" Barreto, 2011, p. 70

No veículo em questão, não há necessidade da inclusão do pico de torque na curva do motor, uma vez que já se está acima do limite de tração dos pneus com o torque constante em baixas rotações como no gráfico da figura 24, como explicado no item 3.1.4. O programa simula um controle de tração, intitulado TCS, impedindo o escorregamento das rodas, trabalhando sempre no limite dos pneus.

\subsubsection{Escalonamento e força trativa}

A caixa de transmissão empregada também é originalmente de uma motocicleta, com cinco velocidades, de trocas sequenciais, com embreagem acionada manualmente.

O escalonamento da transmissão (tabela 2) resulta no gráfico dente de serra da figura 26, com as indicações de melhor rotação para troca de marcha, visando desempenho. Esses valores podem ser utilizados para orientar o piloto, ou mesmo para uma futura automatização da transmissão. A troca da marcha ocorre quando a força disponível nas rodas da marcha 
seguinte supera a força da marcha atual. No gráfico de força trativa (figura 27), se evidencia pelo cruzamento das curvas de força trativa.

Figura 26 - Gráfico dente de serra da transmissão do RS8

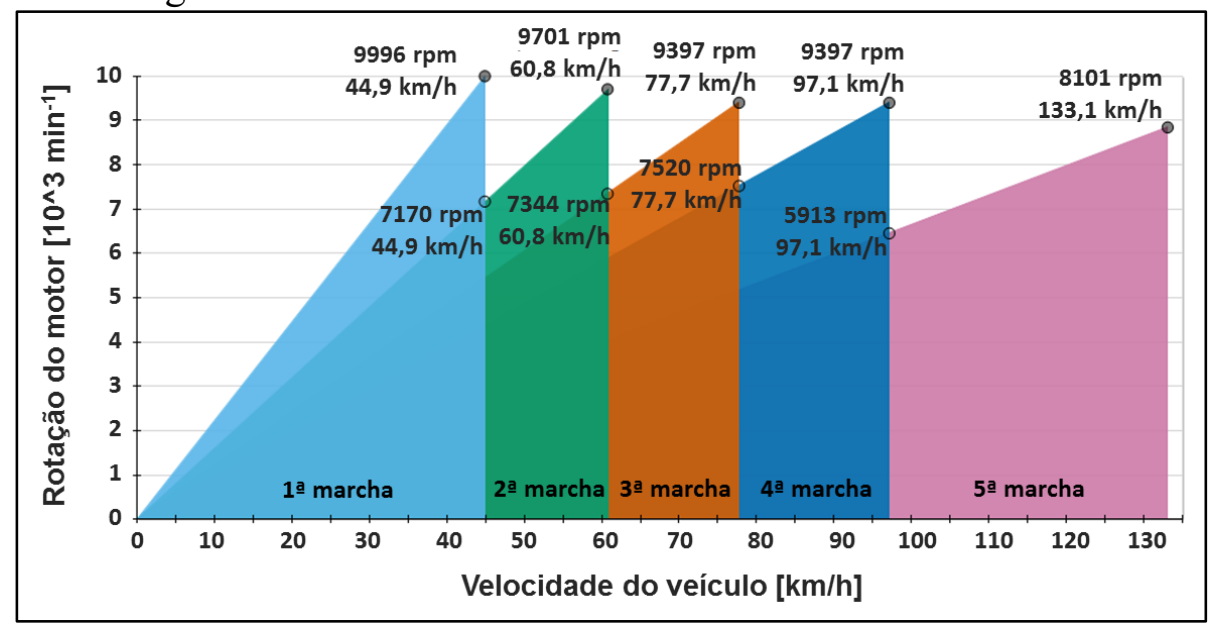

Fonte: autor

Também foi gerado um gráfico como o da figura 27, que correlaciona a força trativa máxima disponível nas rodas com a velocidade longitudinal do veículo para cada uma das cinco marchas.

Figura 27 - Gráfico de força trativa por marcha do RS8

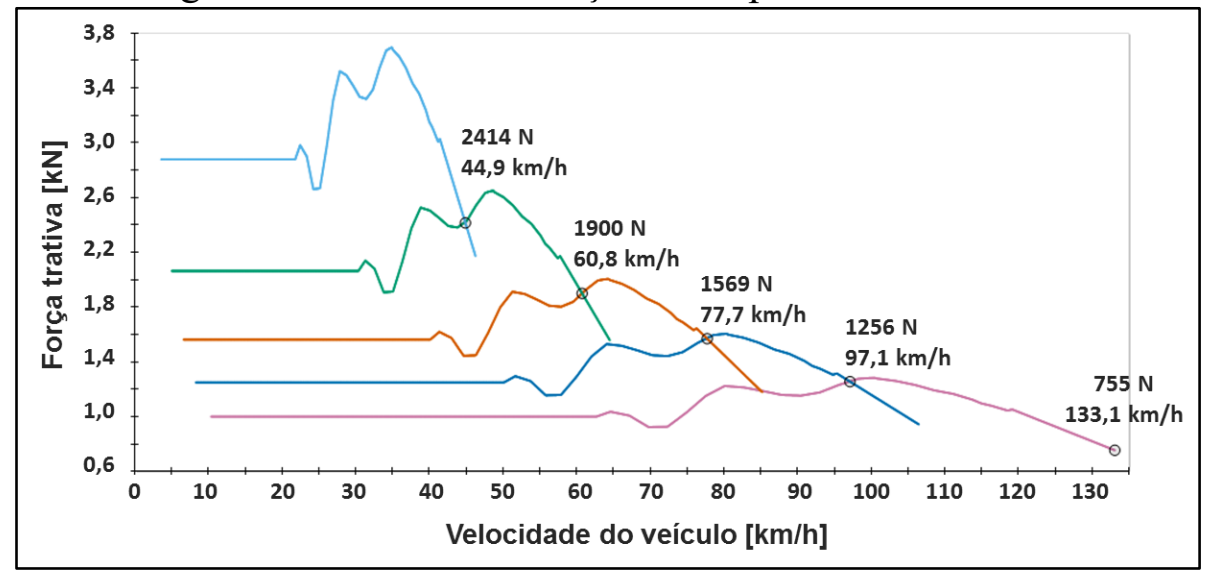

Fonte: autor

Os pneus do eixo trativo precisam ser capazes de transferir toda a força disponível ao solo, caso contrário haverá escorregamento. No caso do programa adotado, em vez do escorregamento, ocorre o corte de potência pelo sistema de controle de tração (TCS). A força trativa excedente pode ser vista no gráfico da figura 28 como área hachurada. Como o protótipo estudado não possui controle de tração, esse corte de potência visando o não escorregamento dos pneus trativos depende exclusivamente da perícia do piloto. 
Observando a figura 28, percebe-se que o limite de tração (linha verde) aumenta com o aumento da velocidade. Esse fenômeno se deve ao fato da força aerodinâmica vertical para baixo aumentar a força normal de contato dos pneus com o solo, favorecendo a tração.

Nas velocidades mais altas, entretanto, a força disponível é menor, pois se engrenam marchas de menor redução, que permitem maiores velocidades, porém menor força trativa (linha preta do gráfico da figura 28).

Figura 28 - Gráfico de força trativa com resistências e limite de tração do RS8

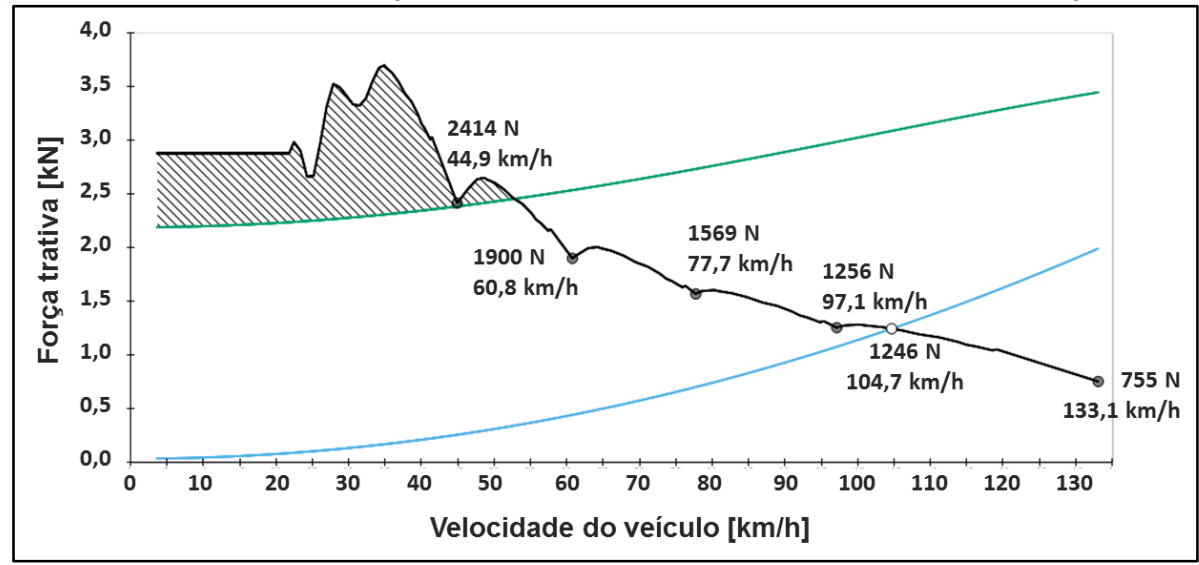

Fonte: autor

Para o RS8, o limite de tração é de $2454 \mathrm{~N}$, correspondente a $53 \mathrm{~km} / \mathrm{h}$. Acima dessa velocidade, a aderência dos pneus não limita a aceleração longitudinal.

Nesse mesmo gráfico, há a indicação de velocidade $133,1 \mathrm{~km} / \mathrm{h}$ ao final da curva de força de tração. Essa seria a velocidade máxima limitada pela transmissão, desprezando as resistências ao movimento.

Considerando as resistências (linha azul), a velocidade máxima fica em 104,7 km/h, como indicado no cruzamento das curvas de resistência e de força trativa.

\subsubsection{Resultados do modelo}

Por fim, foi gerado um relatório compilando os principais resultados, aqui apresentados na tabela 5. A unidade empregada para aceleração lateral máxima atingida nas pistas circulares de skid-pad é G, ou seja, unidade equivalente à aceleração da gravidade $(9,81$ $\mathrm{m} / \mathrm{s}^{2}$ ), comumente empregada na literatura automobilística.

As unidades de potência e velocidade são, respectivamente, horse-power e $\mathrm{km} / \mathrm{h}$. Há opção de se alterar as unidades e trabalhar, por exemplo, com o Sistema Internacional (SI), mas como a proposta do programa, assim como do presente trabalho, é a aplicação prática em competições automobilísticas, é preferível utilizar as unidades mais comuns no meio. 
Tabela 5 - Relatório do veículo RS8

\begin{tabular}{|c|c|c|c|}
\hline Parâmetro OptimumLap & Parâmetro traduzido & Resultado & Unidade \\
\hline VEHICLE CONFIGURATION & Configuração do Veículo & & \\
\hline Total Mass & Massa Total & 255 & {$[\mathrm{~kg}]$} \\
\hline Max Torque & Torque Máximo & 4,93@7775 rpm & [kgf.m] \\
\hline Type of Fuel & Tipo de Combustível & E85 & {[]} \\
\hline Type of Transmission & Tipo de Transmissão & Sequential Gearbox & [ ] \\
\hline Max Power & Potência Máxima & $54,43 @ 8200$ rpm & [hp] \\
\hline Power Mass Ratio & Relação Potência/Peso & 0,21 & {$[\mathrm{hp} / \mathrm{kg}]$} \\
\hline Downforce@100km/h & $\begin{array}{l}\text { Força Aerodinâmica } \\
\text { Vertical Para Baixo }\end{array}$ & 1455,96 & {$[\mathrm{~N}]$} \\
\hline Drag@100km/h & Arrasto Aerodinâmico & 1140,71 & {$[\mathrm{~N}]$} \\
\hline PERFORMANCE METRICS & Medidas de Desempenho & & \\
\hline Top Speed & Velocidade Máxima & 104,67 & {$[\mathrm{~km} / \mathrm{h}]$} \\
\hline Time for 0 to $100 \mathrm{~km} / \mathrm{h}$ & Tempo de $0-100 \mathrm{~km} / \mathrm{h}$ & 6,99 & {$[\mathrm{~s}]$} \\
\hline Time for 100 to $0 \mathrm{~km} / \mathrm{h}$ & Tempo de $100-0 \mathrm{~km} / \mathrm{h}$ & 1,40 & {$[\mathrm{~s}]$} \\
\hline Distance for 100 to $0 \mathrm{~km} / \mathrm{h}$ & Distância de $100-0$ km/h & 17,3 & [m] \\
\hline $\begin{array}{l}\text { Lateral Acceleration - Skidpad } \\
50 \mathrm{~m}\end{array}$ & $\begin{array}{l}\text { Aceleração Lateral } \\
\text { Máxima - Skidpad } 50 \text { m }\end{array}$ & 1,72 & {$[\mathrm{G}]$} \\
\hline $\begin{array}{l}\text { Lateral Acceleration - Skidpad } 9 \\
\mathrm{~m}\end{array}$ & $\begin{array}{l}\text { Aceleração Lateral } \\
\text { Máxima - Skidpad } 9 \text { m }\end{array}$ & 2,01 & {$[\mathrm{G}]$} \\
\hline
\end{tabular}

\subsection{MODELAGEM DO VEÍCULO RS9}

O veículo RS9 foi desenvolvido baseado no RS8. O aerofólio traseiro teve de ser redesenhado como consequência de uma mudança no regulamento da Fórmula SAE para o ano de 2016, sofrendo uma redução de tamanho. A modelagem do veículo RS9, cujos dados estão na tabela 6 , é análoga à do RS8. 
Tabela 6 - Parâmetros para modelo do veículo RS9

\begin{tabular}{|c|c|c|c|}
\hline Parâmetro OptimumLap & Parâmetro traduzido & Preencher com & Unidade \\
\hline GENERAL DATA & Dados Gerais & & \\
\hline Vehicle Type & Tipo de Veículo & FSAE & [ ] \\
\hline Mass & Massa & 252 & {$[\mathrm{~kg}]$} \\
\hline Driven Type & Tração & $2 \mathrm{WD}$ & [ ] \\
\hline AERO DATA & Aerodinâmica & Drag-Lift & [ ] \\
\hline Drag Coefficient & Coeficiente de Arrasto & 1,500 & [ ] \\
\hline Downforce Coefficient & Coeficiente de Downforce & 2,24 & [ ] \\
\hline Front Area & Área Frontal Projetada & 1,000 & {$\left[\mathrm{~m}^{2}\right]$} \\
\hline Air Density & Densidade do Ar & 1,226 & {$\left[\mathrm{~kg} / \mathrm{m}^{3}\right]$} \\
\hline TIRE DATA & Dados dos Pneus & & \\
\hline Tire Radius & Raio Dinâmico do Pneu & 0,226 & [m] \\
\hline Rolling Resistance & $\begin{array}{l}\text { Coeficiente de Resistência } \\
\text { ao Rolamento }\end{array}$ & 0,015 & [ ] \\
\hline Longitudinal Friction & $\begin{array}{l}\text { Limite de Aderência } \\
\text { Longitudinal }\end{array}$ & 1,750 & [ ] \\
\hline $\begin{array}{l}\text { Longitudinal Load } \\
\text { Sensitivity }\end{array}$ & $\begin{array}{l}\text { Sensibilidade Longitudinal à } \\
\text { Carga }\end{array}$ & 0,006 & {$\left[\mathrm{kgf}^{1}\right]$} \\
\hline Lateral Friction & Limite de Aderência Lateral & 1,750 & [ ] \\
\hline Lateral Load Sensitivity & $\begin{array}{l}\text { Sensibilidade Lateral à } \\
\text { Carga }\end{array}$ & 0,006 & {$\left[\mathrm{kgf}^{1}\right]$} \\
\hline ENGINE DATA & Dados do Motor & & \\
\hline Engine Speed & $\begin{array}{l}\text { Velocidade Angular do } \\
\text { Motor }\end{array}$ & 802 a 10300 & {$\left[\min ^{-1}\right]$} \\
\hline Engine Torque & Torque do Motor & 3,84 a 4,93 & [kgf.m] \\
\hline Thermal Efficiency & Eficiência Térmica & 30,000 & {$[\%]$} \\
\hline Fuel Energy Density & $\begin{array}{l}\text { Densidade Energética do } \\
\text { Combustível }\end{array}$ & E85 & {$[\mathrm{J} / \mathrm{kg}]$} \\
\hline TRANSMISSION DATA & Dados da Transmissão & & \\
\hline Transmission Type & Tipo de Transmissão & Sequential Gearbox & [ ] \\
\hline Gear 1 & Relação da Marcha 1 & 2,4160 & [ ] \\
\hline Gear 2 & Relação da Marcha 2 & 1,7330 & [ ] \\
\hline Gear 3 & Relação da Marcha 3 & 1,3120 & [ ] \\
\hline Gear 4 & Relação da Marcha 4 & 1,0500 & [ ] \\
\hline Gear 5 & Relação da Marcha 5 & 0,8400 & \\
\hline Final Drive Ratio & Relação Final & 7,850 & \\
\hline Drive Efficiency & Eficiência da Transmissão & 91 & [\%] \\
\hline SCALING FACTORS & Fatores de Correção & & \\
\hline Power Factor & Fator de Potência & 100 & [\%] \\
\hline Aero Factor & Fator de Aerodinâmica & 90 & [\%] \\
\hline Grip Factor & Fator de Aderência & 100 & [\%] \\
\hline
\end{tabular}


A figura 29 apresenta o gráfico de força trativa em função da velocidade, e a área hachurada representa o limite de tração, ou seja, intervalo de velocidade no qual o desempenho é limitado pela aderência dos pneus, e não pela potência do motor.

Figura 29 - Gráfico de força trativa com resistências e limite de tração do RS9

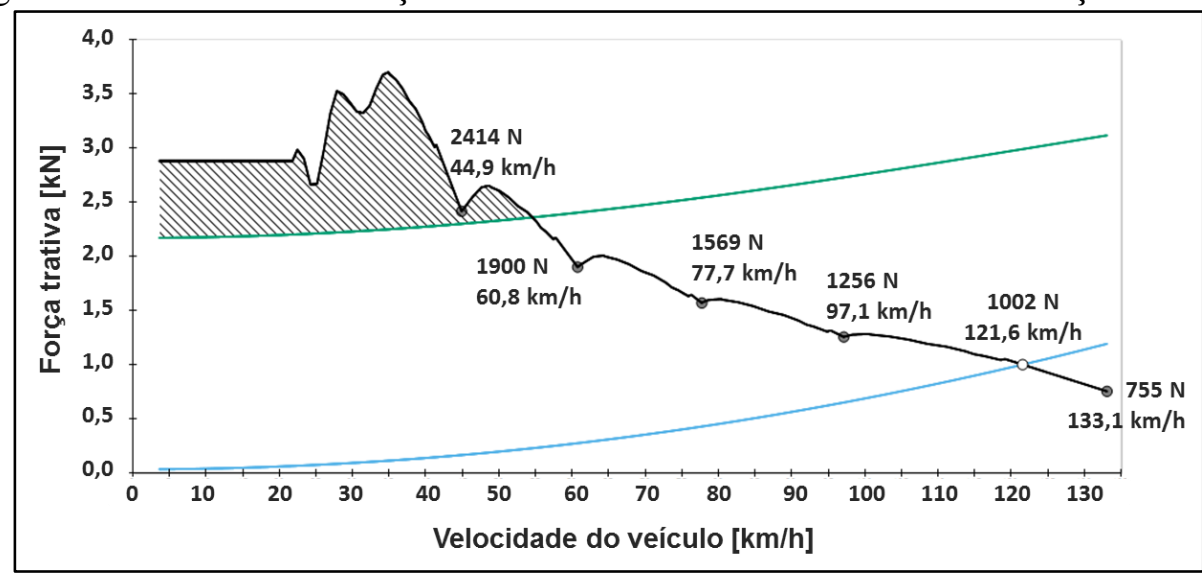

Fonte: autor

Comparando o gráfico da figura 29, referente ao protótipo RS9, com o gráfico da figura 28, referente ao RS8, nota-se que o RS9 ganhou velocidade final, subindo de 104,7 $\mathrm{km} / \mathrm{h}$ para $121,6 \mathrm{~km} / \mathrm{h}$, provavelmente melhorando o desempenho em trechos de alta velocidade. Em contrapartida, perdeu capacidade de tração, pois o limite de aderência passou de $53 \mathrm{~km} / \mathrm{h}$ para $55 \mathrm{~km} / \mathrm{h}$, correspondente à força trativa de $2358 \mathrm{~N}$.

Foi gerado um relatório compilando os principais resultados do RS9, apresentados na tabela 7. 
Tabela 7 - Relatório do veículo RS9

\begin{tabular}{|c|c|c|c|}
\hline $\begin{array}{l}\text { Parâmetro } \\
\text { OptimumLap }\end{array}$ & Parâmetro traduzido & Resultado & Unidade \\
\hline VEHICLE & & & \\
\hline CONFIGURATION & Contiguraçao do veiculo & & \\
\hline Total Mass & Massa Total & 252 & {$[\mathrm{~kg}]$} \\
\hline Max Torque & Torque Máximo & 4,93@7775 rpm & [kgf.m] \\
\hline Type of Fuel & Tipo de Combustível & E85 & [ ] \\
\hline Type of Transmission & Tipo de Transmissão & Sequential Gearbox & [ ] \\
\hline Max Power & Potência Máxima & $54,43 @ 8200$ rpm & [hp] \\
\hline Power Mass Ratio & Relação Potência/Peso & 0,21 & [hp/kg] \\
\hline Downforce@100km/h & $\begin{array}{l}\text { Força Aerodinâmica } \\
\text { Vertical Para Baixo }\end{array}$ & 953,57 & {$[\mathrm{~N}]$} \\
\hline Drag@100km/h & Arrasto Aerodinâmico & 689,94 & {$[\mathrm{~N}]$} \\
\hline $\begin{array}{l}\text { PERFORMANCE } \\
\text { METRICS }\end{array}$ & Medidas de Desempenho & & \\
\hline Top Speed & Velocidade Máxima & 121,56 & {$[\mathrm{~km} / \mathrm{h}]$} \\
\hline Time for 0 to $100 \mathrm{~km} / \mathrm{h}$ & Tempo de $0-100 \mathrm{~km} / \mathrm{h}$ & 4,56 & {$[\mathrm{~s}]$} \\
\hline Time for 100 to $0 \mathrm{~km} / \mathrm{h}$ & Tempo de $100-0 \mathrm{~km} / \mathrm{h}$ & 1,54 & {$[\mathrm{~s}]$} \\
\hline $\begin{array}{l}\text { Distance for } 100 \text { to } 0 \\
\mathrm{~km} / \mathrm{h}\end{array}$ & Distância de $100-0$ km/h & 18,7 & {$[\mathrm{~m}]$} \\
\hline $\begin{array}{l}\text { Lateral Acceleration - } \\
\text { Skidpad } 50 \mathrm{~m}\end{array}$ & $\begin{array}{l}\text { Aceleração Lateral } \\
\text { Máxima - Skidpad } 50 \text { m }\end{array}$ & 2,32 & {$[\mathrm{G}]$} \\
\hline $\begin{array}{l}\text { Lateral Acceleration - } \\
\text { Skidpad } 9 \mathrm{~m}\end{array}$ & $\begin{array}{l}\text { Aceleração Lateral } \\
\text { Máxima - Skidpad } 9 \text { m }\end{array}$ & 1,92 & [G] \\
\hline
\end{tabular}

\subsection{MODELAGEM DAS PISTAS}

Neste trabalho, optou-se pela simplificação de modelar a linha média da pista. Com um simulador de tempo de volta desenvolvido na Universidade de Brescia, que considera a transferência de carga em função da rigidez torcional da suspensão, modelo não linear do pneu e rigidez do chassi, Cambiaghi et al (1996) conseguiram simular tempo de volta em circuito misto com erro de $+2,31 \%$ empregando a linha mais rápida calculada (racing line). $\mathrm{O}$ erro caiu para $-1,05 \%$ modelando a linha real percorrida. No presente trabalho, esperam-se erros de até 5\% no tempo de volta, tendo como referência a prova de Michigan de 2014. As pistas relativamente estreitas da categoria Fórmula SAE devem minimizar a influência da largura do traçado no tempo de volta simulado.

Os modelos das pistas podem ser criados ou baixados de um banco de dados disponível na página eletrônica OptimumG ([2015?c]). As pistas do banco de dados são todas 
planas e horizontais. Para muitos circuitos essa aproximação é verdadeira, especialmente os das competições de Fórmula SAE (SAE, 2015a).

Foram criadas as pistas da prova de aceleração e skid-pad. Uma pista de autocross (e enduro) foi baixada do banco de dados disponível para o programa. Os parâmetros para criação das pistas estão registrados nos itens 3.3.1 a 3.3.3.

\subsubsection{Prova de aceleração}

“A prova de aceleração avalia a aceleração do carro em linha reta em pavimento plano" (SAE, 2015a, p. 158, tradução do autor).

Ela consiste em partir do repouso e percorrer uma pista retilínea de comprimento $75 \mathrm{~m}$ no menor tempo. Essa pista pode ser modelada como indicado na tabela 8 .

Tabela 8 - Parâmetros para modelo da pista de aceleração

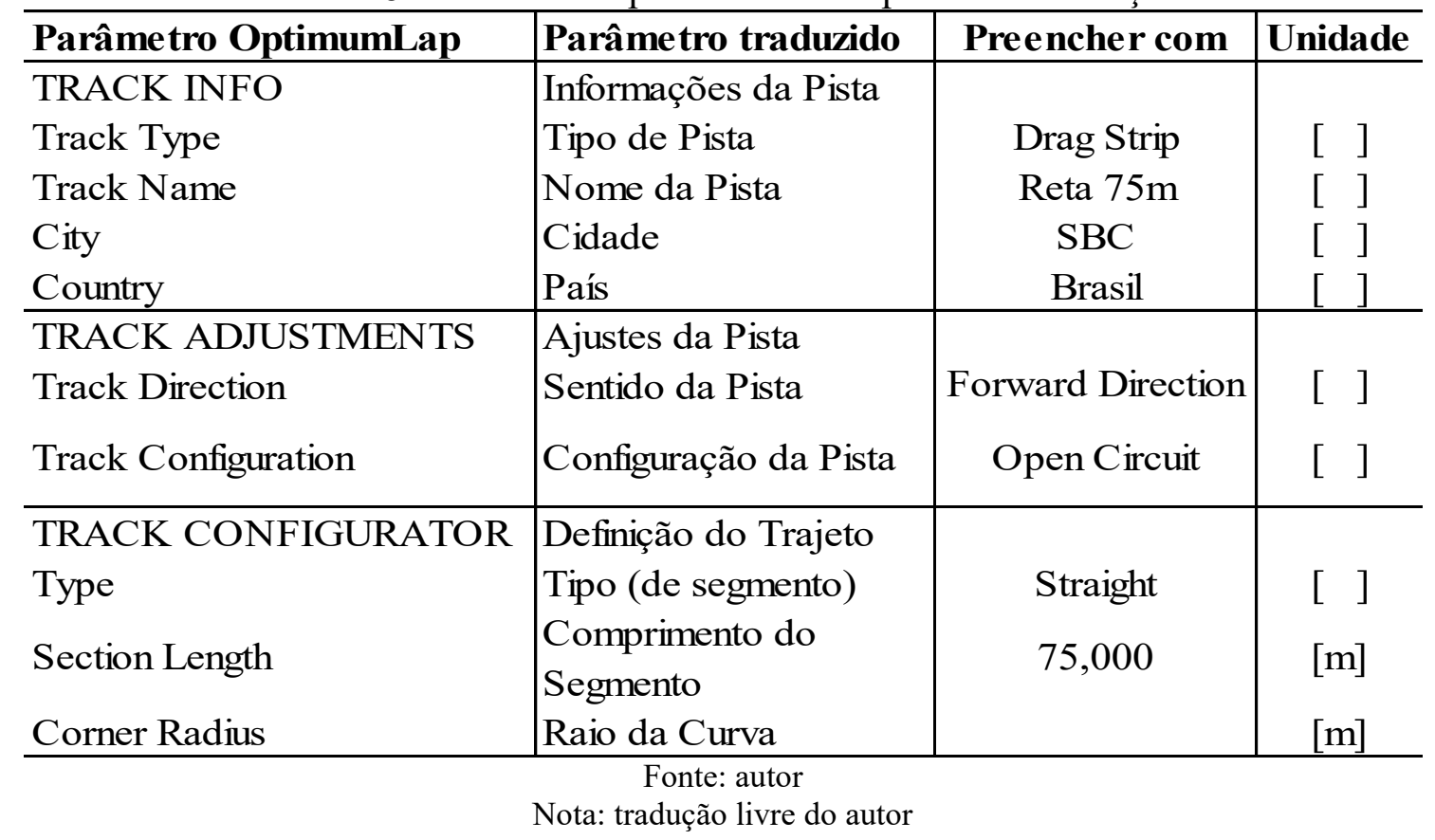

A representação gráfica resultante do modelo da pista de aceleração pode ser vista na figura 30.

Figura 30 - Representação gráfica da pista de aceleração de 75 m

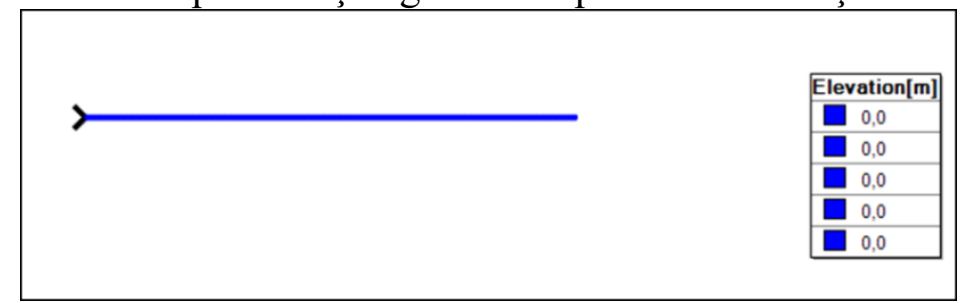

Fonte: autor

Nota: vista em planta 


\subsubsection{Prova de skid-pad}

O objetivo da prova de skid-pad é medir a capacidade do carro contornar curvas de raio constante em uma pista plana (SAE, 2015a).

A figura 31 representa a pista de skid-pad em planta. A linha tracejada que une os centros dos círculos define o início e final da volta. Uma volta é contada cada vez que se contorna um círculo.

Nessa prova, o veículo deve entrar pelo caminho marcado como "IN", contornar duas vezes o círculo à direita e, imediatamente após, duas vezes o círculo à esquerda. Dessas quatro voltas, as voltas um e três são para estabilizar o veículo, enquanto que as voltas dois e quatro são para cronometragem. Ao final, o veículo sai pelo caminho marcado como "OUT".

Figura 31 - Pista de skid-pad conforme regulamento

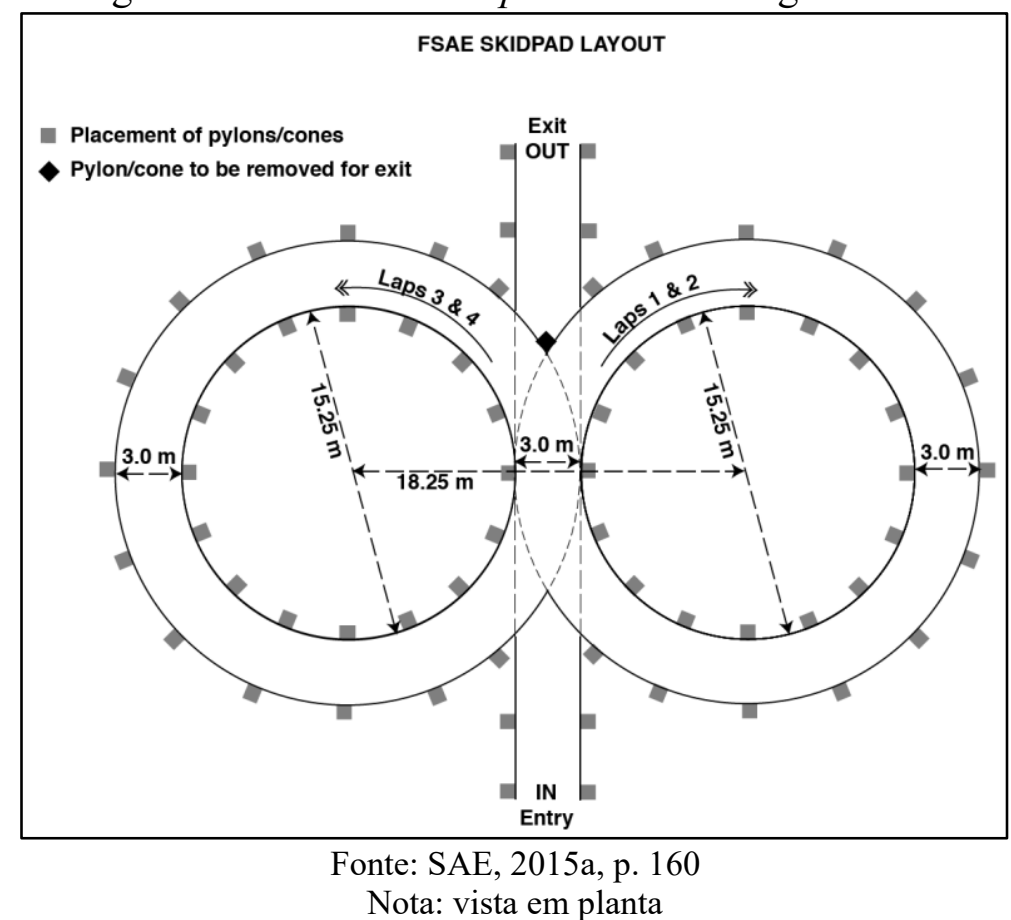

Como a cronometragem acontece apenas nas voltas dois e quatro, a manobra de entrada deve ser desprezada na simulação. A saída também deve ser desprezada, uma vez que acontece após a passagem pela linha de chegada. Dessa maneira, o trajeto para simulação é uma circunferência. Optou-se por simular apenas uma volta lançada, das duas cronometradas na prova. Em uma volta lançada, o veículo inicia o percurso em velocidade, diferentemente da prova de aceleração, onde se parte da imobilidade. Como o chassi é simétrico, pode-se modelar a pista tanto no sentido horário quanto no anti-horário. 
A tabela 9 contém os parâmetros para se criar a pista circular utilizada na simulação de tempo de volta na prova de skid-pad.

Tabela 9 - Parâmetros para modelo da pista de skid-pad

\begin{tabular}{|c|c|c|c|}
\hline Parâmetro OptimumLap & Parâmetro traduzido & Preencher com & Unidade \\
\hline TRACK INFO & Informações da Pista & & \\
\hline Track Type & Tipo de Pista & Temporary Circuit & [ ] \\
\hline Track Name & Nome da Pista & Skid-Pad & [ ] \\
\hline City & Cidade & SBC & [ ] \\
\hline Country & País & Brasil & [ ] \\
\hline TRACK ADJUSTMENTS & Ajustes da Pista & & \\
\hline Track Direction & Sentido da Pista & Forward Direction & [ ] \\
\hline Track Configuration & Configuração da Pista & Closed Circuit & {[]} \\
\hline TRACK CONFIGURATOR & Definição do Trajeto & & \\
\hline Type & Tipo (de segmento) & Right & [ ] \\
\hline Section Length & $\begin{array}{l}\text { Comprimento do } \\
\text { Segmento }\end{array}$ & 57,334 & {$[\mathrm{~m}]$} \\
\hline Corner Radius & Raio da Curva & 9,125 & {$[\mathrm{~m}]$} \\
\hline
\end{tabular}

A representação gráfica da pista de skid-pad gerada pelo OptimumLap pode ser vista na figura 32 .

Figura 32 - Representação gráfica da pista de skid-pad

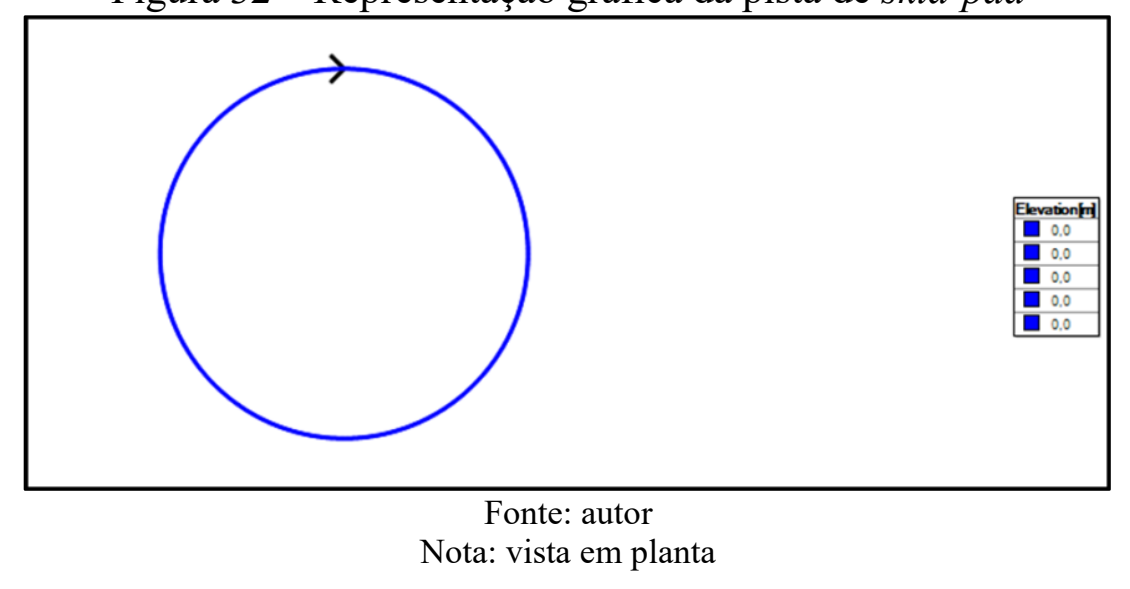

\subsubsection{Prova de autocross}

Assim como a pista de skid-pad, a pista de autocross é um circuito fechado, e o programa calcula o tempo da volta lançada. 
A prova de autocross pode sofrer alterações em seu traçado a cada ano, e o modelo da pista de 2014 da prova de Michigan, Estados Unidos, foi baixado da página eletrônica OptimumG ([2015?c]). A figura 33 ilustra o traçado de 1070 metros de extensão.

Figura 33 - Representação gráfica da pista de autocross de Michigan 2014

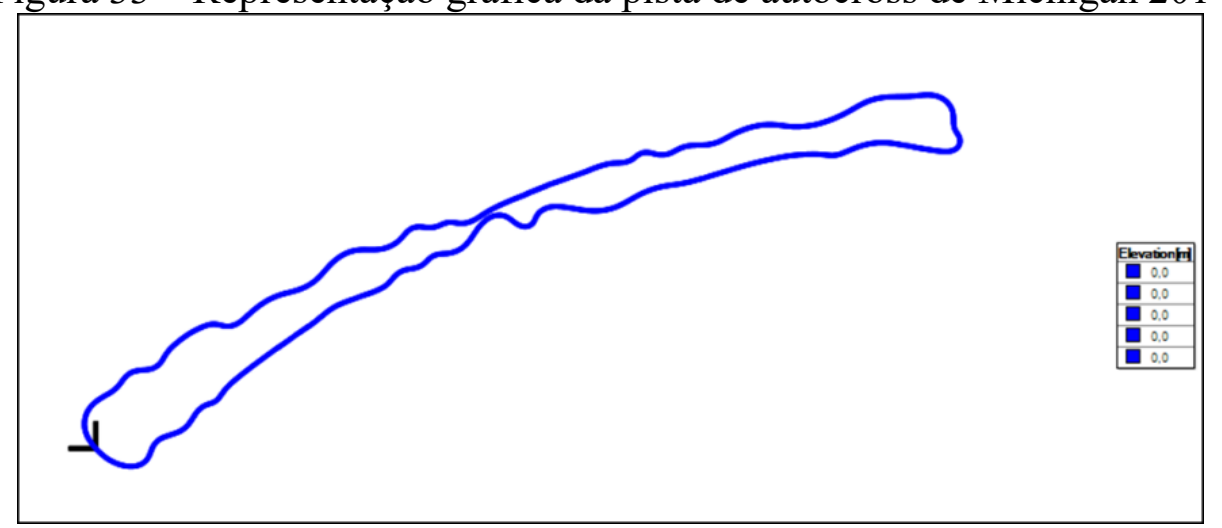

Fonte: autor

Nota: vista em planta

Esse mesmo circuito é utilizado para a prova de enduro, onde são dadas várias voltas consecutivas. 


\section{VALIDAÇÃO DO MODELO}

Ao utilizar os resultados de uma simulação computacional para criar ou ajustar um veículo, é preciso que eles sejam confiáveis. Para isso, é fundamental que se alimente o modelo com dados precisos, cuidadosamente coletados em bancos de prova e pista.

Após a modelagem, ainda é importante confrontar o resultado da simulação com os dados aquisitados em pista. Nas competições se registram os tempos de volta, gerando um banco de dados valioso para aferição do modelo. Testes também podem ser realizados em circuitos desenhados para um propósito específico.

\subsection{SIMULAÇÃO EM MATLAB}

"MATLAB é um ambiente de computação técnica de visualização e processamento numérico de alto desempenho" (MATLAB..., 1994, p. 2). Na presente obra, o programa MATLAB foi escolhido como ferramenta de apoio por ser conhecido do autor e por permitir simular o veículo sem a incerteza introduzida por incógnitas, uma vez que todo o código é conhecido e editável.

Segundo Siegler (2002, p. 16, tradução do autor), "todos os pacotes de simulação computacional relacionados a problemas de dinâmica de sistemas multicorpos usam uma das quatro diferentes técnicas para gerar as equações do movimento que definem o modelo do veículo". A tabela 10 contém um exemplo de cada técnica.

Tabela 10 - Métodos empregados na geração das equações do movimento de sistemas multicorpos

\begin{tabular}{l|c|l}
\hline Técnica & $\begin{array}{c}\text { Programa como } \\
\text { exemplo }\end{array}$ & $\begin{array}{l}\text { Método de ge ração de } \\
\text { equação }\end{array}$ \\
\hline $\begin{array}{l}\text { Códigos multicorpos } \\
\text { numéricos }\end{array}$ & ADAMS & $\begin{array}{l}\text { Equações são geradas na } \\
\text { forma numérica. }\end{array}$ \\
$\begin{array}{l}\text { Códigos multicorpos } \\
\text { simbólicos }\end{array}$ & Autosim & $\begin{array}{l}\text { Equações são geradas na } \\
\text { forma simbólica. }\end{array}$ \\
$\begin{array}{l}\text { Códigos específicos } \\
\text { (purpose built) }\end{array}$ & Carsim & $\begin{array}{l}\text { Um modelo genérico, com } \\
\text { equações predefinidas. } \\
\text { Ferramentas de } \\
\text { Simulação (toolkits) }\end{array}$ \\
\hline
\end{tabular}

Fonte: autor "adaptado de" Siegler, 2002, p. 16 


\subsubsection{Justificativa}

No caso em que se migra de um programa para outro, o primeiro passo pode ser comparar o resultado da nova ferramenta com os resultados mais confiáveis do programa já conhecido.

No manual do programa OptimumLap são dadas as equações do movimento, com exceção da resistência ao rolamento e da sustentação. Estas foram encontradas aplicando-se algumas equações da bibliografia, e comparando o resultado da simulação do OptimumLap com o resultado do MATLAB. As equações fornecidas no manual também foram testadas para conferência.

\subsubsection{Metodologia}

Optou-se por simular a aceleração longitudinal do protótipo RS8, partindo do repouso até atingir velocidade máxima. A prova de aceleração é suficiente para se determinar as incógnitas, que estão relacionadas ao deslocamento longitudinal.

Os dois parâmetros a serem avaliados são a velocidade de troca de cada marcha, fundamental na determinação da aceleração, e a velocidade máxima, importante para final de reta e entrada de curva. Almeja-se uma divergência menor ou igual a $\%$ para as velocidades de escalonamento e máxima, baseada no estudo de Siegler, 2002, p. 91.

A velocidade máxima é função da potência nas rodas, resistência aerodinâmica e resistência de rolamento (SMITH, 1978). Para se validar as forças resistivas, propõe-se determinar a velocidade máxima sem nenhuma resistência, depois com diferentes combinações delas. A princípio, uma incógnita era, por exemplo, a influência da força de sustentação aerodinâmica na resistência ao rolamento.

O programa desenvolvido para MATLAB não simula o limite de escorregamento dos pneus, crucial para se determinar a velocidade em função do tempo, mas irrelevante para se definir a velocidade de mudança de marchas, assim como a velocidade final. Como não se deseja comparar o tempo, e sim as velocidades, o limite de aderência foi desprezado. A troca de marchas é realizada objetivando maximizar a força trativa nos pneus.

O código do programa criado está descrito no Apêndice B. Partiu-se de um código originalmente desenvolvido pelo Prof. Dr. Marko Ackermann, para a disciplina Dinâmica de Sistemas Veiculares, ministrada no Programa de Mestrado do Centro Universitário FEI, que sofreu alterações pelo autor da presente obra. 


\subsubsection{Resultados}

Pode-se ver na figura 34 o gráfico das curvas de torque $[$ N.m] e potência $[\mathrm{kW}]$ do motor em função da sua velocidade angular. Observa-se a equivalência ao gráfico gerado pelo OptimumLap, da figura 24.

Figura 34 - Curvas de torque e potência do motor no MATLAB

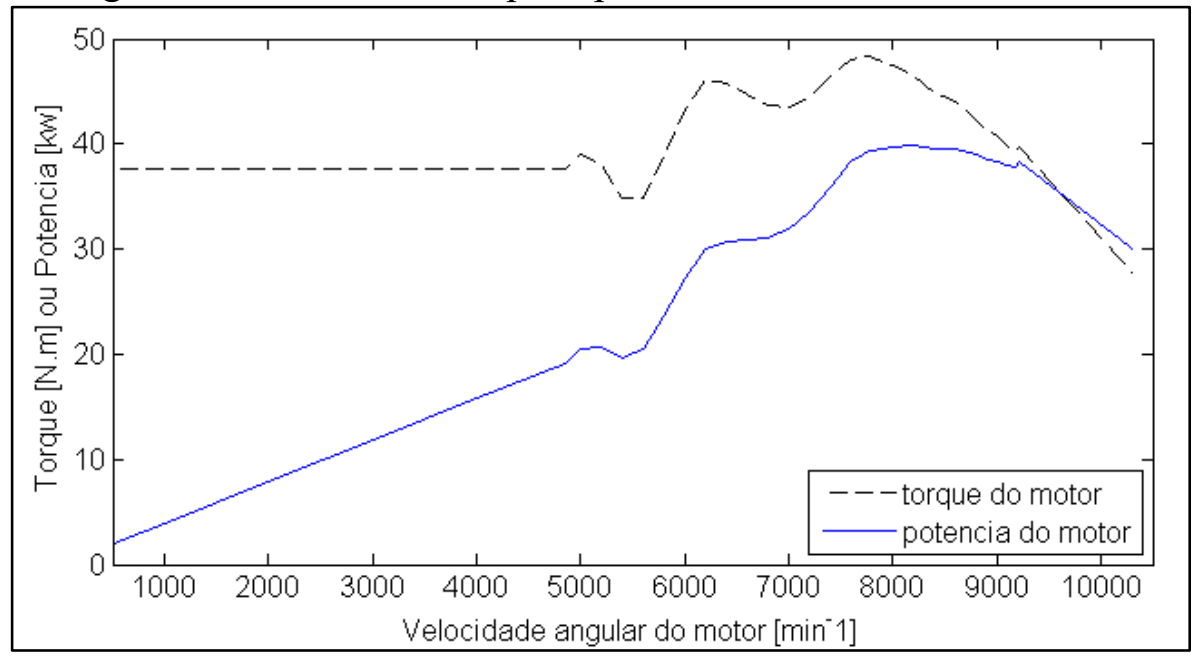

Fonte: autor

As relações da transmissão e final convertem o torque para as rodas trativas (traseiras), com as perdas do rendimento do engrenamento. O gráfico da figura 35 compara a curva de força trativa para a condição ideal de potência máxima constante "Pmax constante" (preta contínua) com a força trativa nas rodas para cada relação de transmissão.

A troca de marchas é realizada quando a força trativa disponível nas rodas se torna maior na marcha seguinte do que na atual, representado pelo cruzamento das curvas de cada marcha no gráfico da figura 35. Foi desprezada a interrupção do torque durante as mudanças de marcha.

A força resistiva aerodinâmica é proporcional ao quadrado da velocidade, enquanto que a resistência ao rolamento não depende da velocidade, somente da variação da força normal em razão da sustentação aerodinâmica. A força resistiva resultante é representada no gráfico da figura 35 pela linha preta tracejada.

O ponto de cruzamento da força trativa com a força resistiva resultante determina a velocidade máxima do veículo, quando a força trativa se iguala à resistiva (equação 4). Para o RS8, são $104,67 \mathrm{~km} / \mathrm{h}$. 
Figura 35 - Força trativa e força resistiva em função da velocidade no MATLAB

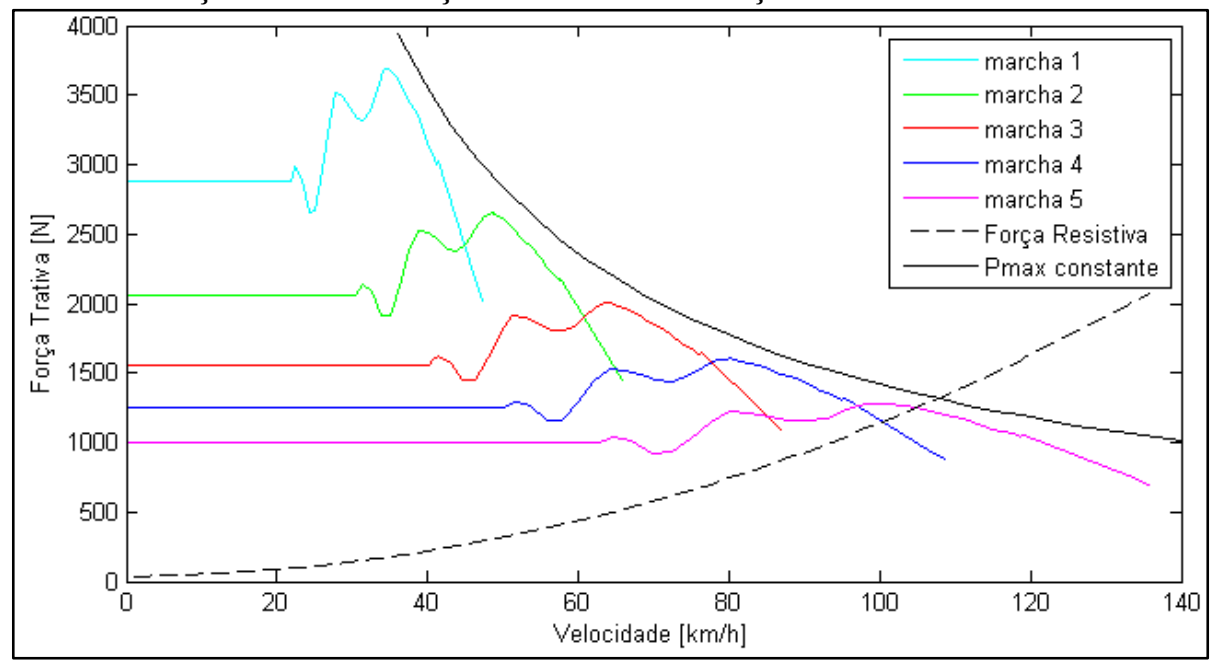

Fonte: autor

O gráfico da figura 36 apresenta a curva da velocidade longitudinal em função do tempo. As velocidades das trocas de marcha são identificadas pelas transições entre os diferentes traços.

Figura 36 - Gráfico da velocidade em função do tempo, com escalonamento

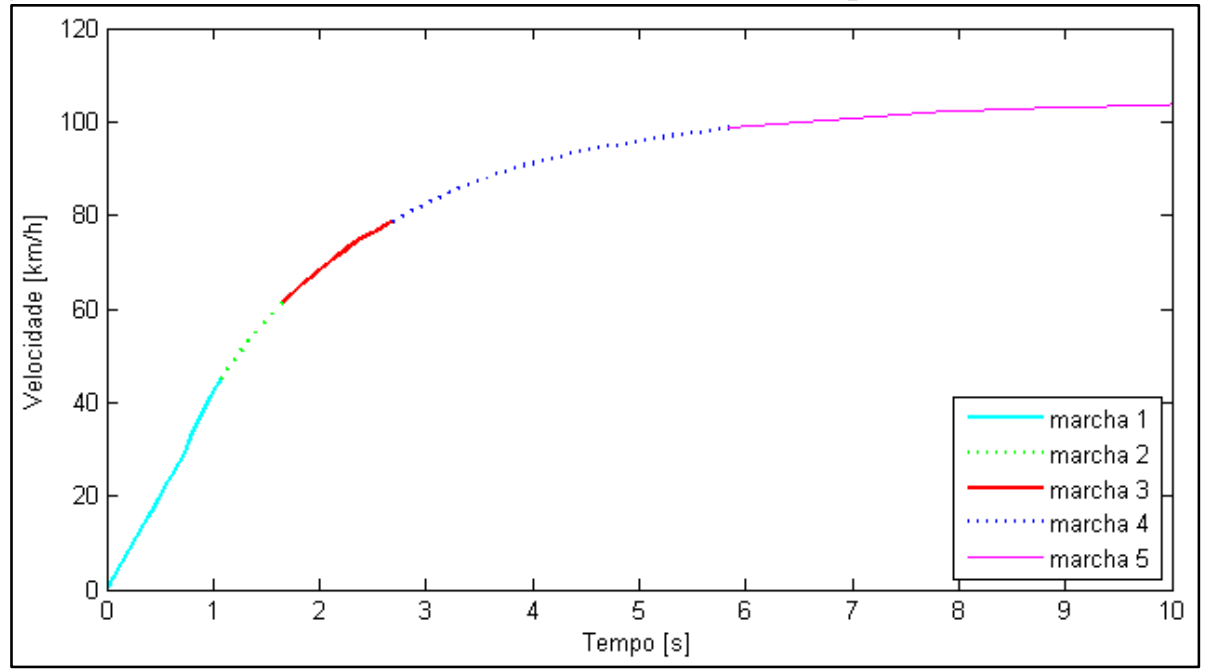

Fonte: autor

As velocidades de troca de marcha e a velocidade máxima estão compiladas na tabela 11, e podem ser comparadas com as obtidas no programa OptimumLap. No cálculo do desvio, a referência é o resultado do MATLAB. 
Tabela 11 - Velocidades de troca de marcha e máxima

\begin{tabular}{c|c|c|c}
\hline Marcha & \multicolumn{2}{|c|}{ Velocidade [km/h] } & Desvio [\%] \\
\hline & MATLAB & OptimumLap & \\
\hline $1-2$ & 45,15 & 44,90 & $-0,6$ \\
$2-3$ & 61,45 & 60,76 & $-1,1$ \\
$3-4$ & 78,85 & 77,73 & $-1,4$ \\
$4-5$ & 98,55 & 97,13 & $-1,4$ \\
5 & 104,67 & 104,67 & 0,0 \\
\hline \multicolumn{3}{|c}{ Fonte: autor }
\end{tabular}

As divergências nas velocidades de escalonamento podem ter sido geradas pela interpolação dos valores de torque e rotação da curva característica do motor.

A tabela 12 apresenta as velocidades máximas para diferentes condições de forças resistivas.

Tabela 12 - Velocidades máximas para diferentes forças resistivas

\begin{tabular}{l|c|c|c}
\hline Força Resistiva & \multicolumn{2}{|c}{ Velocidade [km/h] } & Desvio [\%] \\
\hline nenhuma & MATLAB & OptimumLap & \\
rolamento & 133,08 & 133,08 & 0,0 \\
aerodinâmica & 133,08 & 133,08 & 0,0 \\
${\text { rolam. e aero. }{ }^{(1)}}^{(2)}$ & 106,43 & 106,43 & 0,0 \\
rolam. e aero. & 105,38 & 105,38 & 0,0 \\
\hline \multicolumn{3}{|c}{ Fonte: autor } \\
\hline
\end{tabular}

Notas: 1 - sem sustentação; 2 - com sustentação

As velocidades máximas dos dois programas coincidem para todas as condições de resistência, incluindo a influência da sustentação na resistência ao rolamento.

Nota-se, observando a tabela 12, que a resistência ao rolamento sozinha não é suficiente para limitar a velocidade máxima do veículo, e que esta fica limitada pela rotação máxima do motor.

Já sob a ação da aerodinâmica, a velocidade é limitada pela resistência. Considerandose todas as resistências, a previsão de velocidade máxima do RS8 é de 104,67 km/h de acordo com ambos os programas.

Para o cálculo de aceleração de 0 a $100 \mathrm{~km} / \mathrm{h}$, o MATLAB prevê um tempo de 6,50 segundos, enquanto que o OptimumLap, desprezando o limite da aderência, calcula 6,61 segundos, uma divergência de 1,7\%. Deve-se, entretanto, utilizar o limite de aderência para simular tempo de volta. Nesse caso, o tempo de 0 a $100 \mathrm{~km} / \mathrm{h}$ sobe para 6,99 segundos, de acordo com o OptimumLap. 


\subsubsection{Conclusão}

Dada a proximidade dos resultados do MATLAB e do OptimumLap, dentro de uma margem de $2 \%$ para velocidades de troca de marcha e máximas, respectivamente conforme tabelas 11 e 12, foram validados os modelos dos seguintes parâmetros do OptimumLap:
a) velocidade de troca de marcha (consequentemente rotação);
b) força de resistência ao rolamento;
c) força de resistência aerodinâmica;
d) força de sustentação.

Verificou-se que a sustentação influencia a resistência ao rolamento.

\subsection{TESTE PRÁTICO}

Trata-se de testar o veículo físico em uma pista real. Nesse caso, acrescenta-se a variável piloto, que não existe no modelo do OptimumLap, uma vez que o programa considera o piloto ideal.

\subsubsection{Justificativa}

Por mais que se refine um modelo com base na bibliografia e na experiência, somente comparando os resultados da simulação com as medições práticas pode-se afirmar que o modelo é confiável. Toda simulação apresenta um erro em relação à realidade, e também é importante que ele seja conhecido. O modelo deve ser refinado até que o erro se torne aceitável. Os níveis de exatidão dependem da finalidade do estudo em questão.

Segundo Gillespie (2015), haverá um dia em que os testes de rotina serão todos substituídos por simulação, mas haverá um protótipo para novas situações, porque estas são infinitas (informação verbal). ${ }^{3}$

\subsubsection{Critérios de validação}

Para a validação do modelo, optou-se por simular as provas disputadas no autódromo Michigan International Speedway em 2014 com o veículo RS8, cujos tempos de volta

\footnotetext{
${ }^{3}$ Informação verbal concedida por Thomas D. Gillespie, no dia 07 de agosto de 2015 em palestra.
} 
serviram de referência. A cronometragem oficial das provas pode ser consultada na página eletrônica da SAE International (2015b).

Os resultados teóricos obtidos com a ferramenta OptimumLap foram comparados com voltas reais, executadas na competição. A meta é que os erros não ultrapassem $5 \%$, embora erros de até $10 \%$ sejam tidos como aceitáveis, de acordo com a exatidão divulgada pela OptimumG.

\subsubsection{Simulação e análise dos resultados}

O modelo do veículo RS8 pode ser encontrado na tabela 2, e as pistas podem ser modeladas conforme descrito no item 3.3.

Os tempos de volta oriundos das simulações estão compilados na tabela 13, onde são comparados com os tempos cronometrados na competição.

Tabela 13 - Comparação dos tempos registrados na competição e simulados no OptimumLap

\begin{tabular}{l|c|c|c}
\hline Prova & $\begin{array}{c}\text { Tempo } \\
\text { regis trado [s] }\end{array}$ & $\begin{array}{c}\text { Tempo da } \\
\text { simulação [s] }\end{array}$ & Erro [\%] \\
\hline Aceleração 75 m & 4,448 & 4,520 & 1,6 \\
Skid-pad & 5,031 & 4,390 & $-12,7$ \\
Autocross (enduro) & 57,232 & 57,010 & $-0,4$ \\
\hline \multicolumn{2}{r}{}
\end{tabular}

Nota-se que o resultado fica dentro de uma margem de erro de $2 \%$ para a prova de aceleração e autocross, mas ultrapassa os $12 \%$ para skid-pad.

O veículo percorre trajetória curva durante toda a prova de skid-pad. O momento de inércia de guinada deixa de ser irrelevante, acarretando em maior erro ao ser desprezado.

Ainda, em teoria, o veículo percorre um círculo de raio constante, com velocidade longitudinal e ângulo de esterçamento constantes, no limite de aderência dos pneus. $\mathrm{Na}$ prática, entretanto, o piloto precisa corrigir constantemente o comportamento do veículo, variando o ângulo de esterçamento para compensar ondulações no pavimento e desequilíbrios do veículo. As provas de aceleração e autocross, por sua vez, não apresentam curvas de raio constante, o que permite maior exatidão no cálculo do tempo de volta.

\subsubsection{Conclusão}

Com base nos resultados dos tempos de volta da tabela 13, pode-se dizer que o modelo está aferido para as provas de aceleração e autocross, com respectivas divergências de 1,6\% e $0,4 \%$ nos tempos de volta, dentro da meta de $5 \%$. Já a simulação da prova de skid-pad atingiu 
um erro de 12,7\%, além dos $10 \%$ assumidos como aceitáveis. Logo, os resultados da simulação de skip-pad devem ser utilizados com cautela. 


\section{SIMULAÇÃO E ANÁLISE DOS RESULTADOS}

Dados os modelos dos veículos e das pistas no item 3, e tendo sido validados no item 4, é possível comparar o desempenho dos dois protótipos nas diversas provas, listadas do item 5.2 ao 5.4. Uma tabela com todos os resultados detalhados de cada simulação se encontra no Apêndice D. Todos os dados deste item 5 foram obtidos das simulações com o programa OptimumLap.

\subsection{DESEMPENHO GERAL}

Antes de analisar o desempenho dos dois protótipos nas pistas, pode-se comparar o desempenho geral simulado dos dois veículos, como velocidade máxima e aceleração, como na tabela 14.

Tabela 14 - Comparação do desempenho geral dos veículos RS8 e RS9

\begin{tabular}{l|c|c|c}
\hline Parâmetro & RS8 & RS9 & Unidade \\
\hline Velocidade máxima & 104,67 & 121,56 & {$[\mathrm{~km} / \mathrm{h}]$} \\
Limite de tração (força) & 2454,60 & 2358,00 & {$[\mathrm{~N}]$} \\
Limite de tração (veloc.) & 52,78 & 54,58 & {$[\mathrm{~km} / \mathrm{h}]$} \\
Tempo de 0-100 km/h & 6,99 & 4,56 & {$[\mathrm{~s}]$} \\
Tempo de 0-100 m & 5,48 & 5,30 & {$[\mathrm{~s}]$} \\
Distância de $100-0 \mathrm{~km} / \mathrm{h}$ & 17,30 & 18,70 & {$[\mathrm{~m}]$} \\
Downforce a $100 \mathrm{~km} / \mathrm{h}$ & 1456 & 954 & {$[\mathrm{~N}]$} \\
Arrasto a $100 \mathrm{~km} / \mathrm{h}$ & 1141 & 690 & {$[\mathrm{~N}]$} \\
Aceleração lateral skid- & 2,01 & 1,92 & {$[\mathrm{G}]$} \\
pad de raio 9 m & & & \\
\hline
\end{tabular}

Fonte: autor

Sendo a redução do aerofólio traseiro a principal modificação no veículo RS9 em relação ao antecessor RS8, obteve-se menor arrasto aerodinâmico, com consequente acréscimo na velocidade máxima. Em contrapartida, reduziu-se a força vertical descendente, ou downforce, tendo como consequência a redução da aceleração lateral máxima no skid-pad de raio $9 \mathrm{~m}$, indicando menor capacidade de curva.

\subsection{PROVA DE ACELERAÇÃO}

Na simulação da prova de aceleração de extensão $75 \mathrm{~m}$, o protótipo RS8 registrou tempo de 4,52 segundos, enquanto que o RS9 foi mais rápido 0,11 segundos, completando o traçado em 4,41 segundos. A tabela 15 apresenta os principais resultados dessa prova. 
Tabela 15 - Resultado resumido da prova de aceleração

\begin{tabular}{|c|c|c|c|}
\hline Parâmetro & RS8 & RS9 & Unidade \\
\hline Tempo de volta & 4,52 & 4,41 & {$[\mathrm{~s}]$} \\
\hline $\begin{array}{l}\text { Atuação do controle de } \\
\text { tração }\end{array}$ & 36,12 & 38,01 & {$[\%]$} \\
\hline Velocidade máxima & 92,34 & 98,70 & {$[\mathrm{~km} / \mathrm{h}]$} \\
\hline Mudanças de marcha & 3 & 4 & [ ] \\
\hline $\begin{array}{l}\text { Aceleração longitudinal } \\
\text { máxima }^{[1]}\end{array}$ & 0,860 & 0,862 & [G] \\
\hline
\end{tabular}

Optou-se por estudar alguns parâmetros de desempenho separadamente, visando facilitar a identificação e compreensão das disparidades entre os veículos. Para a prova de aceleração, estes parâmetros estão descritos nos itens 5.2.1 a 5.2.4.

\subsubsection{Velocidade}

O gráfico da figura 37 mostra a velocidade em função da distância percorrida. Observa-se que não há diferença significativa na velocidade no intervalo do limite de tração, ou seja, até aproximadamente $55 \mathrm{~km} / \mathrm{h}$, evidenciando que a diferença de aderência entre os veículos é irrelevante. A partir dessa velocidade, o menor arrasto do RS9 lhe confere uma crescente vantagem, permitindo maior ganho de velocidade longitudinal.

Figura 37 - Gráfico da velocidade longitudinal em função da distância para prova de aceleração

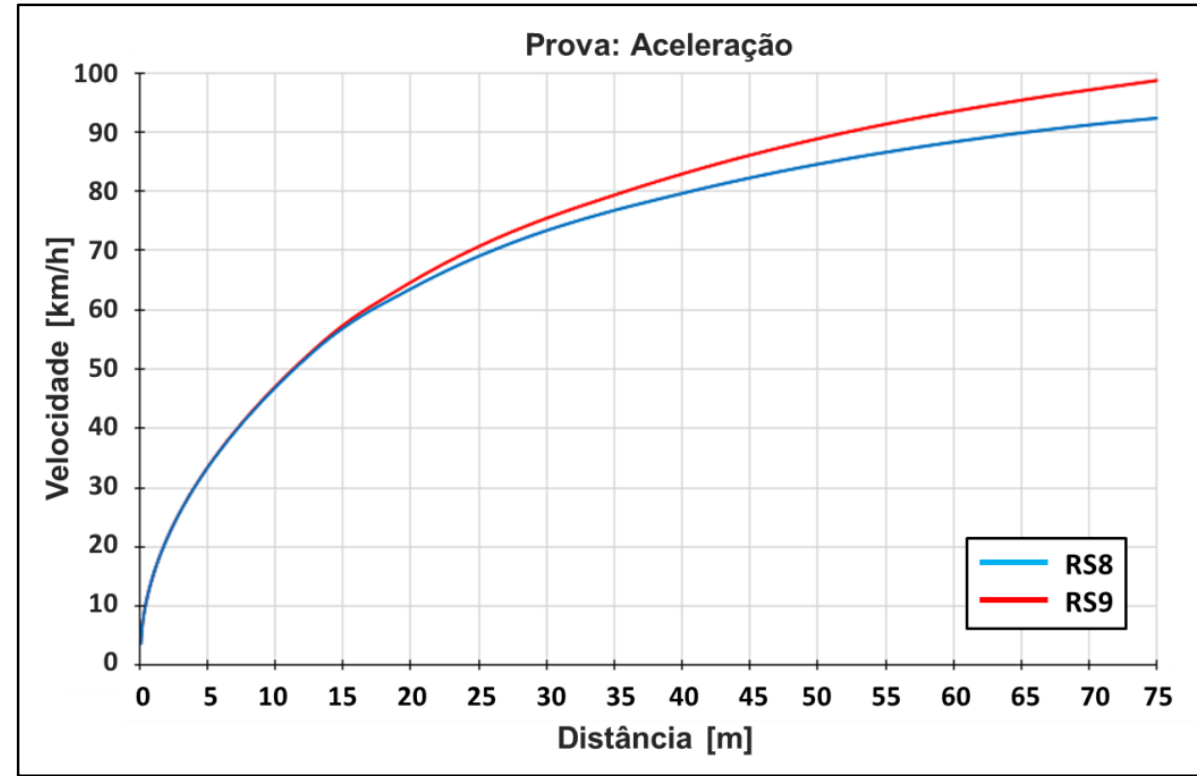

Fonte: autor 


\subsubsection{Aceleração}

Analisando o gráfico da aceleração longitudinal pela distância percorrida na figura 38, é possível perceber uma ligeira vantagem do RS9 na largada. Apesar de sua menor aderência (limite de escorregamento $55 \mathrm{~km} / \mathrm{h}$, contra $53 \mathrm{~km} / \mathrm{h}$ do RS8), desenvolve aceleração longitudinal maior desde os primeiros metros. Isso se dá pelas menores resistências e massa, como pormenorizado no item 5.2.3.

O patamar entre zero e aproximadamente 13 metros indica a atuação do controle de tração (TCS), ou seja, o limite de aderência longitudinal dos veículos. Nesse trecho, a perícia do piloto é fundamental, uma vez que o veículo real não possui o recurso de controle de tração. A partir dos 13 metros, correspondentes a $53 \mathrm{~km} / \mathrm{h}$ para o RS8 e $55 \mathrm{~km} / \mathrm{h}$ para o RS9, os pneus não mais limitam a aceleração, e o piloto pode efetuar aceleração plena do motor.

Figura 38 - Gráfico da aceleração longitudinal em função da distância para prova de aceleração

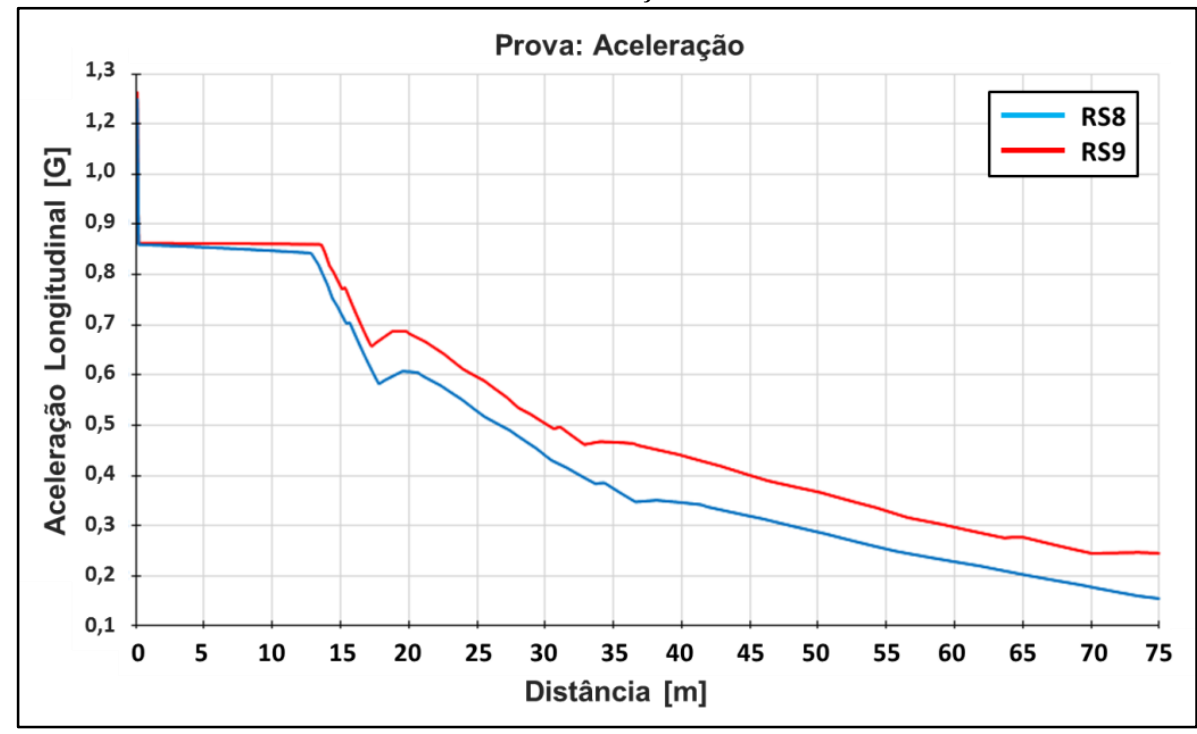

Fonte: autor

\subsubsection{Arrasto aerodinâmico}

O gráfico da figura 39 confirma que o arrasto aerodinâmico é menor no RS9, justificando seu menor tempo. No final dos 75 metros, o arrasto do RS9 é 33\% menor que o do seu antecessor. Mesmo no início da prova, em baixa velocidade, a diferença no arrasto é significativa. Para uma distância de 13 metros, por exemplo, tem-se 306 N para o RS 8 contra $183 \mathrm{~N}$ do RS9. Essa menor resistência aerodinâmica, aliada a um chassi $3 \mathrm{~kg}$ mais leve, é a explicação para a melhor largada do RS9, mesmo com o limite de tração ligeiramente inferior. 
Figura 39 - Gráfico do arrasto aerodinâmico em função da distância para prova de aceleração

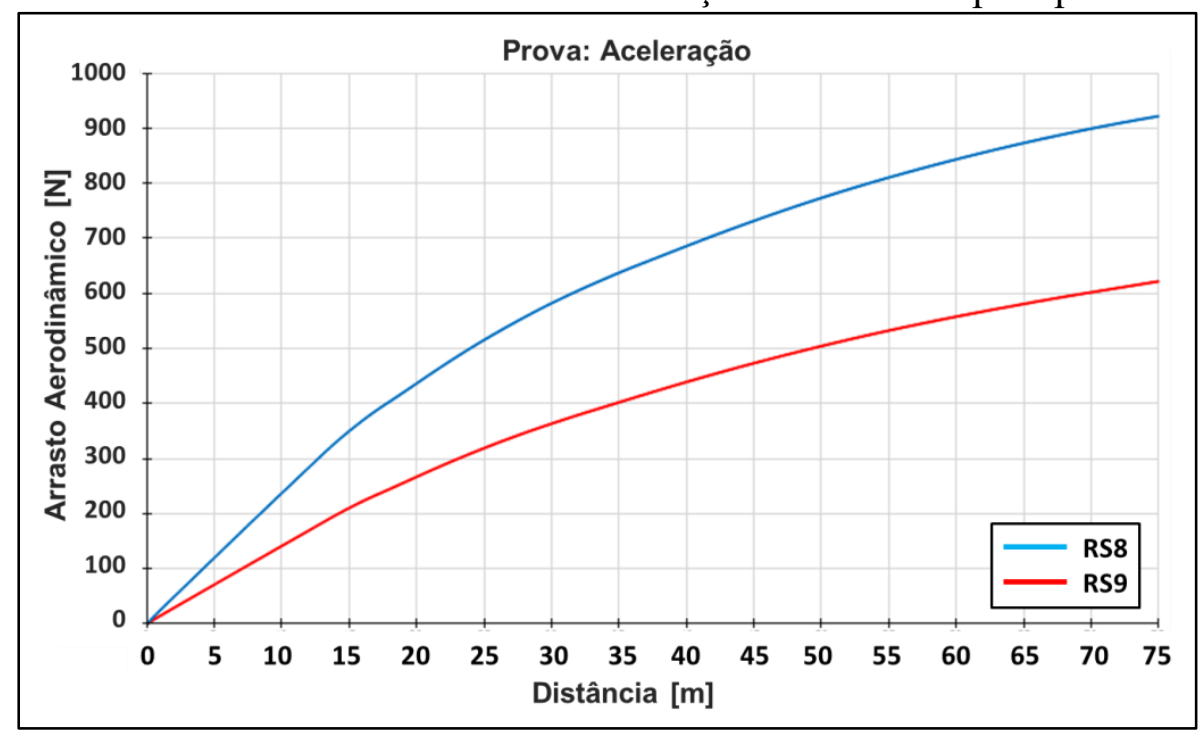

Fonte: autor

\subsubsection{Troca de marcha}

Com o gráfico de rotação do motor em função do tempo, podem-se determinar os momentos das trocas de marcha, indicados como uma queda brusca na rotação. Como se observa na figura 40, as rotações das trocas de marcha se mantiveram inalteradas, entretanto, sendo desenvolvida maior aceleração, as trocas de marcha devem ser realizadas antes no RS9. Com a maior velocidade final do RS 9 de $98,70 \mathrm{~km} / \mathrm{h}$, contra $92,34 \mathrm{~km} / \mathrm{h}$ do RS8, é necessário engrenar a quinta marcha no final do traçado, enquanto que o RS8 deve cruzar a linha de chegada ainda em quarta marcha.

Figura 40 - Gráfico da velocidade angular do motor em função do tempo para prova de aceleração

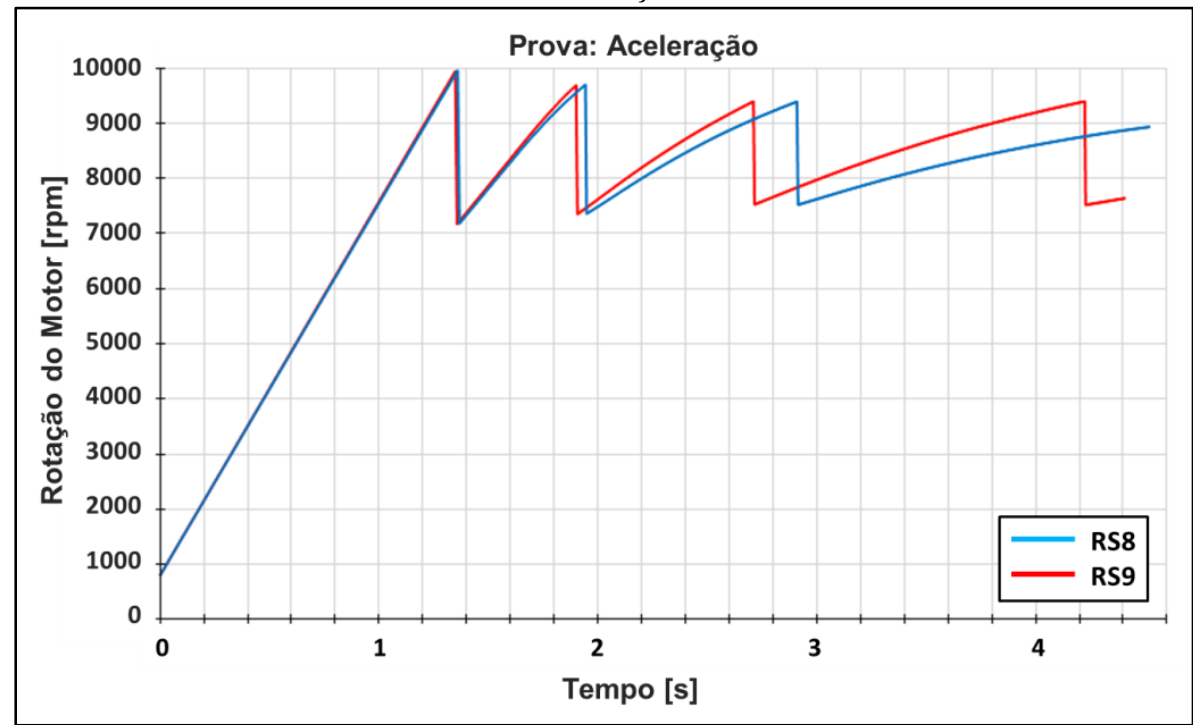

Fonte: autor 


\subsection{PROVA DE SKID-PAD}

Na simulação da prova de skid-pad, o protótipo RS8 contornou a pista circular de diâmetro 18,25 m em 4,39 segundos. Seu sucessor não conseguiu superá-lo, completando o traçado em 4,44 segundos. A tabela 16 apresenta os principais resultados da prova.

Tabela 16 - Resultado resumido da prova de skid-pad, uma volta

\begin{tabular}{l|c|c|c}
\hline Parâme tro / Veículo & RS8 & RS9 & unidade \\
\hline Tempo de volta & 4,39 & 4,44 & {$[\mathrm{~s}]$} \\
Velocidade mínima & 47,03 & 46,46 & {$[\mathrm{~km} / \mathrm{h}]$} \\
Velocidade média & 47,03 & 46,46 & {$[\mathrm{~km} / \mathrm{h}]$} \\
Velocidade máxima & 47,03 & 46,46 & {$[\mathrm{~km} / \mathrm{h}]$} \\
Aceleração lateral máxima & 1,91 & 1,86 & {$[\mathrm{G}]$} \\
Marcha engrenada & $2^{\mathrm{a}}$ & $2^{\mathrm{a}}$ & {[]} \\
\hline
\end{tabular}

Pela mesma razão da prova de aceleração, optou-se por estudar alguns parâmetros de desempenho separadamente.

\subsubsection{Velocidade}

O gráfico da velocidade longitudinal em função da distância percorrida da figura 41 confirma a hipótese, levantada no item 4.2.3, que o veículo mantém velocidade constante nessa prova. Essa deve ser a maior fonte de erro entre o cálculo teórico e a prova física. Comparando os protótipos entre si, vê-se um desempenho ligeiramente melhor do RS8.

Figura 41 - Gráfico de velocidade longitudinal em função da distância para prova de skid-pad

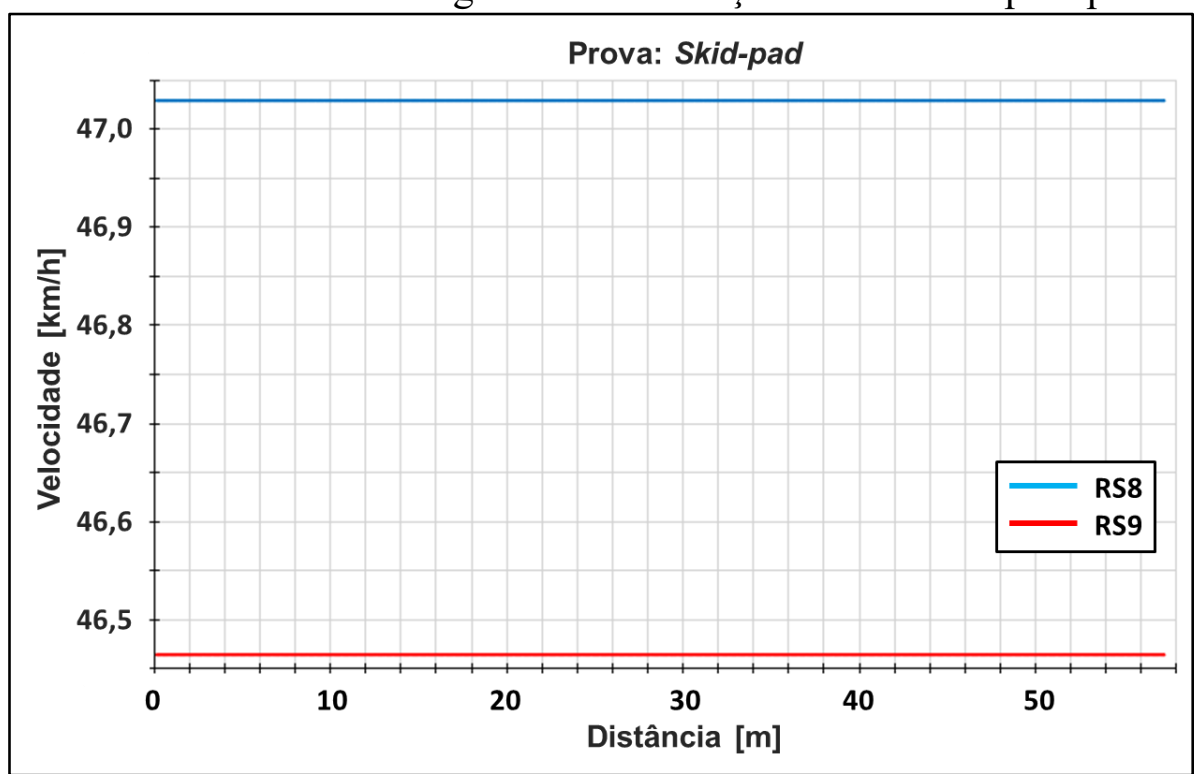

Fonte: autor 


\subsubsection{Downforce e aceleração lateral}

O maior coeficiente aerodinâmico de downforce, aliado à maior área frontal, gera maior força vertical descendente no RS8. Como se vê no gráfico da figura 42, o RS9, com menor aerofólio traseiro, gera apenas $206 \mathrm{~N}$ de downforce, contra $322 \mathrm{~N}$ do RS8.

Figura 42 - Gráfico de downforce em função da distância para prova de skid-pad

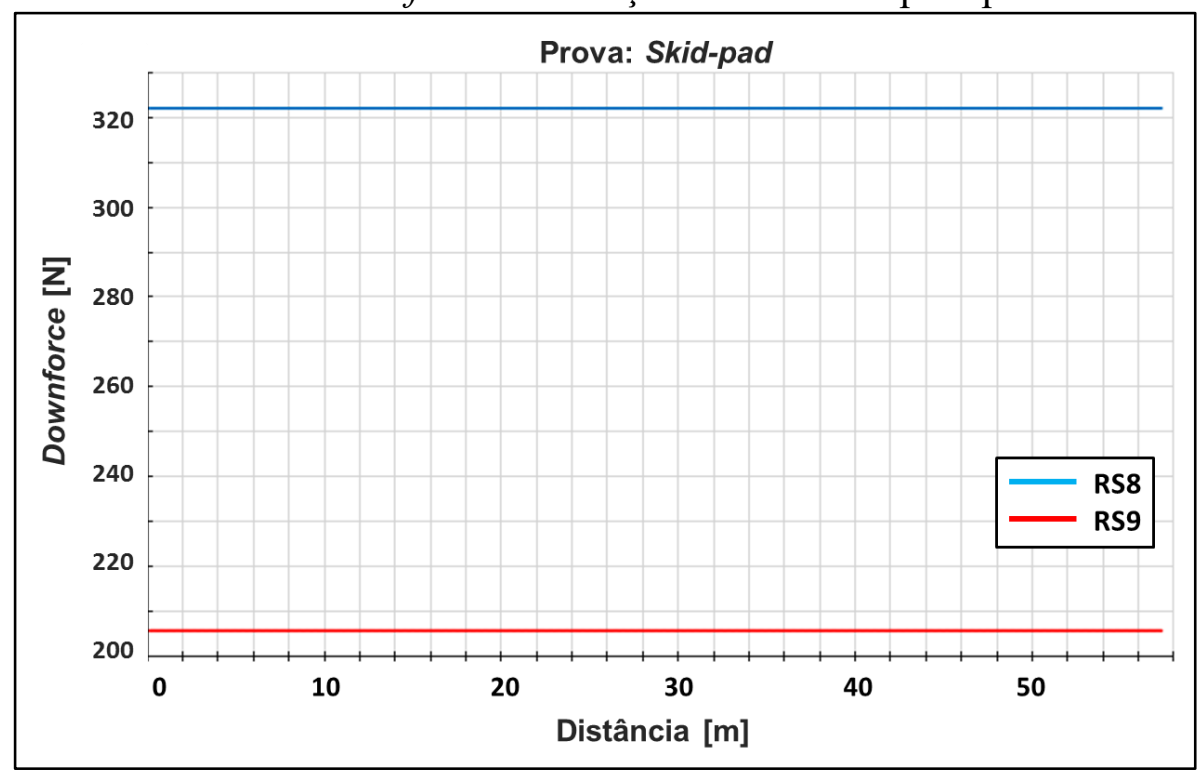

Fonte: autor

A maior velocidade do RS8 é consequência da maior aceleração lateral suportada, como indicado no gráfico da figura 43. Como descrito na tabela 16, a aceleração lateral máxima do RS8 é de 1,91 G, enquanto que a do RS9 não deve ultrapassar 1,86 G.

Figura 43 - Gráfico de aceleração lateral em função da distância para prova de skid-pad

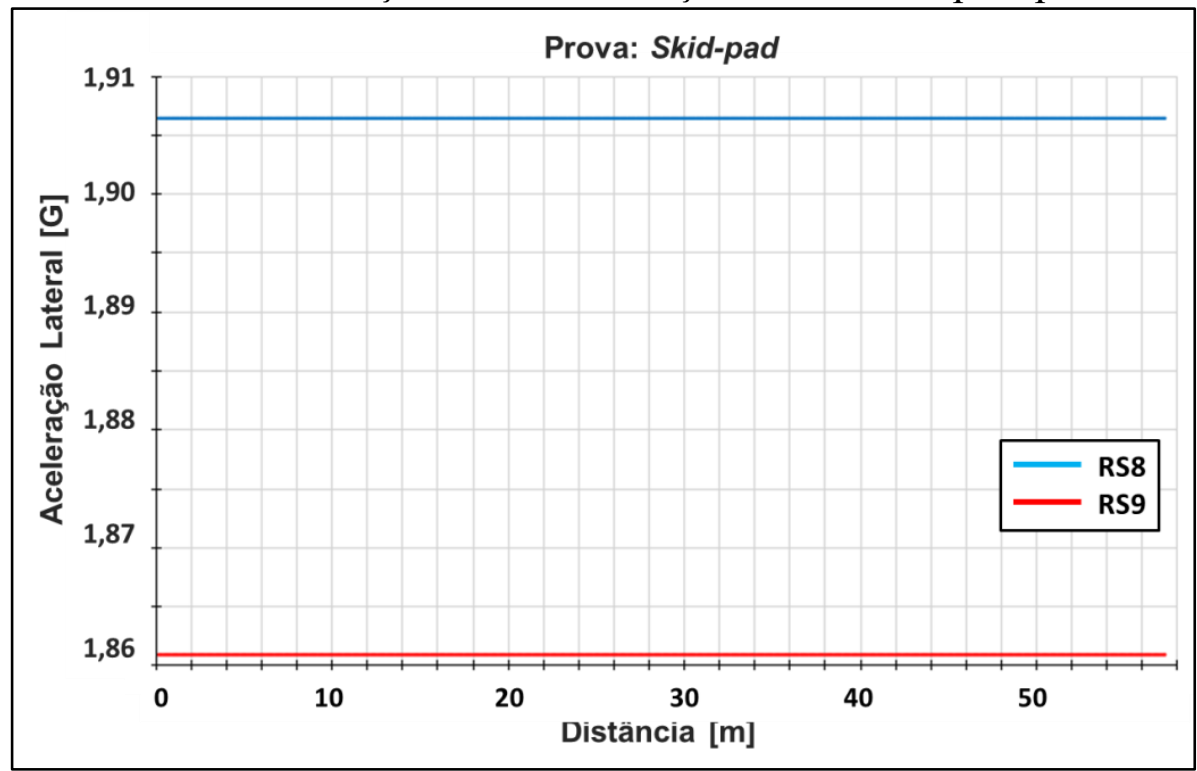

Fonte: autor 


\subsection{PROVA DE AUTOCROSS}

As principais medidas de desempenho referentes à prova de autocross se encontram na tabela 17. Vale ressaltar que os resultados são para uma volta lançada.

Tabela 17 - Resultado resumido da prova de autocross, uma volta

\begin{tabular}{l|c|c|c}
\hline Parâme tro & RS8 & RS9 & Unidade \\
\hline Tempo de volta & 57,01 & 56,74 & {$[\mathrm{~s}]$} \\
\% Acelerando & 72,21 & 69,12 & {$[\%]$} \\
\% Freando & 27,37 & 30,23 & {$[\%]$} \\
\% Desengrenado & 4,36 & 3,94 & {$[\%]$} \\
\% TCS & 38,20 & 41,81 & {$[\%]$} \\
Velocidade média & 72,29 & 73,63 & {$[\mathrm{~km} / \mathrm{h}]$} \\
Velocidade máxima & 100,50 & 112,73 & {$[\mathrm{~km} / \mathrm{h}]$} \\
Consumo de combustível & 0,17 & 0,15 & {$[\mathrm{~kg}]$} \\
Trocas de marcha & 54,00 & 60,00 & []$]$ \\
Aceleração lateral máx. & 2,38 & 2,27 & {$[\mathrm{G}]$} \\
Aceleração longit. máx. & 0,85 & 0,86 & {$[\mathrm{G}]$} \\
Desaceleração long. máx. & 2,79 & 2,53 & {$[\mathrm{G}]$} \\
\hline \multicolumn{4}{|c}{ Fonte: autor }
\end{tabular}

Analisando o consumo energético, percebe-se que o RS9, ligeiramente mais leve, com menor área frontal e menor coeficiente de arrasto aerodinâmico, consome menos combustível por volta.

O traçado de autocross de Michigan 2014 possui um trecho de alta velocidade longo o suficiente para que a menor resistência aerodinâmica do RS9 lhe permita atingir uma velocidade final $12,23 \mathrm{~km} / \mathrm{h}$ maior que a do RS8. Por outro lado, este atinge maiores acelerações em frenagem, graças justamente à sua maior resistência aerodinâmica.

O menor downforce do RS9 não permite que ele ultrapasse 2,27 G de aceleração lateral, enquanto que seu precursor teoricamente atinge 2,38 G. Dessa maneira, o menor aerofólio confere vantagens e desvantagens ao RS9. Em suma, o tempo de volta do RS9 foi 0,27 segundos mais baixo, superando o RS8.

Dada a complexidade do trajeto da prova de autocross, optou-se por dividir sua análise em trechos com características particulares, enumerados na figura 44. Nessa figura se encontra o traçado de autocross com indicação de velocidade por cores para o veículo RS9. 
Figura 44 - Traçado de autocross com indicação de velocidade por cores para veículo RS9

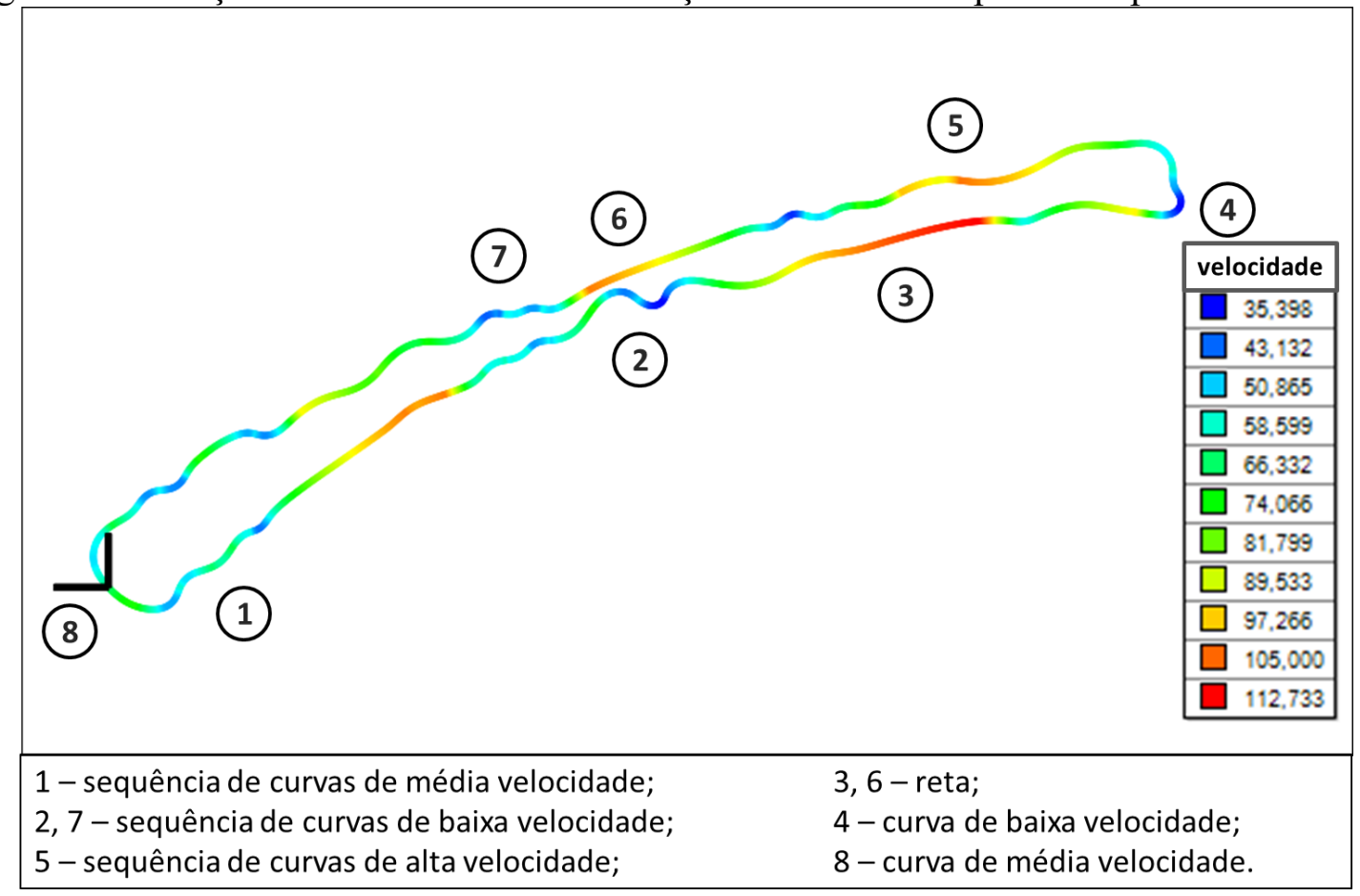

Fonte: autor

Nota: velocidade $\mathrm{em} \mathrm{km} / \mathrm{h}$

Para os dois protótipos, a velocidade em cada ponto da pista pode ser consultada no gráfico da figura 45. Os indicadores de 1 a 8 se referem às posições aproximadas dos trechos.

Figura 45 - Gráfico de velocidade longitudinal em função da distância para prova de autocross

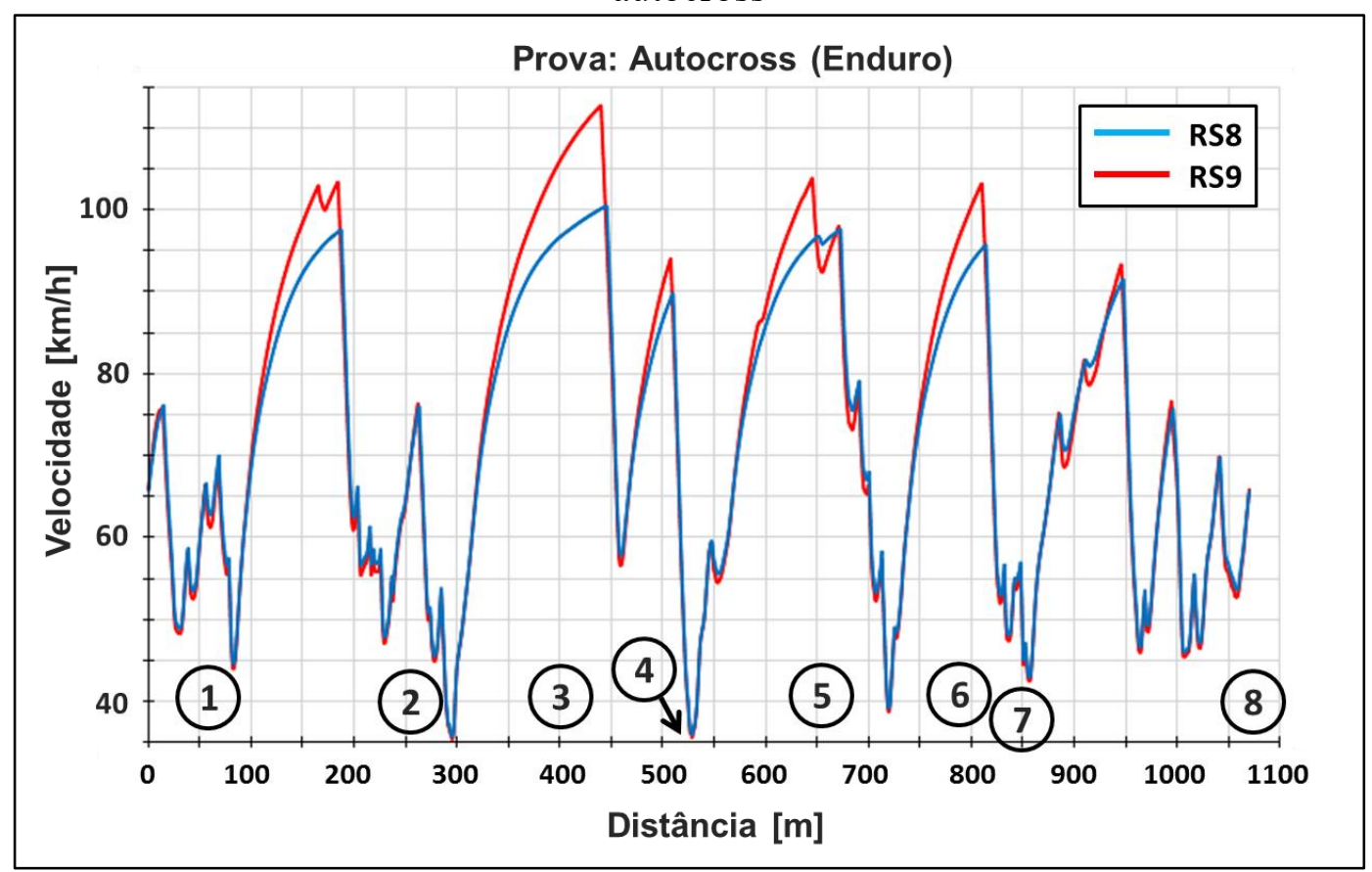

Fonte: autor 
Pormenores de cada trecho e sua análise são dados nos itens 5.4.1 a 5.4.3.

\subsubsection{Retas}

Os trechos marcados como 3 e 6 foram escolhidos como retas representativas pois, apesar de não serem segmentos perfeitamente retilíneos, seus raios de curvatura são amplos, permitindo altas velocidades longitudinais com baixas acelerações laterais.

A reta denominada trecho 3 , em detalhe na figura 46, possui 80 metros de comprimento. A seta preta indica o sentido de marcha. No início da reta, marcado como 3i, os veículos já estão ganhando velocidade. No final da reta, marcado como 3f, o RS8 atinge 100,5 $\mathrm{km} / \mathrm{h}$, enquanto que o RS9 ultrapassa os $112,7 \mathrm{~km} / \mathrm{h}$. Dada sua maior velocidade e menor resistência aerodinâmica, o RS9 precisa antecipar o início da frenagem.

Figura 46 - Comparativo de velocidade do trecho 3

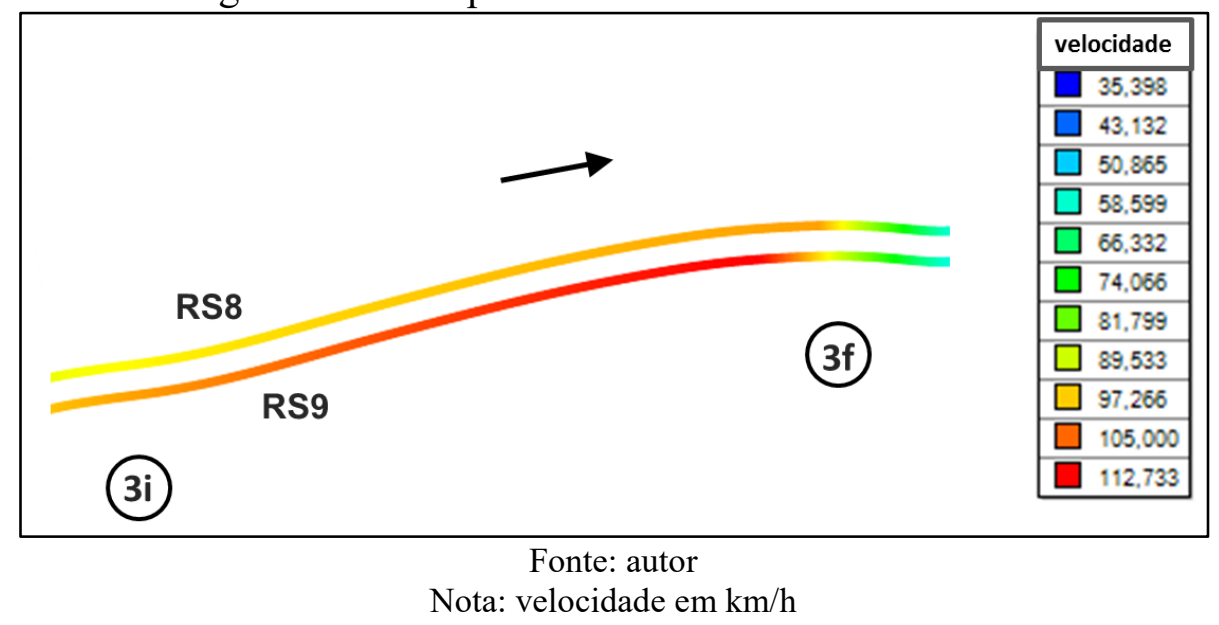

O gráfico da velocidade longitudinal pela distância percorrida se encontra na figura 47. Em sua análise, é possível perceber que 75 metros antes da entrada da reta os veículos já vêm ganhando velocidade, e continuam até o ponto de maior velocidade do circuito, sucedido pela frenagem do final da reta. Observa-se também que o ponto de frenagem do RS9 ocorre aos 440 metros, cinco metros antes do RS8. 
Figura 47 - Gráfico de velocidade longitudinal no trecho 3 (reta)

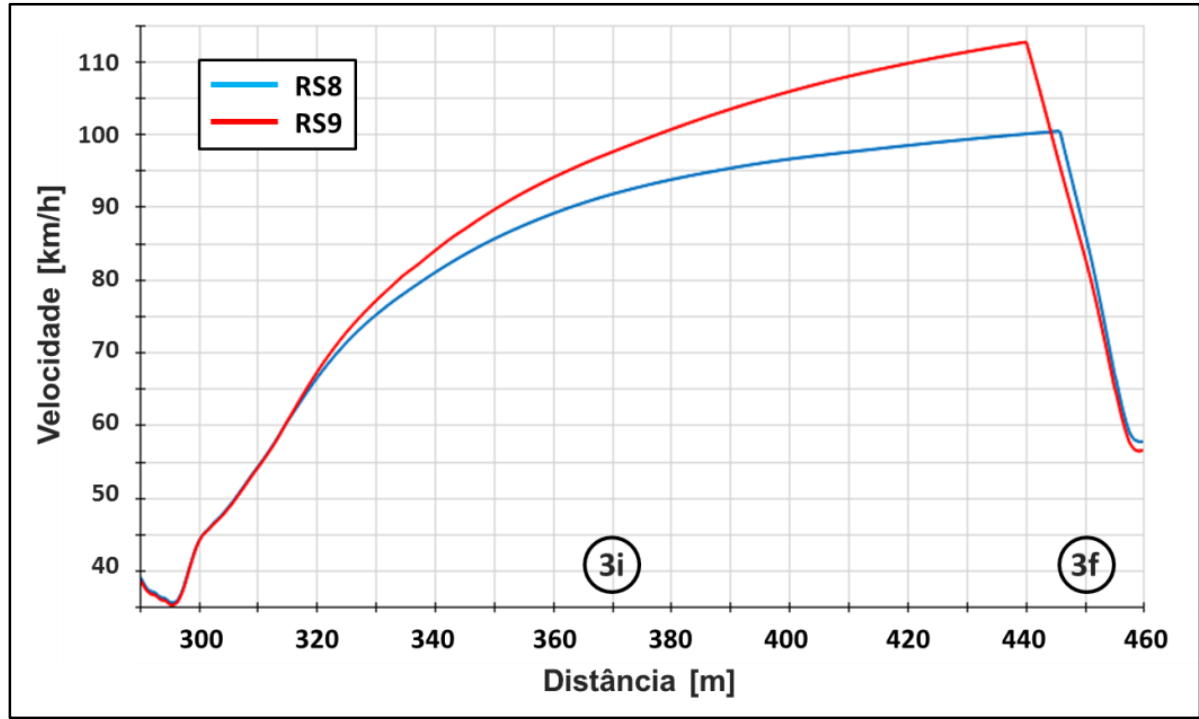

Fonte: autor

Analisando a aceleração longitudinal dos dois veículos pelo gráfico da figura 48, observa-se que o RS9 desenvolve maior aceleração longitudinal em toda a reta, porém não atinge a mesma desaceleração que seu antecessor na frenagem, como indica a última linha da tabela 17. A frenagem é caracterizada pela aceleração menor que zero.

Figura 48 - Gráfico de aceleração longitudinal no trecho 3 (reta)

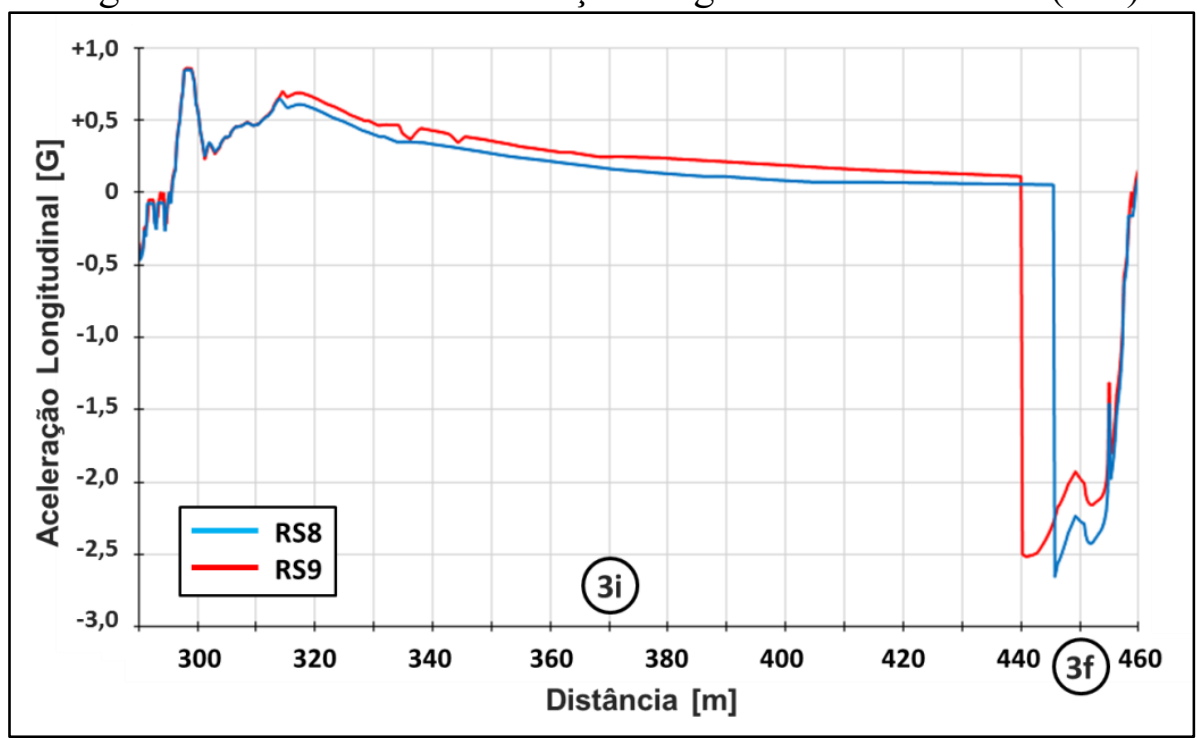

Fonte: autor

O tempo para o RS8 percorrer o trecho 3 foi de 2,98 segundos, contra 2,75 segundos do RS9 (este 7,7\% menor).

$\mathrm{Na}$ reta intitulada trecho 6 , também de 80 metros, o comportamento dos veículos é similar ao do trecho 3, porém com menor velocidade de entrada de reta. Esse trecho está 
representado graficamente na figura 49. Assim como na figura 46, a seta preta indica o sentido de marcha, e da mesma maneira para as figuras seguintes deste item 5.

Figura 49 - Comparativo de velocidade do trecho 6

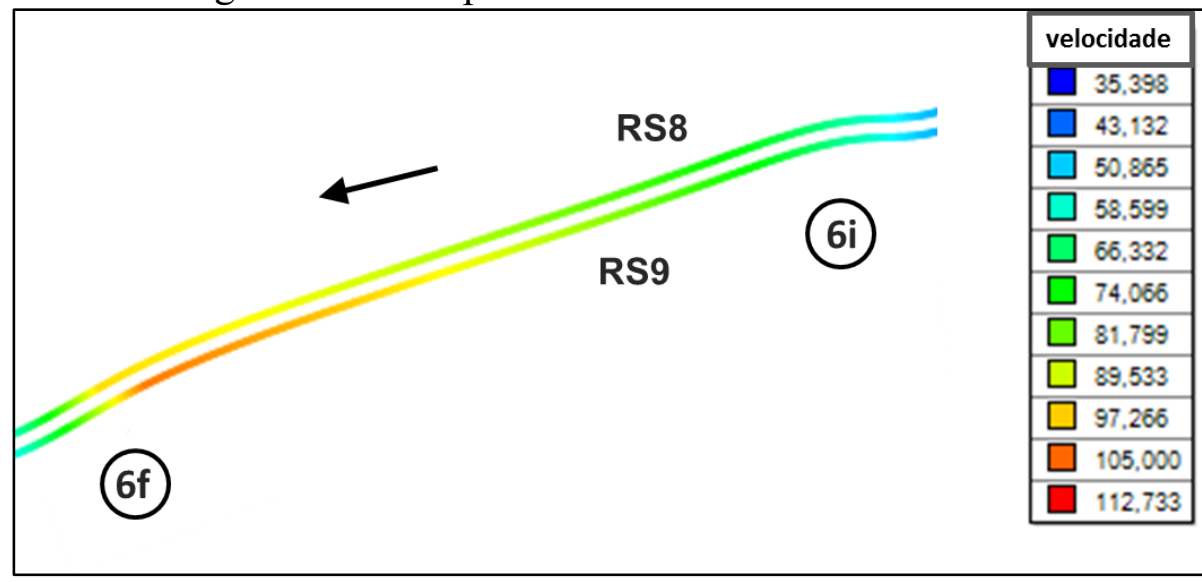

Fonte: autor

Nota: velocidade em $\mathrm{km} / \mathrm{h}$

Comparando o gráfico da figura 50 com o da figura 49, nota-se um padrão de comportamento em retas, onde a menor resistência aerodinâmica do RS9 lhe confere vantagem acima dos $65 \mathrm{~km} / \mathrm{h}$. Mais uma vez, a frenagem do RS9 deve ser antecipada em aproximadamente cinco metros. Essa necessidade de antecipar a frenagem se traduz num maior percentual de frenagem. O RS9 freia em 30,23\% do percurso, enquanto que o RS8 percorre apenas $27,37 \%$ do trajeto com os freios acionados, como já mostrado na tabela 17.

Figura 50 - Gráfico de velocidade longitudinal no trecho 6 (reta)

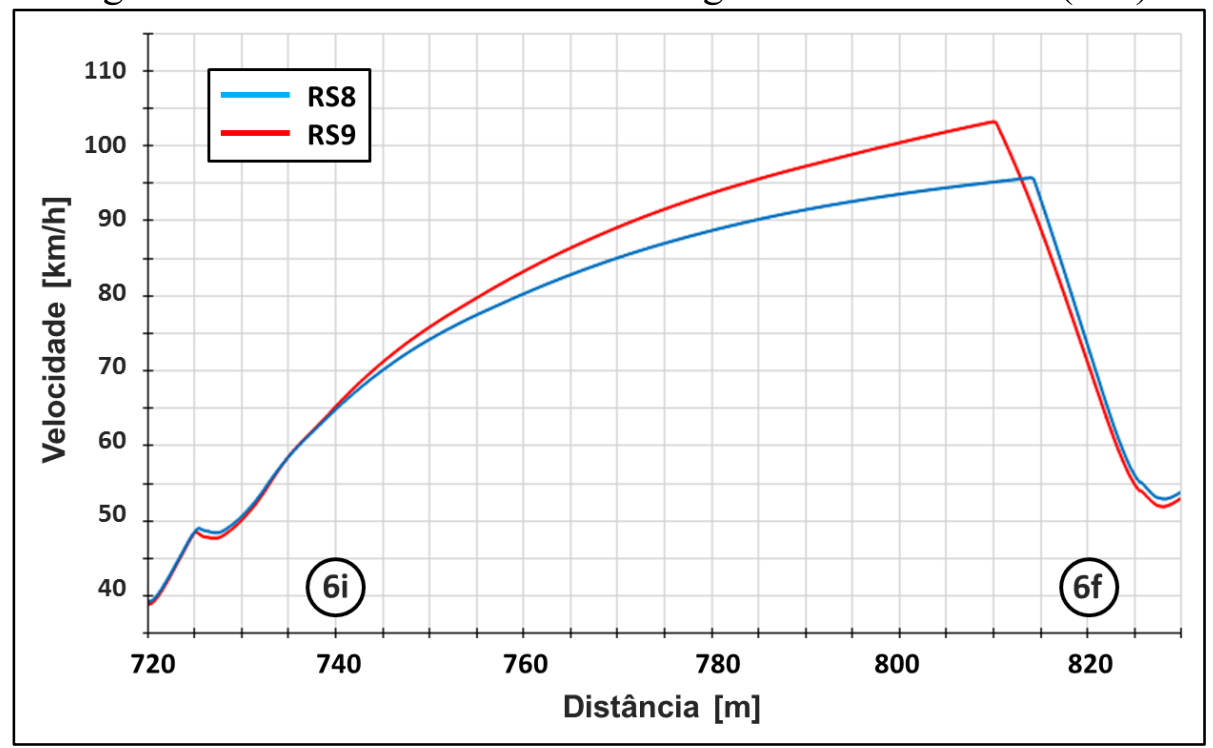

Fonte: autor 
Apesar dos trechos 3 e 6 apresentarem o mesmo comprimento de reta, a menor velocidade de entrada deste não permite que o RS9 ultrapasse 103,9 km/h, sendo a velocidade do RS8 limitada a $97,6 \mathrm{~km} / \mathrm{h}$.

O tempo para o RS8 percorrer o trecho 6 foi de 3,41 segundos, contra 3,28 segundos do RS9 (este 3,8\% menor).

\subsubsection{Curvas}

Tomou-se como exemplo de curva de baixa velocidade o trecho 4, compreendido entre $4 \mathrm{i}$ e 4f, ilustrado pela figura 51. O raio é de 55,5 metros no início da curva (4i), reduzindo-se gradativamente até atingir o mínimo de 5,46 metros, aumentando novamente até o final da curva, quando seu sentido se inverte, cobrindo uma extensão de 18 metros.

A impressão de que o veículo RS8 percorreu raios menores se dá pelo efeito da sobreposição de gráficos, a fim de comparar os resultados em uma única figura. Na verdade, as trajetórias dos dois carros são idênticas.

Figura 51 - Comparativo de velocidade do trecho 4

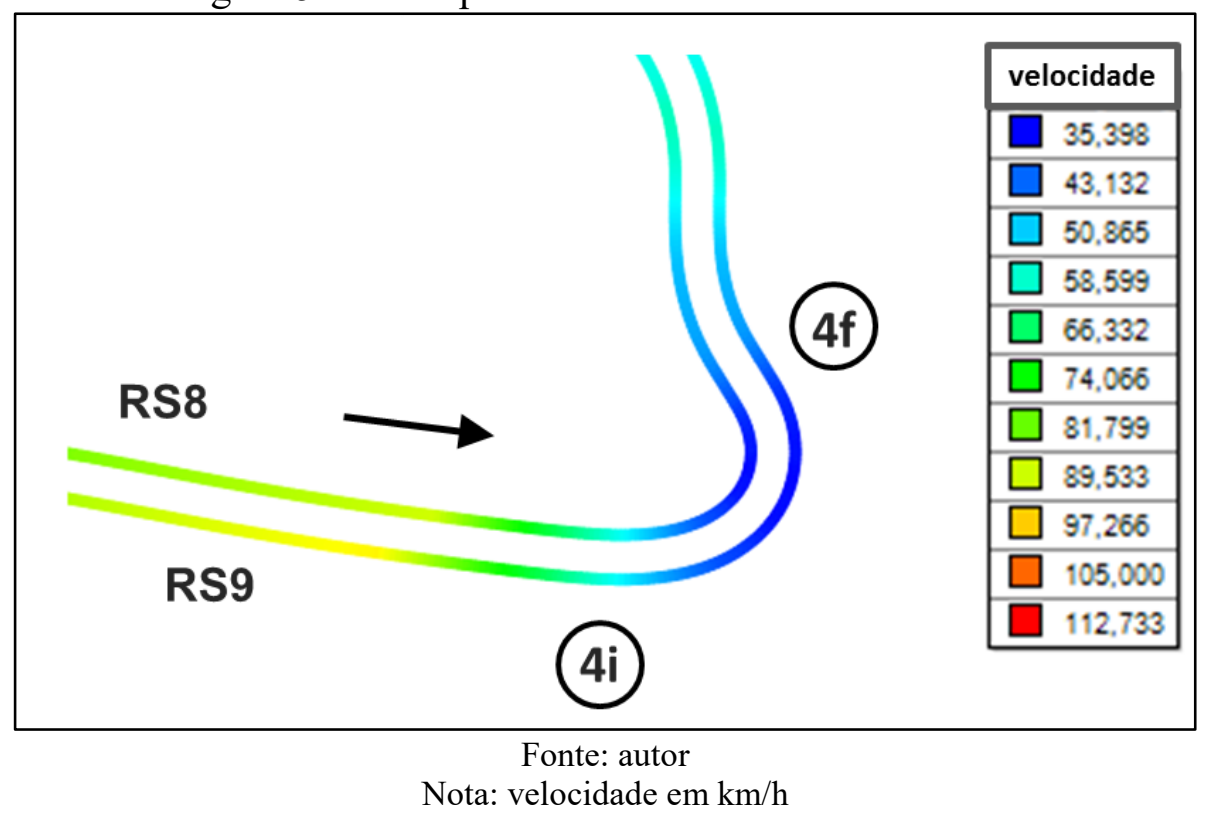

Com auxílio do gráfico da figura 52, observa-se que o RS8 entra mais veloz na curva, resultado da maior capacidade de desaceleração. São $62 \mathrm{~km} / \mathrm{h}$ do RS8, contra $60 \mathrm{~km} / \mathrm{h}$ do RS9 no ponto 4i. À medida que os veículos avançam na curva, o raio desta vai diminuindo, assim como a diferença de velocidade entre eles. 
No ponto de menor raio, situado aos 529 metros, tem-se as menores velocidades. Nesse ponto de baixa velocidade, a vantagem aerodinâmica do RS8 se torna pequena, vide figura 53. Consequentemente, os dois carros desenvolvem velocidades similares.

Na saída da curva, aos 535 metros, os veículos mantêm desempenho semelhante. Isto porque as velocidades ainda estão dentro do limite de tração, quando não há vantagem significativa de um veículo sobre o outro, como verificado no item 5.2.1.

Figura 52 - Gráfico de velocidade longitudinal no trecho 4 (curva de baixa velocidade)

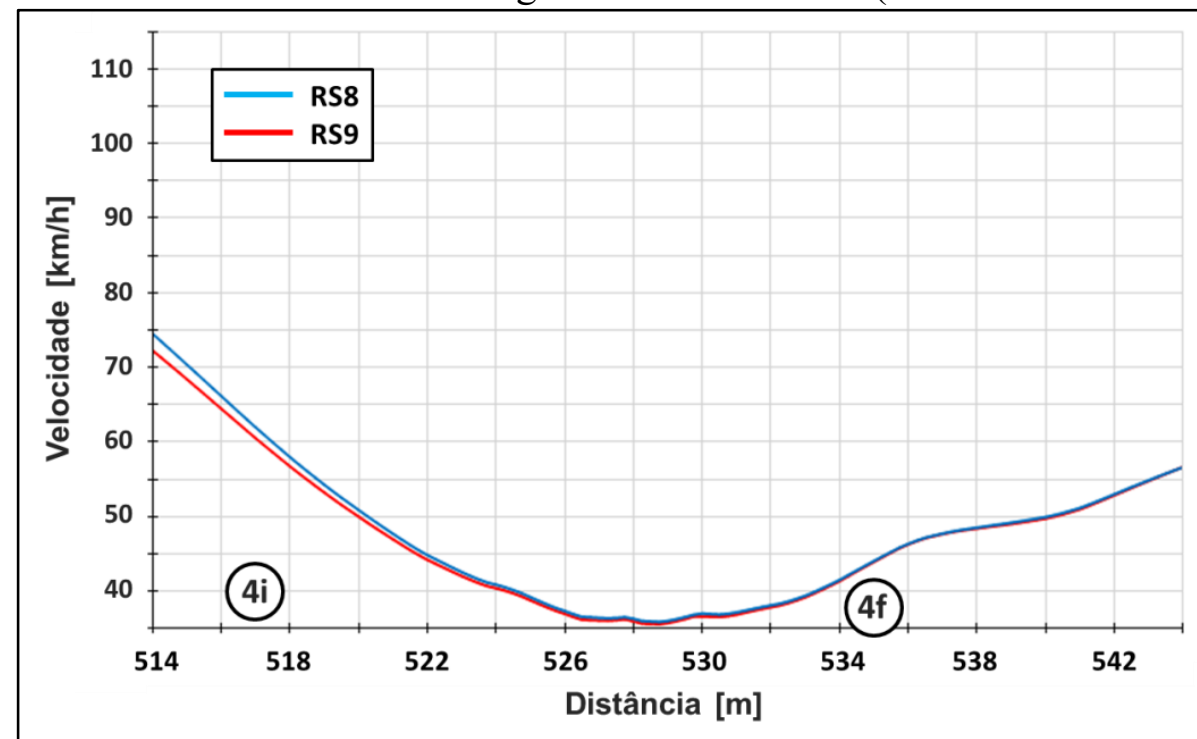

Fonte: autor

O gráfico da figura 53 mostra como o downforce dos veículos diminui ao entrarem na curva, resultado da redução de velocidade. No ponto de menor raio e menor velocidade, aos 529 metros, a diferença entre as forças aerodinâmicas verticais é de apenas 65 N, com ligeira vantagem do RS8. 
Figura 53 - Gráfico de downforce no trecho 4 (curva de baixa velocidade)

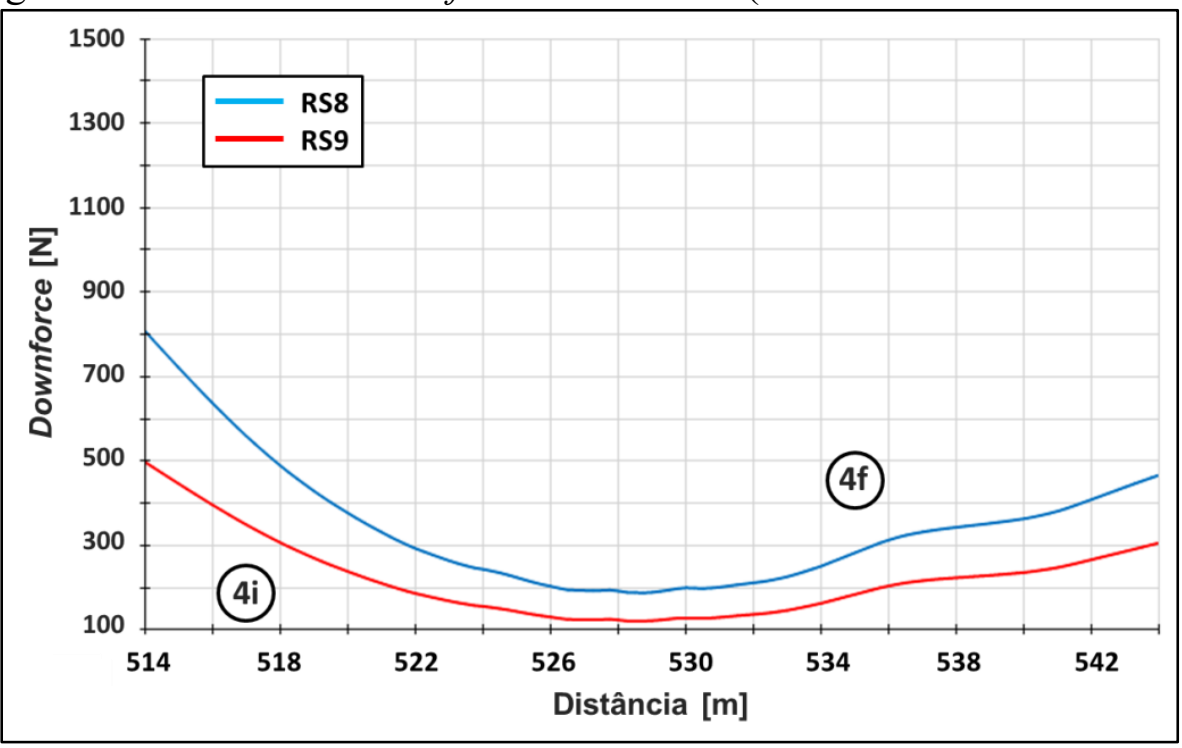

Fonte: autor

Corroborando as análises de velocidade e downforce, o gráfico comparativo da figura 54 exibe acelerações laterais próximas, sendo de 1,86 G para o RS8 e 1,84 G para o RS9, ambas aos 527 metros, indicando capacidade de curva equivalente a baixas velocidades. Acelerações laterais positivas indicam curvas à esquerda, enquanto que negativas indicam curvas à direita, conforme definido pelo programa.

O tempo do RS8 no trecho 4 foi de 1,57 segundos, contra 1,59 segundos do RS9, sendo este $1,3 \%$ maior.

Figura 54 - Gráfico de aceleração lateral no trecho 4 (curva de baixa velocidade)

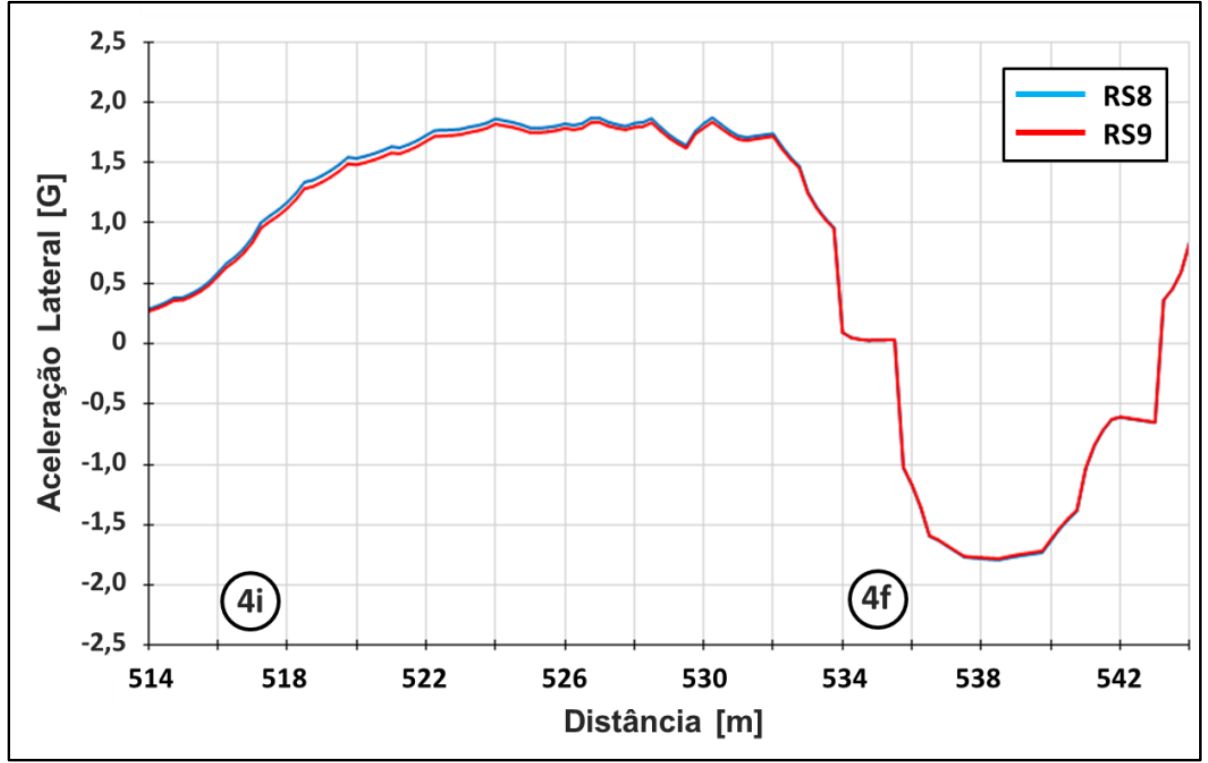

Fonte: autor 
Analisando o trecho 8, aqui representado na figura 55, é possível comparar o desempenho dos veículos em curva de média velocidade. O trecho se estende do ponto 8i, aos 1038 metros, passando pela linha de chegada $(1070 \mathrm{~m})$ até o ponto 8f, aos 35 metros, resultando em uma extensão de 67 metros.

$\mathrm{Na}$ entrada da curva, o raio é de 48,9 metros, com mínimo de 9,8 metros próximo ao final da curva, onde as velocidades são as mais baixas do trecho.

Figura 55 - Comparativo de velocidade do trecho 8

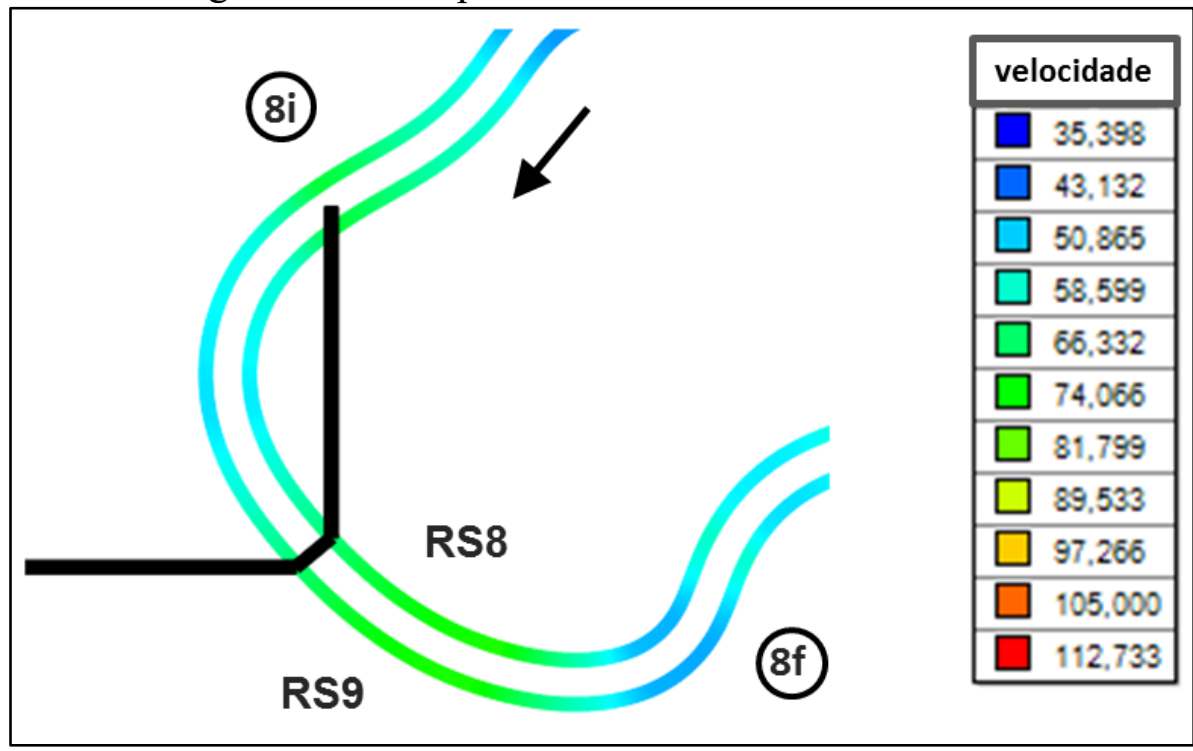

Fonte: autor

Nota: velocidade em $\mathrm{km} / \mathrm{h}$

Como pode ser visto na figura 56, o RS8 desenvolve maior downforce ao longo de todo o trecho 8, e a diferença aumenta com o aumento da velocidade (figura 57). Comparando os gráficos das figuras 56 e 57, percebe-se que o maior downforce desenvolvido pelo RS8 não lhe confere vantagem entre zero e 14 metros. Ali o raio da curva é grande o suficiente para que desenvolvam velocidades acima dos $65 \mathrm{~km} / \mathrm{h}$, e o arrasto aerodinâmico se torna mais relevante. 
Figura 56 - Gráfico de downforce no trecho 8 (curva de média velocidade)

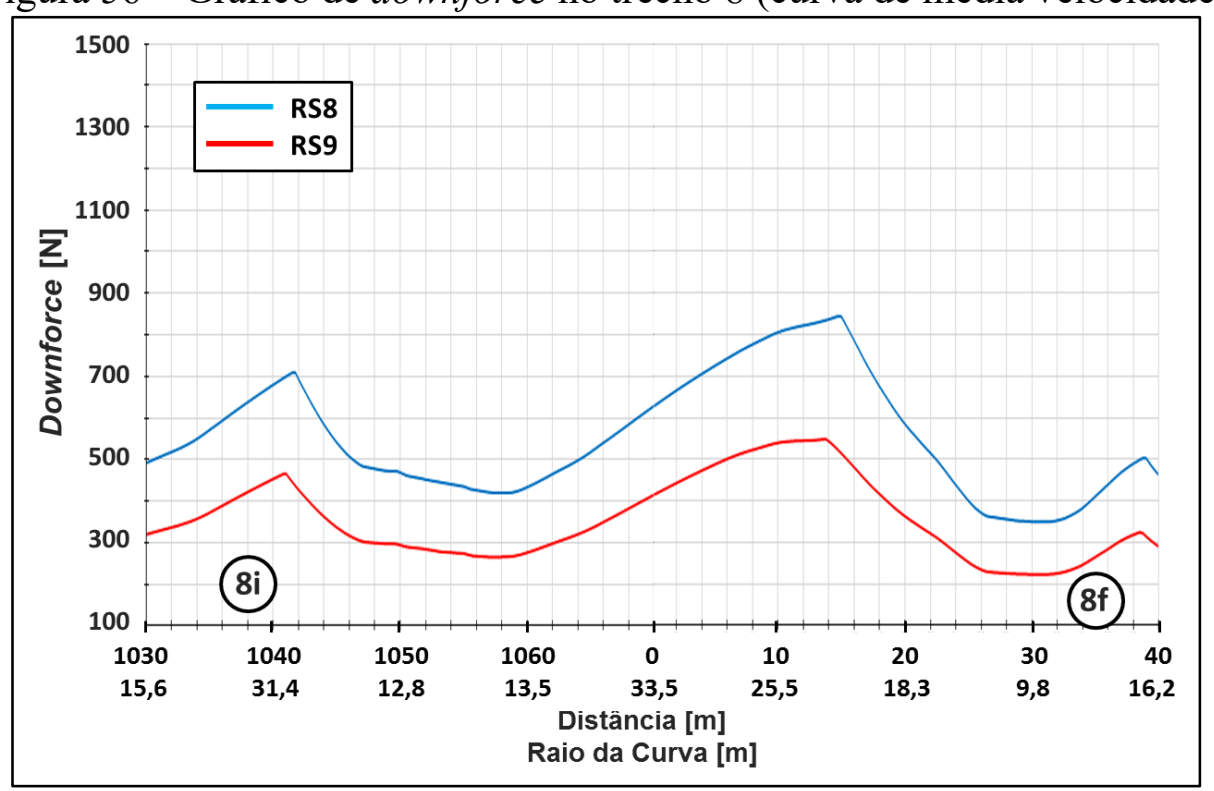

Fonte: autor

Pelo gráfico da figura 57, os veículos entram na curva ganhando velocidade e ambos atingem $70 \mathrm{~km} / \mathrm{h}$. Nota-se que o RS9 atinge essa velocidade antes do RS8, quando precisa frear para a entrada da curva. Nesse caso, a diferença entre os pontos de frenagem é de menos de um metro. À medida que o raio da curva diminui, também diminui a velocidade longitudinal, com vantagem do RS8 por conta de seu maior downforce, que lhe confere maior capacidade de curva.

Ao se aproximarem da linha de chegada, com o aumento do raio de curvatura, os veículos ganham velocidade e o RS9 supera seu oponente, mostrando que o menor arrasto aerodinâmico é mandatório nesse segmento. Sua frenagem antecipada, entretanto, acarreta uma menor velocidade final: $75,8 \mathrm{~km} / \mathrm{h}$, enquanto que o RS8 atinge $76,2 \mathrm{~km} / \mathrm{h}$.

O RS8 volta a ser mais veloz a partir do segundo ponto de frenagem, localizado aos 14 metros, e assim se mantém até a saída da curva. Esse comportamento confirma que o maior downforce do RS8 favorece a entrada e contorno de curvas de média velocidade, mas que seu maior arrasto aerodinâmico o prejudica (em relação ao RS9) nas saídas de curva acima dos 65 $\mathrm{km} / \mathrm{h}$. 
Figura 57 - Gráfico de velocidade longitudinal no trecho 8 (curva de média velocidade)

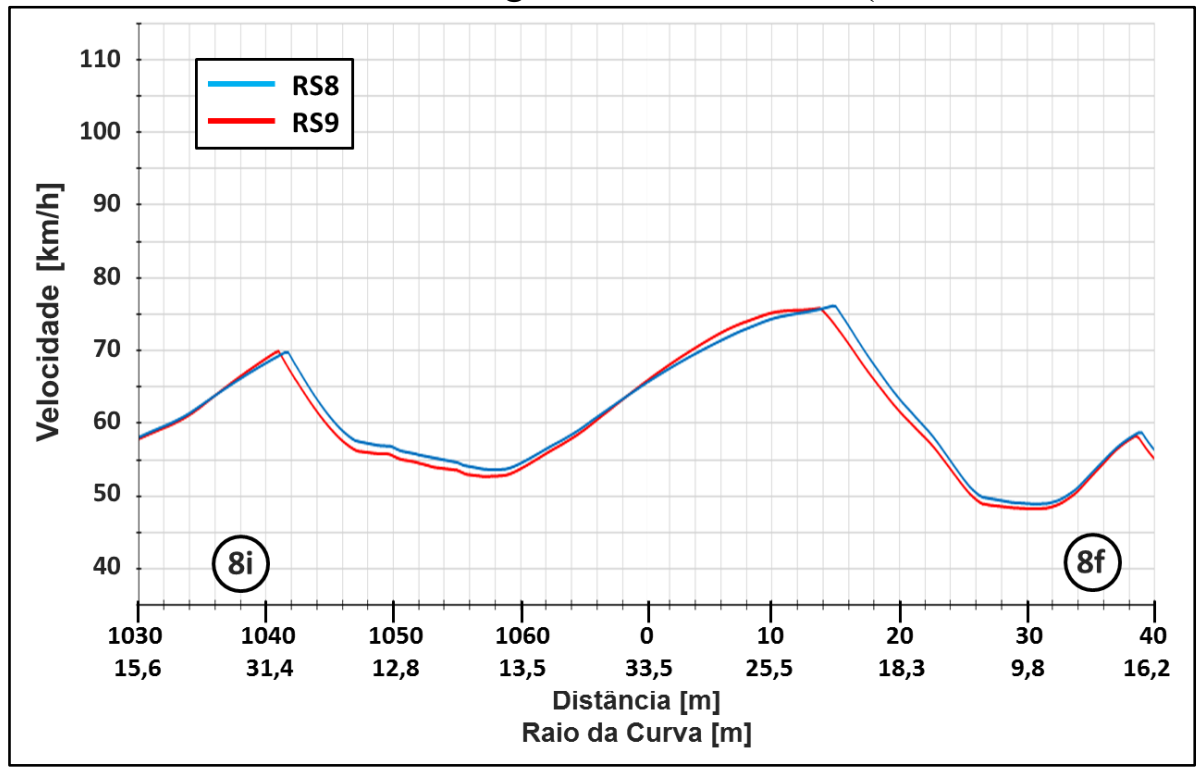

Fonte: autor

Ao comparar os gráficos de aceleração lateral da figura 58 e da figura 54, percebe-se que os veículos desenvolveram maiores acelerações laterais no trecho 8. Isso foi possível pelo maior raio de curva, que permitiu desenvolverem maior velocidade, portanto maior downforce. Este, por sua vez, aumenta a capacidade de curva, garantindo maiores acelerações laterais.

Figura 58 - Gráfico de aceleração lateral no trecho 8 (curva de média velocidade)

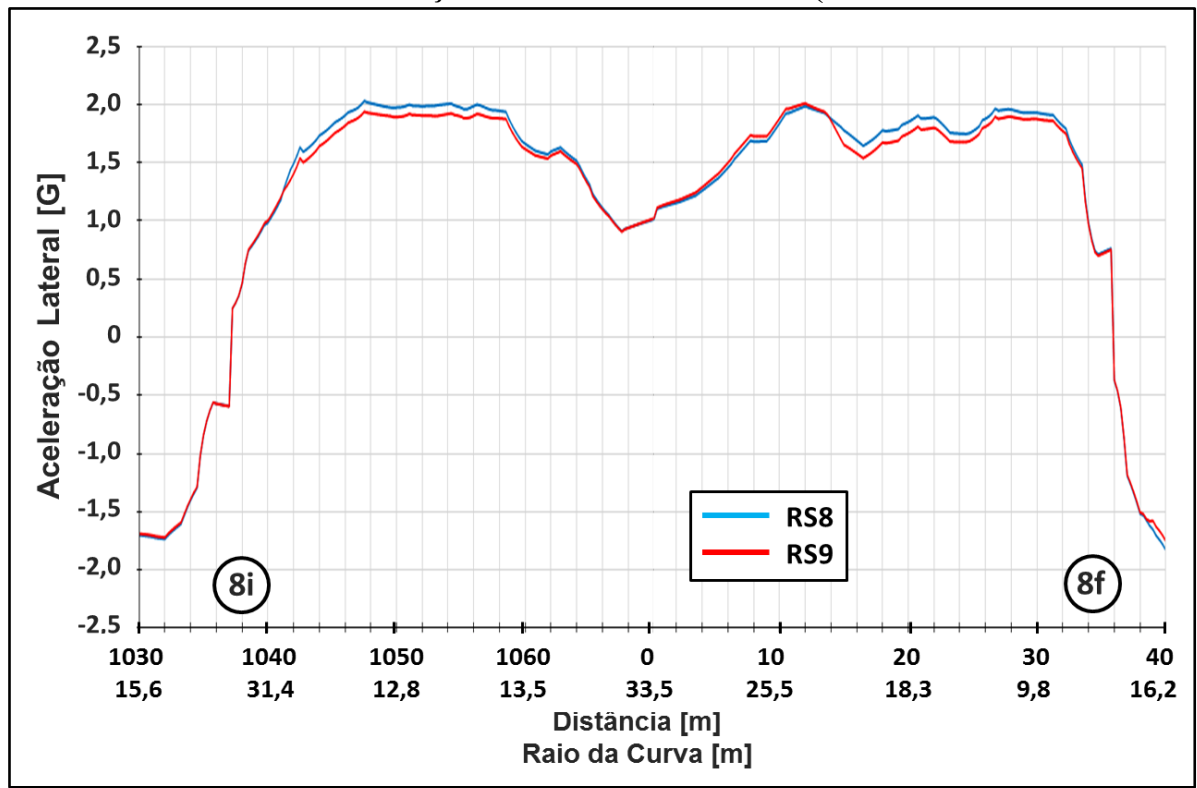

Fonte: autor

Assim como a velocidade, a aceleração lateral do RS8 supera a do RS9 em curvas de raios relativamente pequenos, enquanto que em curvas mais abertas o RS9 leva vantagem. O 
gráfico da figura 59 exibe as acelerações laterais em função dos raios de curva não só para o trecho 8, mas para todo o circuito. As curvas para a direita foram omitidas, dada uma aproximada simetria, bem como as de raio superior a 100 metros, haja vista semelhança com uma reta.

Observa-se que o RS8 suporta maiores acelerações laterais que o RS9 nas curvas de menor raio como consequência do maior downforce, sendo a vantagem crescente até os 36 metros.

Nas curvas de raio maior que 36 metros, o RS9 passa a desenvolver maiores acelerações laterais como consequência da maior velocidade, por sua vez consequência da menor resistência aerodinâmica.

Figura 59 - Gráfico de aceleração lateral para toda a pista

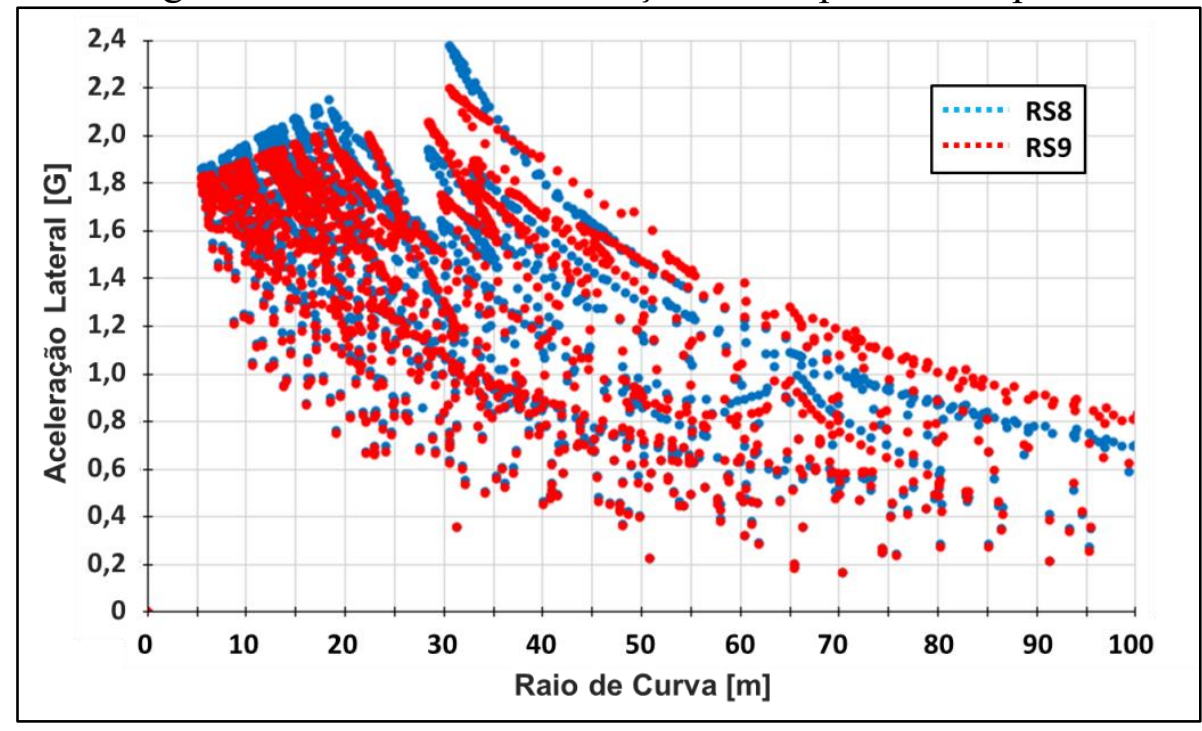

Fonte: autor

Nota: apenas curvas à esquerda, de raio até $100 \mathrm{~m}$

O tempo para o RS8 percorrer o trecho 8 foi de 4,33 segundos, contra 4,38 segundos do RS9 (este 1,2\% maior).

\subsubsection{Sequências de curvas}

O trecho 2, delimitado pelos pontos $2 \mathrm{i}$ e $2 \mathrm{f}$ conforme figura 60 , foi escolhido como sequência de curvas de baixa velocidade por conter a curva de menor raio de todo o circuito: 5,40 metros, onde as velocidades são as mais baixas. A sequência de três curvas se estende por 56 metros, dos 260 aos 316 metros. 
Figura 60 - Comparativo de velocidade do trecho 2

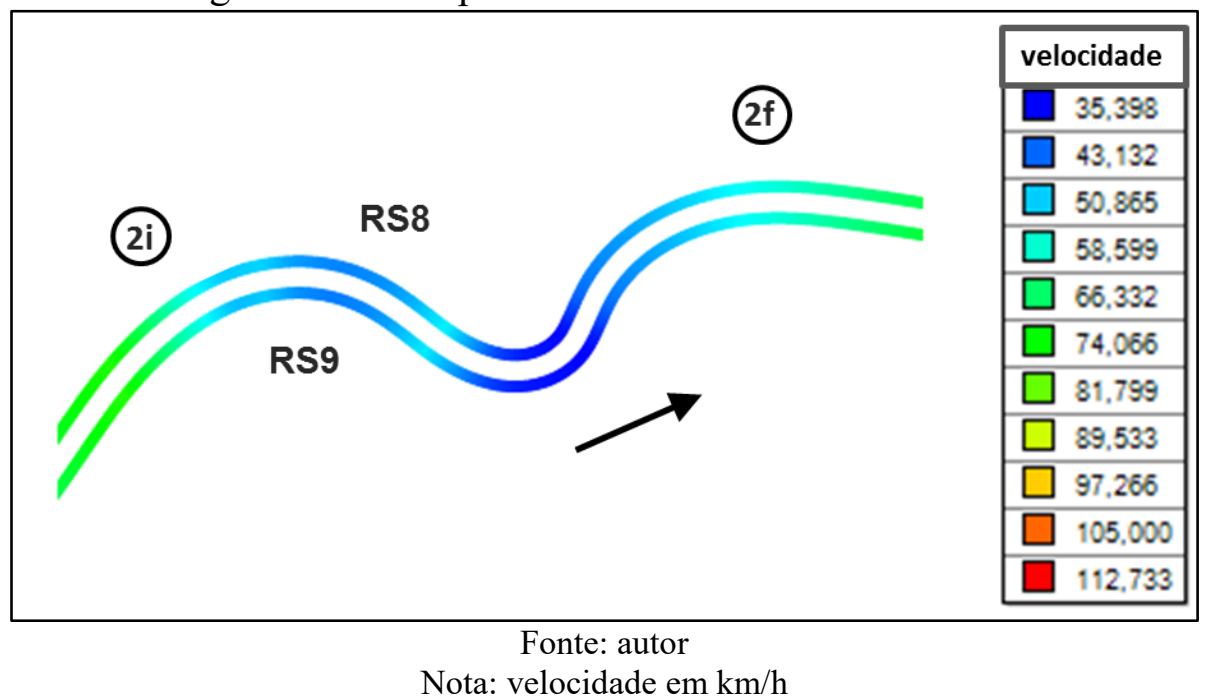

Analisando a figura 61, percebe-se que o RS9 entra mais veloz na curva até o ponto da frenagem, aos 262 metros. O RS8 freia 1,1 metros à frente, contornando a primeira curva (260 a 284 metros) com maior velocidade. Com a redução da velocidade, diminui também a vantagem sobre o RS9. Como já explicado no item 5.4.2, isso ocorre pela vantagem em curvas do RS8 ser aerodinâmica, proporcional à velocidade longitudinal. Em baixas velocidades, a diferença dos dois veículos é pequena.

Figura 61 - Gráfico de velocidade no trecho 2 (sequência de curvas de baixa velocidade)

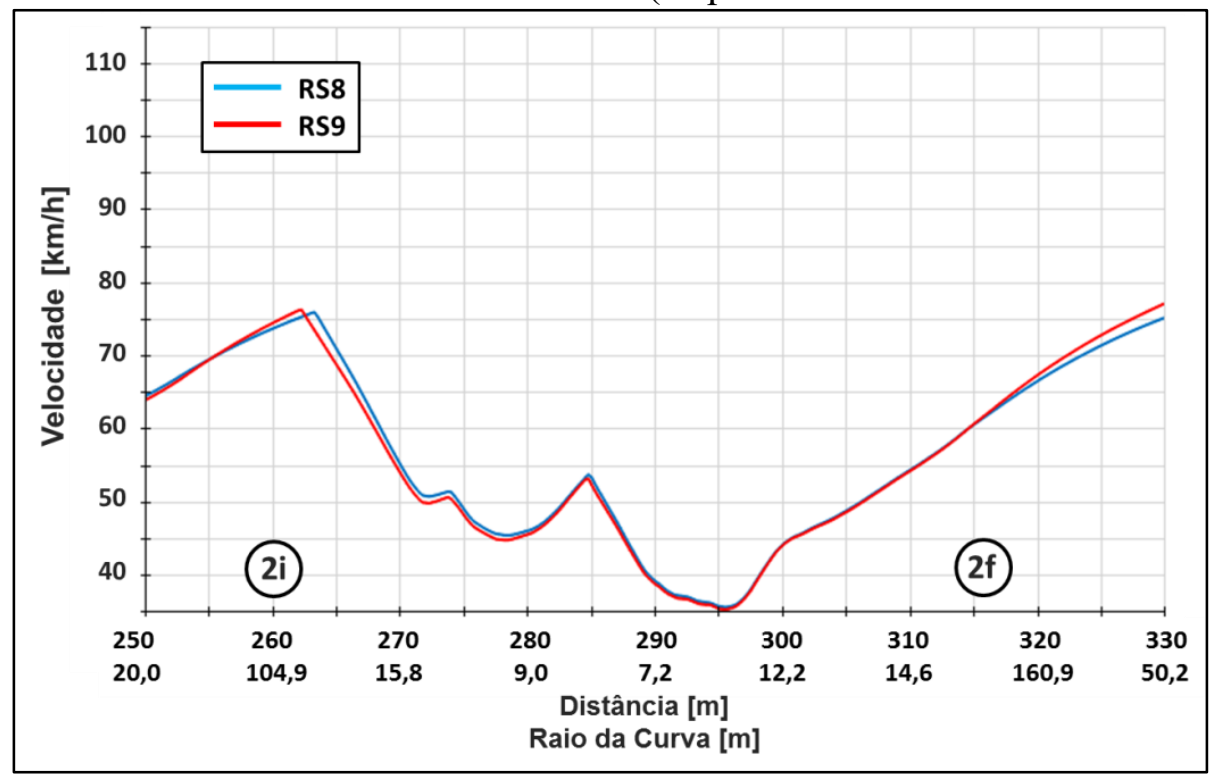

Fonte: autor

A segunda curva do trecho (284 a 300 metros) é a mais lenta. O RS8 leva ligeira vantagem durante a frenagem, mas a partir dos 296 metros, início da aceleração, o desempenho dos dois protótipos é equivalente. Aos 315 metros, já na saída da terceira e 
última curva do trecho 2, onde o raio é de 35 metros, o RS9 começa a superar o RS8. Nesse ponto, as velocidades superam os $60 \mathrm{~km} / \mathrm{h}$, e o menor arrasto aerodinâmico do RS9 mais uma vez lhe confere vantagem.

As maiores acelerações laterais no trecho 2 ocorreram aos 272 metros, na tangência da primeira curva, tendo o RS8 atingido 1,97 G, contra 1,90 G do RS9.

O RS8 levou 4,12 segundos para percorrer todo o trecho 2, enquanto que o RS9 levou 4,16 segundos (tempo 1,0\% maior) para cobrir o mesmo trecho.

O trecho 7, representado graficamente na figura 62 , é composto por uma sequência de quatro curvas alternadas de baixa velocidade, iniciando à direita e terminando à esquerda, precedido pela reta do trecho 6. A entrada da primeira curva se dá aos 820 metros (7i), e a saída da quarta curva se dá aos 865 metros, no ponto 7f, totalizando 45 metros.

Como visto na figura 62, as curvas mais lentas do trecho são a segunda e a quarta, ambas à esquerda, com velocidades abaixo dos $43 \mathrm{~km} / \mathrm{h}$. As curvas um e três, ambas à direita, possuem maior raio e são, portanto, mais velozes. Entretanto, as velocidades não ultrapassam os $56 \mathrm{~km} / \mathrm{h}$ em cada uma delas.

Figura 62 - Comparativo de velocidade do trecho 7

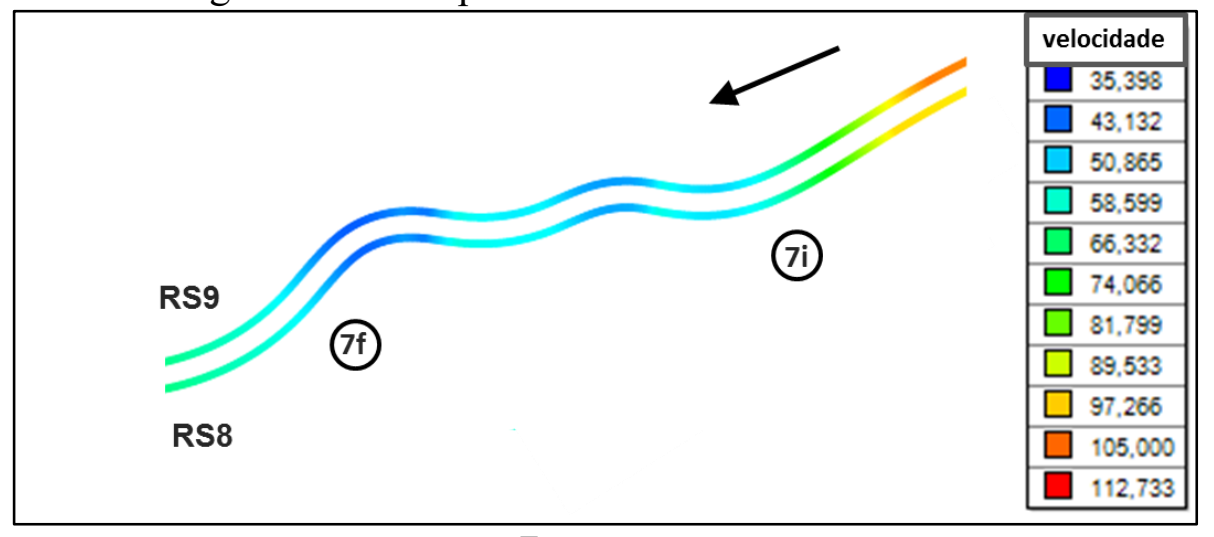

Fonte: autor

Nota: velocidade em $\mathrm{km} / \mathrm{h}$

As velocidades dos veículos ao longo do trecho 7 podem ser consultadas no gráfico da figura 63. O RS8 entra mais veloz na primeira curva (7i) como consequência da frenagem mais tardia no final da reta. Seu maior downforce lhe permite maior geração de força dos pneus, garantindo maior velocidade na entrada e tangência das curvas. A velocidade longitudinal do RS9 se aproxima à do RS8 nos segmentos entre as curvas, onde a inversão de lado da curva proporciona curtos momentos de aceleração. Mas é somente na saída da quarta e última curva que o desempenho do RS9 se iguala ao do RS8. 
Figura 63 - Gráfico de velocidade no trecho 7 (sequência de curvas de baixa velocidade)

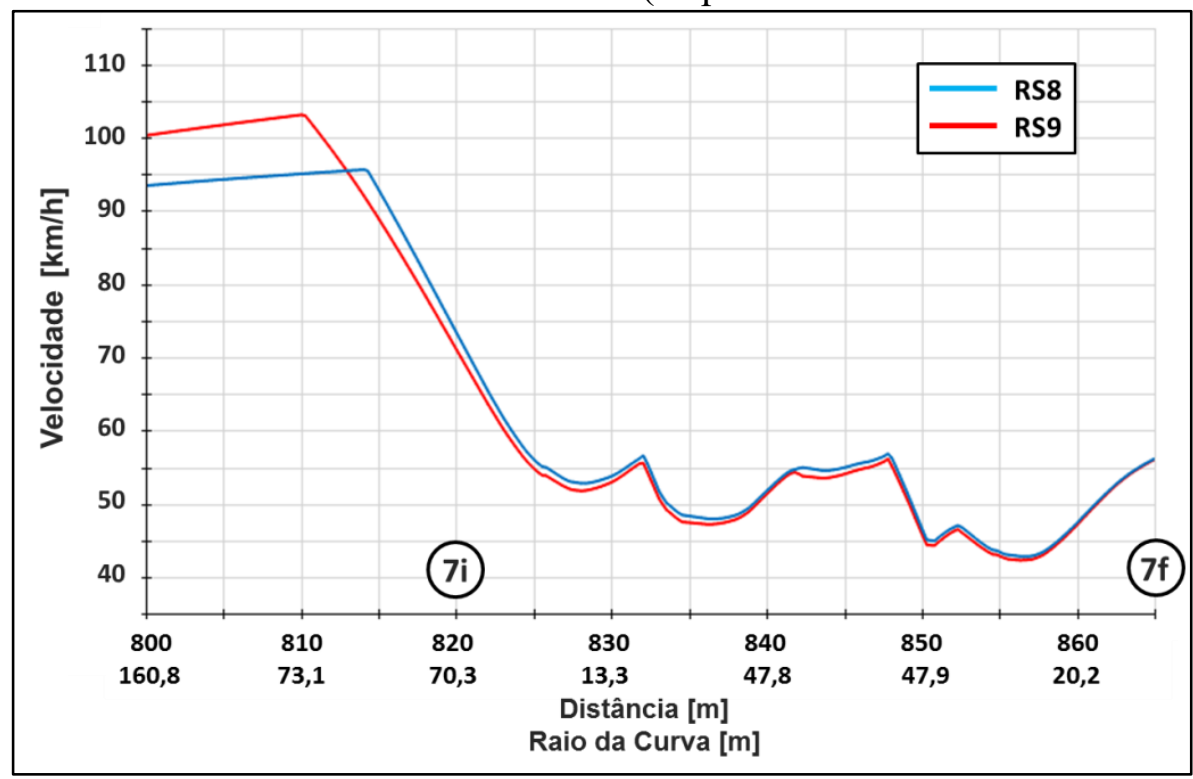

Fonte: autor

Analisando as acelerações laterais produzidas na sequência de curvas por meio da figura 64, observa-se que o RS8 suporta maiores acelerações laterais em todas as curvas do trecho 7.

Figura 64 - Gráfico de aceleração lateral no trecho 7 (sequência de curvas de baixa velocidade)

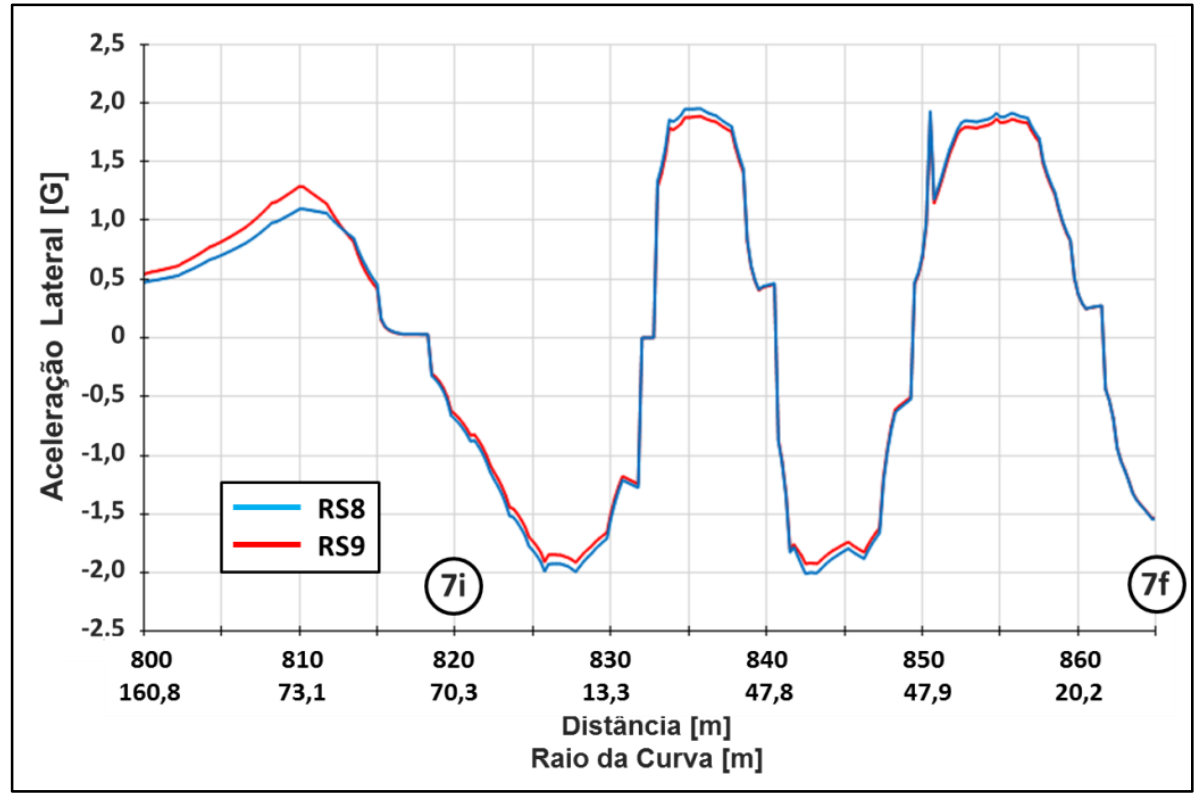

Fonte: autor

Aos 842 metros, o RS8 atinge o pico de 2,01 G (em módulo), enquanto que o RS9 não supera 1,92 G (em módulo). 
O RS8 gastou 3,16 segundos para percorrer todo o trecho 7, enquanto que o RS9 precisou de 3,21 segundos (tempo 1,6\% maior) para cobrir o mesmo trecho. O RS8 mostrouse mais rápido nas duas sequências de curva de baixa velocidade.

Para comparar os desempenhos em sequência de curvas de média velocidade, foi escolhido o trecho 1 , compreendido entre os pontos $1 \mathrm{i}(40 \mathrm{~m})$ e $1 \mathrm{f}(80 \mathrm{~m})$, totalizando 40 metros. O trecho é composto de três curvas alternadas, iniciando e terminando à direita, e é delimitado por duas curvas de baixa velocidade, como visto na figura 65 .

\section{Figura 65 - Comparativo de velocidade do trecho 1}

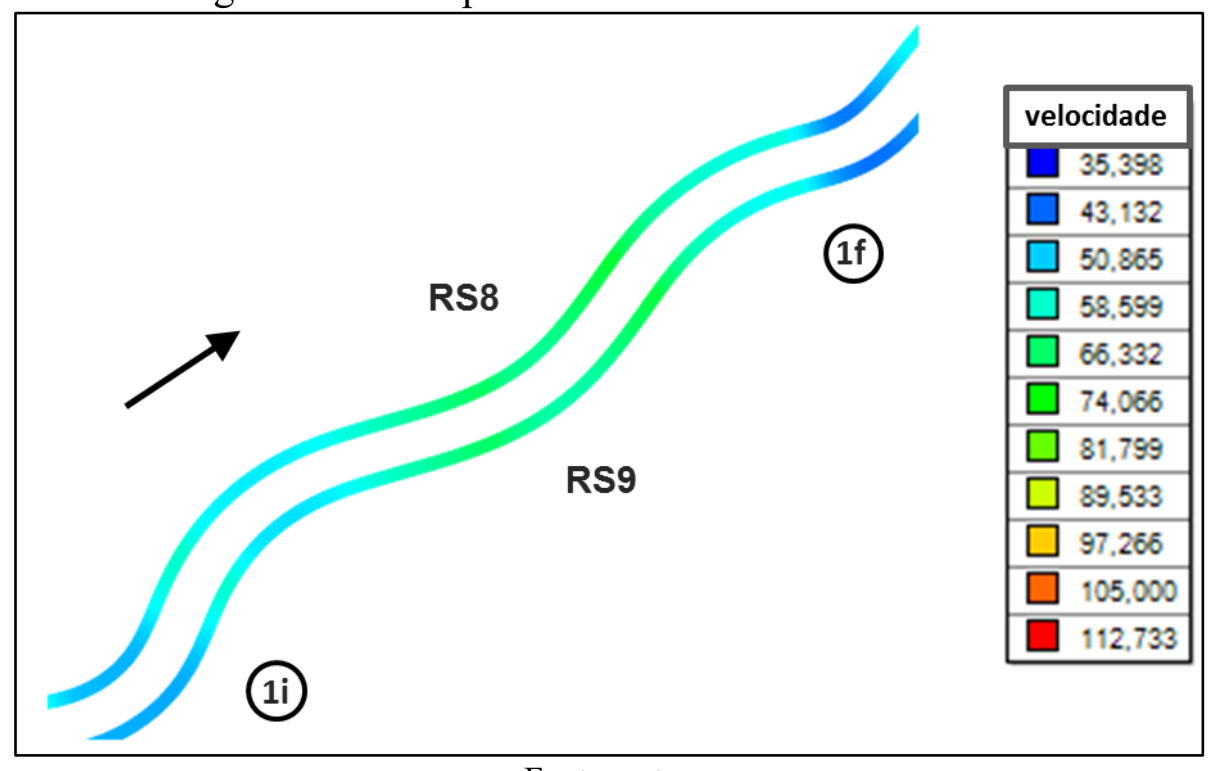

Fonte: autor

Nota: velocidade $\mathrm{em} \mathrm{km} / \mathrm{h}$

$\mathrm{Na}$ sequência de curvas de média velocidade, o comportamento dos veículos se assemelha ao das sequências de baixa. No gráfico da figura 66 , pode-se ver a vantagem do RS8 nas entradas e tangência de curvas (por exemplo, dos $40 \mathrm{~m}$ aos $50 \mathrm{~m}$ ) e a recuperação do RS9 nas saídas de curva (por exemplo, dos $50 \mathrm{~m}$ aos $56 \mathrm{~m}$ ). 
Figura 66 - Gráfico de velocidade no trecho 1 (sequência de curvas de média velocidade)

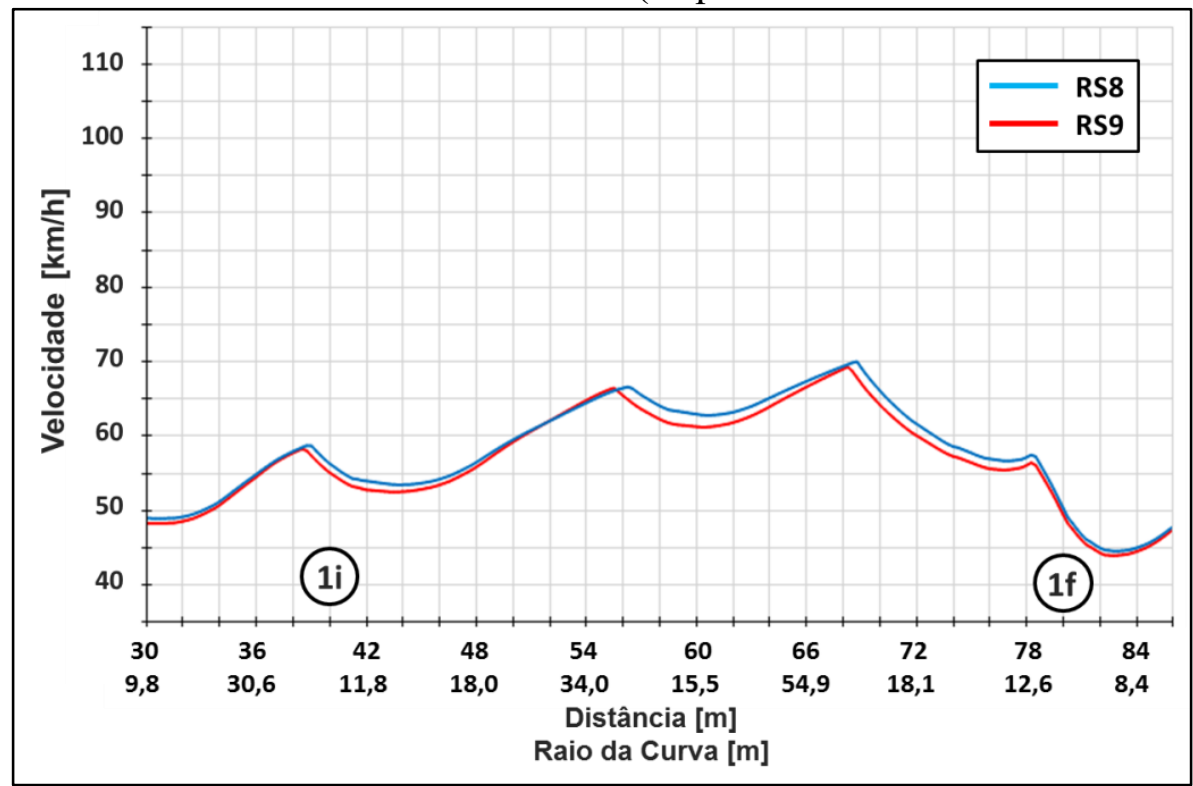

Fonte: autor

Por se desenvolverem médias velocidades, as forças aerodinâmicas são maiores, permitindo maiores acelerações laterais em relação às sequências de baixa velocidade. Como visto na figura 67, o RS8 atingiu 2,08 G aos 60 metros, tangenciando a curva 2 à esquerda, a curva mais veloz das três. Já a aceleração lateral do RS9 ficou limitada a 1,97 G no mesmo ponto.

Figura 67 - Gráfico de aceleração lateral no trecho 1 (sequência de curvas de média velocidade)

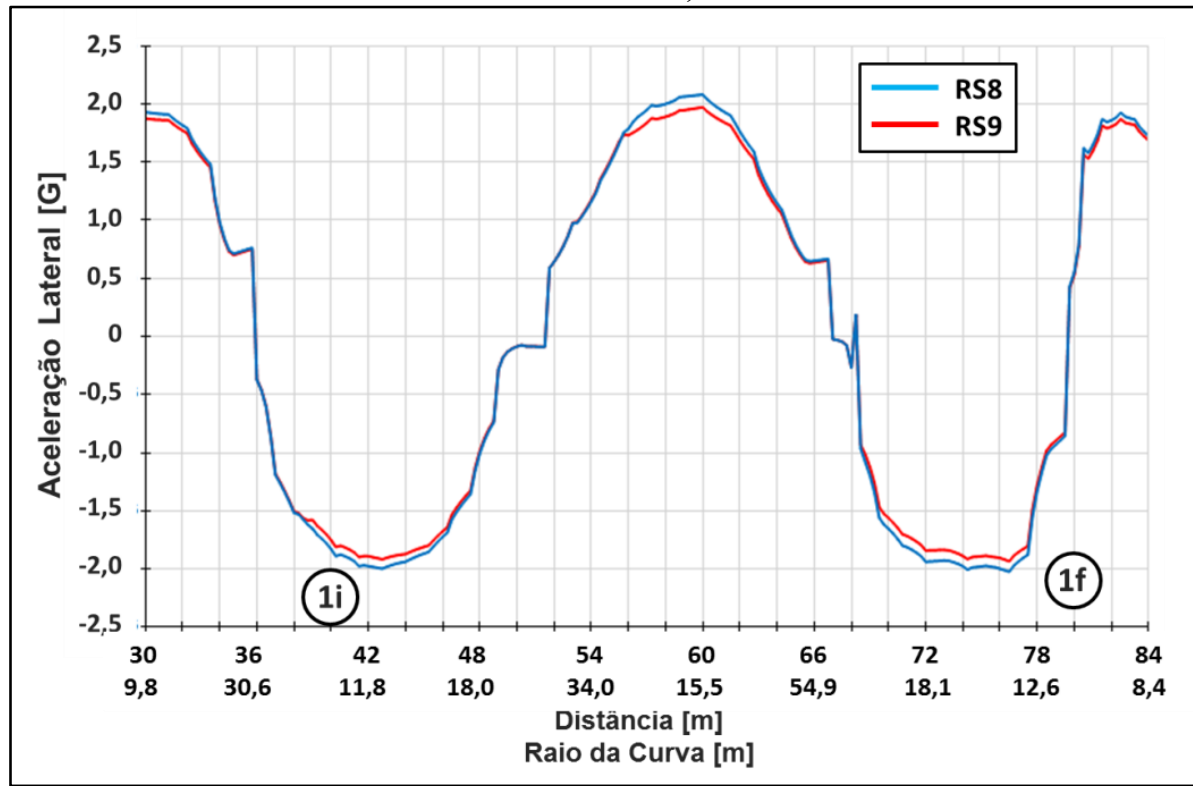

Fonte: autor 
Comparando as acelerações laterais do trecho 1 com as do trecho 7, composto de curvas de baixa velocidade, nota-se que os dois protótipos desenvolvem maiores acelerações laterais no trecho mais veloz. Repetiu-se o comportamento visto no item 5.4.2, onde foram analisadas curvas de baixa e média velocidade (mas não em sequência).

O RS8 levou 2,40 segundos para percorrer todo o trecho 1, enquanto que o RS9 levou 2,44 segundos (tempo 1,7\% maior).

Por fim, foi estudado o trecho 5, contendo três curvas alternadas de alta velocidade, delimitadas pelos pontos $5 \mathrm{i}$ e $5 \mathrm{f}$, como indicado na figura 68. O trecho percorre 95 metros, dos 580 aos 675 metros, iniciando com uma curva à esquerda.

Figura 68 - Comparativo de velocidade do trecho 5

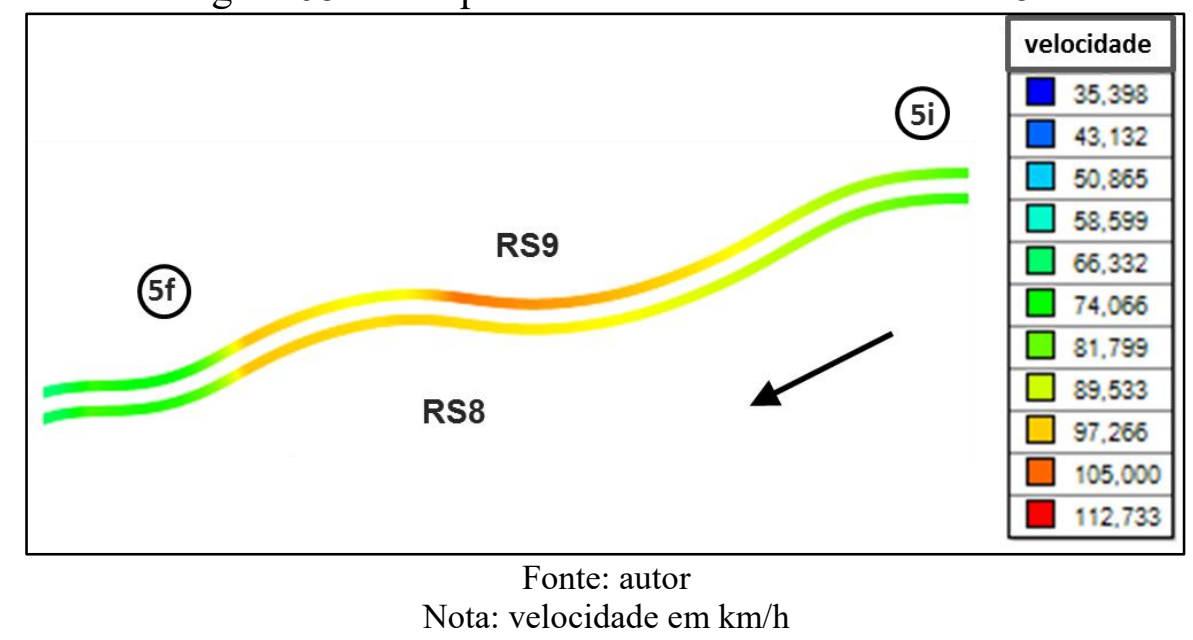

Ao que indica o gráfico da figura 69, os veículos entram na primeira curva do trecho 5 ganhando velocidade, com ligeira vantagem do RS9. Com a redução do raio, o RS9 - mais veloz e com menor capacidade de curva - precisa interromper a aceleração longitudinal dos 593 aos 597 metros, enquanto que o piloto pode manter a aceleração a bordo do RS8. O gráfico de downforce da figura 72 mostra a maior atuação do aerofólio do RS8 em relação ao RS9 nesse trecho. 
Figura 69 - Gráfico de velocidade no trecho 5 (sequência de curvas de alta velocidade)

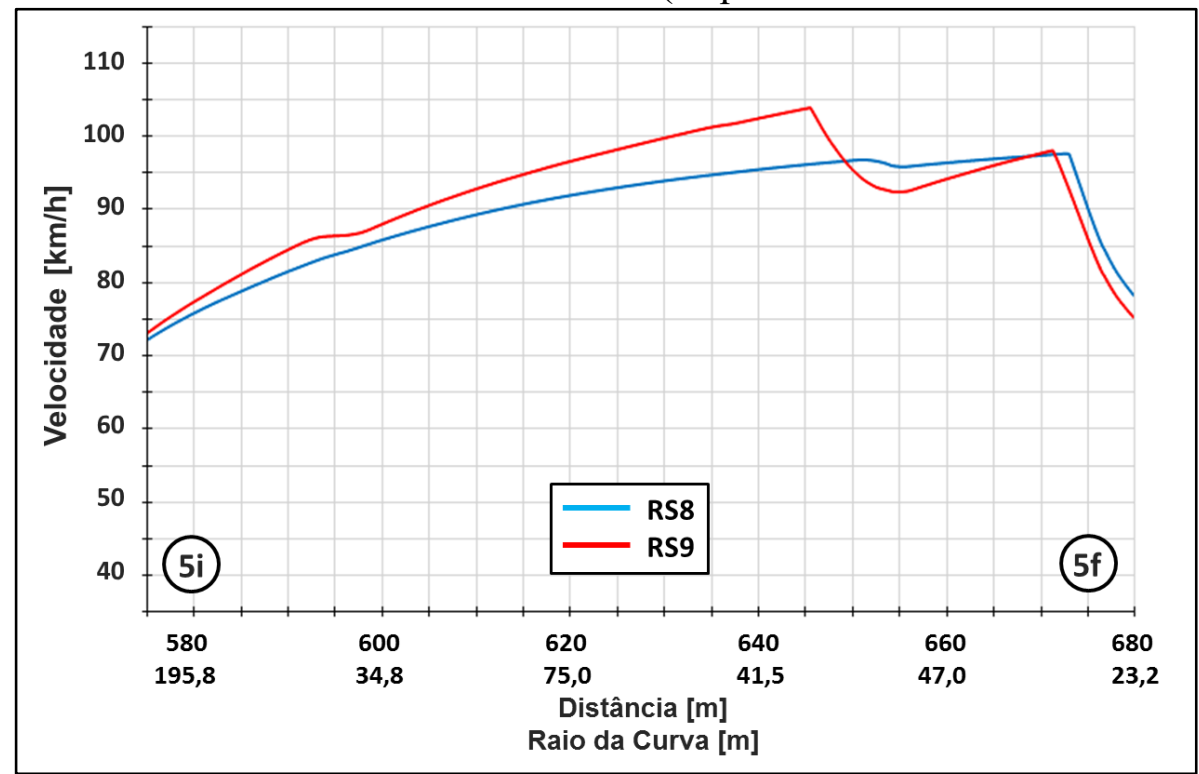

Fonte: autor

A transição da primeira curva para a segunda ocorre aos 608 metros, indicada pela inversão da aceleração lateral no gráfico da figura 70. A aceleração longitudinal não é afetada pela manobra, e a velocidade continua aumentando para os dois veículos.

$\mathrm{Na}$ transição da segunda para a terceira curva, aos 644 metros, o RS8 precisa desenvolver $0,41 \mathrm{G}$ de desaceleração, correspondentes a uma redução de $2 \mathrm{~km} / \mathrm{h}$. Já o RS9 precisa reduzir de $104 \mathrm{~km} / \mathrm{h}$ para $92 \mathrm{~km} / \mathrm{h}$, atingindo uma desaceleração de pico 1,86 G. A maior desaceleração é exigida pela maior velocidade e menor capacidade de curva do RS9 em comparação ao seu antecessor. O piloto deve ficar atento a essa mudança de comportamento do novo veículo, e adequar seu estilo de condução.

A diferença de conduta dos dois protótipos na manobra de transição da segunda para a terceira curva com redução de velocidade fica clara na figura 68. A velocidade máxima do trecho ocorre aos 673 metros para o RS8, na saída da terceira curva, e aos 645 metros para o RS9, na saída da segunda curva.

As acelerações laterais resultantes das manobras atingem seu máximo aos 654 metros para ambos (raio 30,9 m), sendo de 2,36 G para o RS8 e de 2,17 G para o RS9. A sequência de curvas de maior velocidade permitiu desenvolverem as maiores acelerações laterais entre os trechos de curva e sequência de curvas analisados (trechos 1, 2, 4, 5, 7 e 8).

A maior diferença entre as acelerações laterais, todavia, aconteceu no final da tangência da segunda curva, aos 637 metros (raio 40,1 m), com vantagem do mais veloz RS9, atingindo 2,09 $\mathrm{G}$ de aceleração lateral absoluta, contra 1,81 G do RS8. Mais uma vez o RS9 
foi mais rápido em curva de raio maior que 36 metros, confirmando a análise da figura 59, item 5.4.2.

Figura 70 - Gráfico de aceleração lateral no trecho 5 (sequência de curvas de alta velocidade)

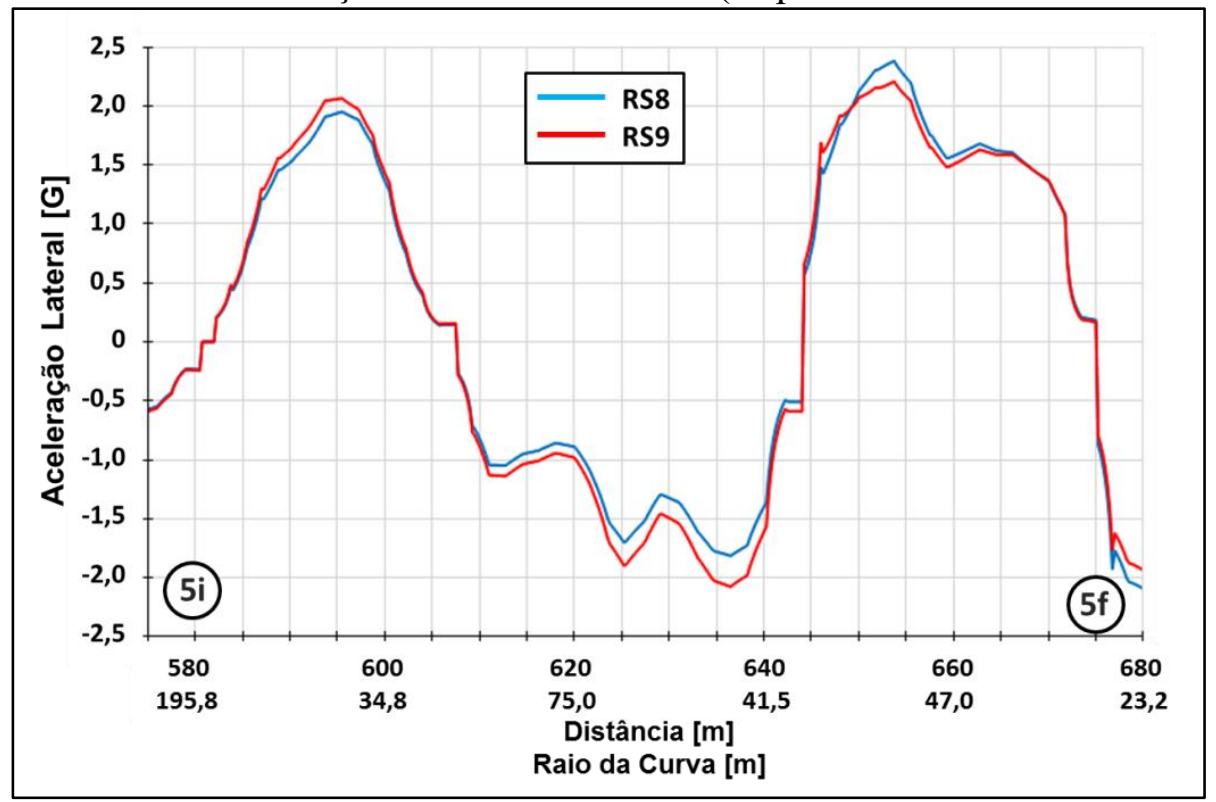

Fonte: autor

Observando a figura 71, nota-se que as maiores desacelerações do trecho 5 ocorrem na saída da curva três, que precede a entrada de uma curva de média velocidade. Aos 671 metros, o piloto precisa acionar $100 \%$ dos freios, atingindo uma desaceleração de pico 2,40 G com o RS9. Com o RS8, a frenagem plena se inicia 1,5 metros adiante, atingindo 2,79 $\mathrm{G}$ em razão do maior arrasto aerodinâmico, que lhe confere maior capacidade de frenagem. Na figura 73, observa-se que o RS8 desenvolve $1028 \mathrm{~N}$ de arrasto no momento da frenagem, contra $610 \mathrm{~N}$ do seu sucessor. 
Figura 71 - Gráfico de aceleração longitudinal no trecho 5 (sequência de curvas de alta velocidade)

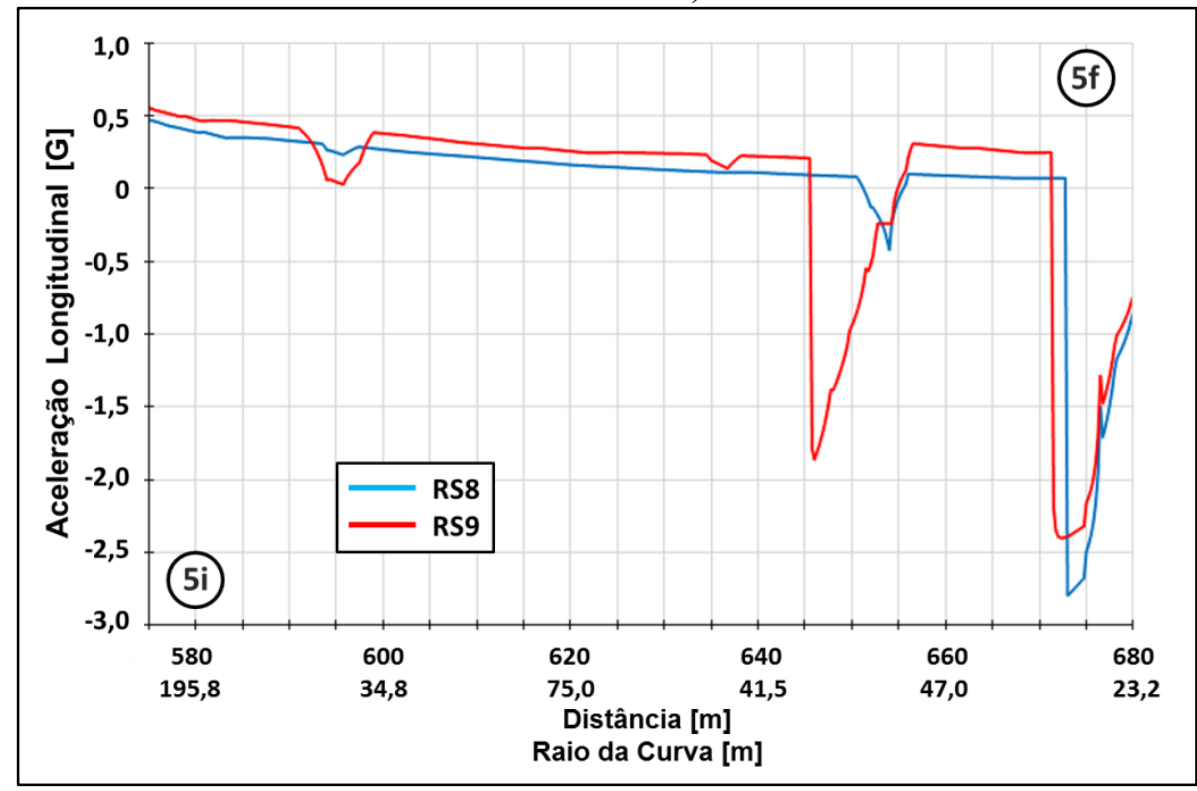

Fonte: autor

O gráfico da figura 72 exibe a diferença substancial entre as forças verticais descendentes originadas pela aerodinâmica dos dois veículos no trecho 5 .

Figura 72 - Gráfico de downforce no trecho 5 (sequência de curvas de alta velocidade)

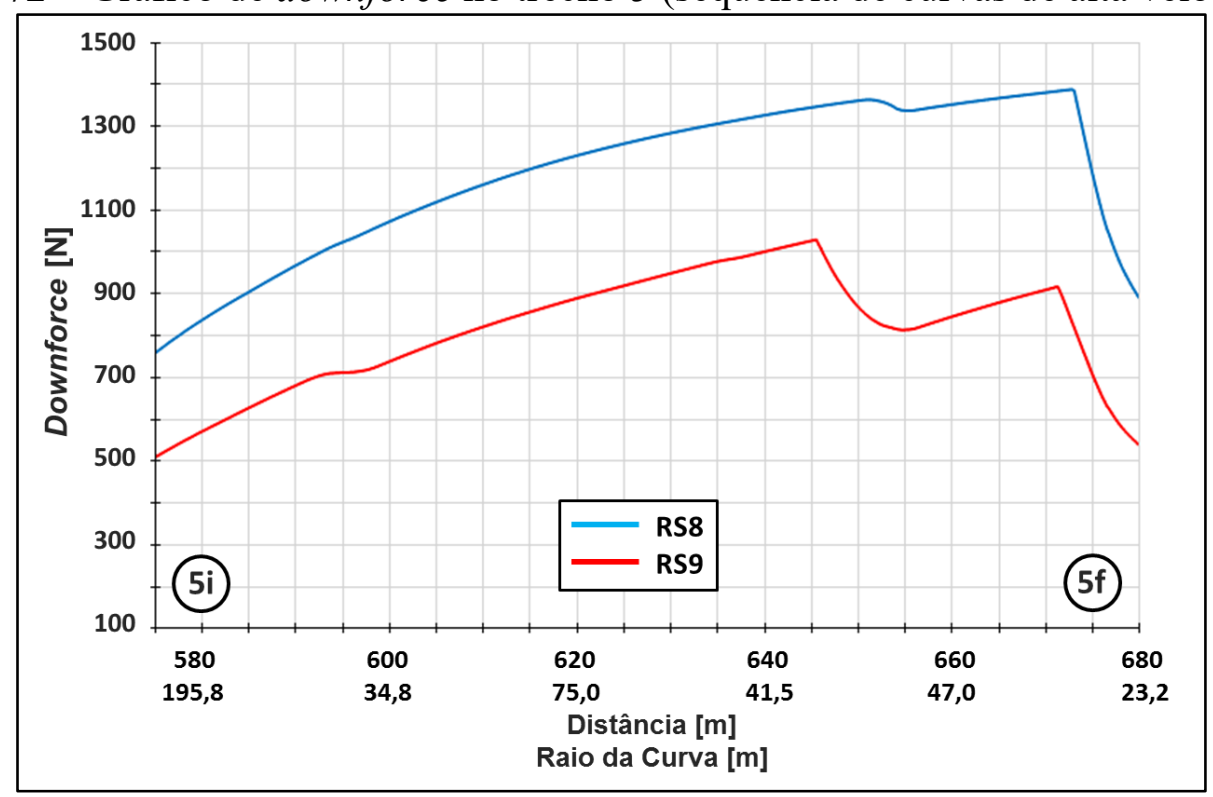

Fonte: autor

Na figura 73, observa-se a força de resistência aerodinâmica. A melhor penetração aerodinâmica do RS9 lhe garante maiores velocidades finais, sob a pena de limitar seu desempenho em frenagem. 
Figura 73 - Gráfico de arrasto aerodinâmico no trecho 5 (sequência de curvas de alta velocidade)

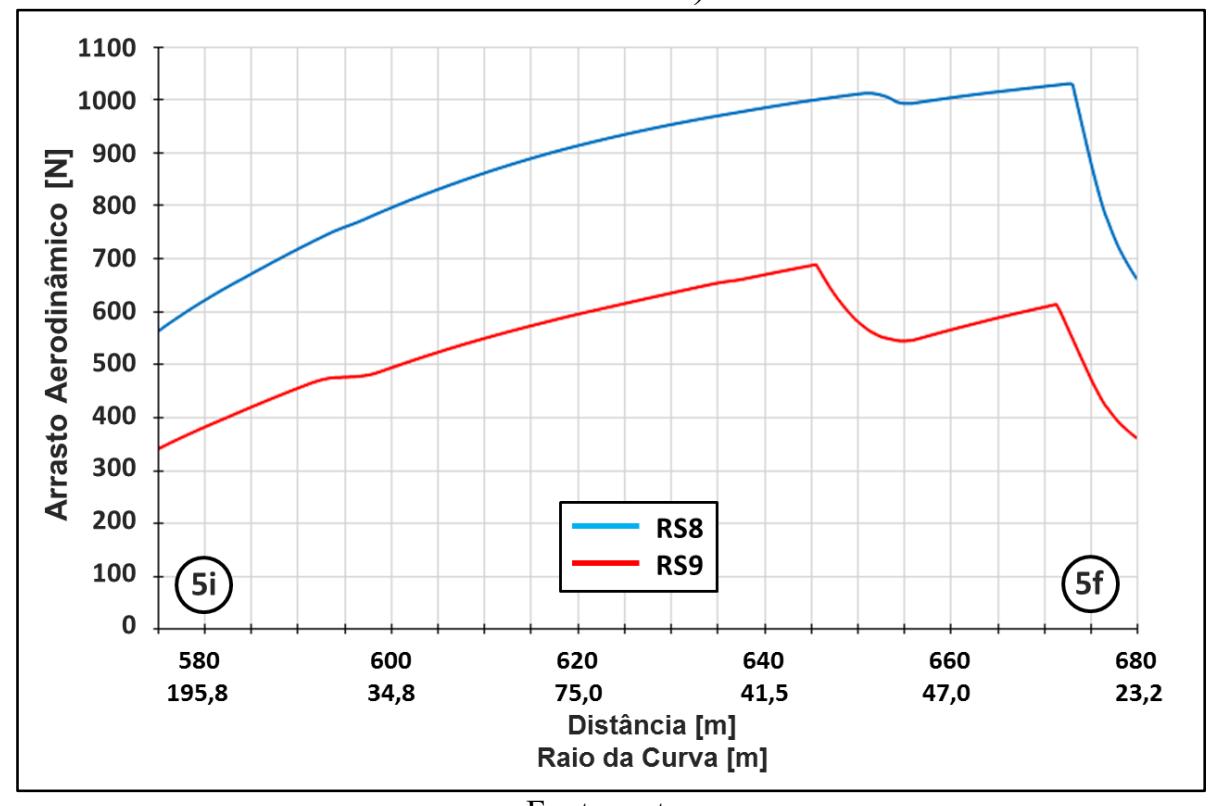

Fonte: autor

O tempo do RS8 no trecho 5 foi de 3,31 segundos, contra 3,23 segundos do RS9 (este $2,4 \%$ menor).

\subsubsection{Resumo}

Os tempos dos oito trechos estudados estão compilados na tabela 18. O tempo do RS8 serve de referência para cálculo da diferença entre os veículos.

Tabela 18 - Compilação dos tempos dos trechos estudados

\begin{tabular}{c|l|c|c|c}
\hline Trecho & Classificação & $\begin{array}{c}\text { Tempo RS8 } \\
{[\mathbf{s}]}\end{array}$ & $\begin{array}{c}\text { Tempo RS9 } \\
{[\mathbf{s}]}\end{array}$ & $\begin{array}{c}\text { Diferença } \\
{[\%]}\end{array}$ \\
\hline 1 & seq. curvas média & 2,40 & 2,44 & 1,7 \\
2 & seq. curvas baixa & 4,12 & 4,16 & 1,0 \\
3 & reta & 2,98 & 2,75 & $-7,7$ \\
4 & curva de baixa & 1,57 & 1,59 & 1,3 \\
5 & seq. curvas alta & 3,31 & 3,23 & $-2,4$ \\
6 & reta & 3,41 & 3,28 & $-3,8$ \\
7 & seq. curvas baixa & 3,16 & 3,21 & 1,6 \\
8 & curva de média & 4,33 & 4,38 & 1,2 \\
\hline \multicolumn{4}{|c}{ Fonte: autor } \\
\hline \multicolumn{3}{|c}{ Nota: RS8 como referência }
\end{tabular}

Nos trechos de alta velocidade, como retas e sequência de curvas de alta velocidade, o RS9 superou seu antecessor, mas nas curvas e sequências de curvas de baixa e média velocidade, o RS8 foi mais rápido. 


\section{CONCLUSÃO}

Apesar das limitações, o modelo quasi-steady state mostrou-se eficiente na representação dos veículos fórmula SAE. Deste modo, com modesto poder de processamento, é possível simular tempo de volta em pista, prevendo o desempenho do protótipo.

O programa adotado (OptimumLap) não simula o acoplamento da embreagem, mas essa limitação pode ser contornada alterando artificialmente a curva do motor. Entretanto, do estudo da força trativa, no item 3.1, concluiu-se que não é necessário modelar o acoplamento da embreagem para o protótipo RS8, pois o torque está acima do limite de tração dos pneus, como no gráfico da figura 28. O mesmo é válido para o RS9. A estratégia de trocas de marcha utilizada foi a de maximizar a força trativa.

Observou-se, no modelo, que o limite de tração dos pneus aumenta em função da velocidade, consequência da sustentação negativa, aumentando a força normal nos pneus. Em contrapartida, tem-se um ligeiro aumento da resistência ao rolamento.

Dos gráficos gerados na modelagem do veículo RS8, concluiu-se que a velocidade máxima está limitada pelas forças resistivas, e não pela relação de transmissão. Uma quinta marcha mais longa não elevaria a velocidade final.

Da comparação entre os resultados do OptimumLap e do programa desenvolvido em MATLAB, detalhada no item 4.1.3, concluiu-se que o programa OptimumLap utiliza as equações de steady state, ou regime permanente, de Gillespie (1992), exceto a resistência ao rolamento, que sofre influência da sustentação.

Ao comparar os tempos de volta simulados com as três provas de Michigan 2014 no item 4.2, foram validadas as simulações das provas de aceleração e autocross, com respectivos erros de $1,6 \%$ e $0,4 \%$ nos tempos de volta, dentro dos $5 \%$ almejados. Todavia, o fato do modelo desprezar o momento de inércia de guinada e tratar a prova de skid-pad como manobra de regime permanente (ou estado estacionário) resultou num erro de 12,7\%, quase $3 \%$ acima dos $10 \%$ aceitáveis. Sabe-se que, na prática, o piloto precisa corrigir o esterçamento para compensar ondulações na pista e desequilíbrios do veículo, condição não simulada.

Na comparação do antigo RS8 com o novo RS9, da prova de aceleração (item 5.2) concluiu-se que a ligeira redução da aderência longitudinal deste foi desprezível no tempo da prova, sendo a menor resistência aerodinâmica decisiva para o melhor resultado do RS9 sobre seu antecessor. O protótipo RS9 desenvolveu maior velocidade e maior aceleração durante todo o percurso, e exigiu uma troca de marchas a mais. Houve um ganho de 0,11 segundos no 
tempo total da prova, que baixou de 4,52 s para 4,41 s. Portanto, as alterações no projeto favoreceram a prova de aceleração.

Conforme simulação da prova de skid-pad (item 5.3), o veículo RS9 não superou seu antecessor. O RS8 foi cinco centésimos de segundo mais rápido por volta, desenvolvendo maiores velocidade e aceleração lateral como consequência do maior downforce desenvolvido, que lhe conferiu maior capacidade de curva. Essa conclusão ainda viria a ser confirmada na análise detalhada da prova de autocross.

Em volta simulada na pista de autocross (item 5.4), a velocidade máxima do RS9 superou em mais de $12 \mathrm{~km} / \mathrm{h}$ a do RS8, enquanto que este obteve maior aceleração lateral: 2,38 G, contra 2,27 G do RS9. O RS9 exigiu maior número de mudanças de marcha: 60 por volta, contra 54 do RS8. O consumo de combustível foi menor com o RS9, de 0,15 kg contra $0,17 \mathrm{~kg}$, em parte graças à sua massa ligeiramente menor, mas principalmente ao menor arrasto aerodinâmico.

Nas duas retas de 80 metros da pista de autocross, abordadas no item 5.4.1, o protótipo RS9 atingiu maiores velocidades, tanto no trecho 6, entrando na reta com velocidade intermediária $(65 \mathrm{~km} / \mathrm{h})$, quanto no trecho 3, onde os veículos já entram na reta acima dos 90 $\mathrm{km} / \mathrm{h}$.

Como consequência da maior velocidade e menor resistência aerodinâmica, o RS9 precisou frear 5 metros antes do RS8 em ambas retas analisadas, indicando uma tendência de necessidade de antecipação de frenagem em fim de reta. O piloto deve prestar especial atenção a essa mudança de comportamento exigida pelo novo veículo, e o desgaste dos freios deve ser observado.

$\mathrm{Na}$ curva de baixa velocidade da figura 51 estudada no item 5.4.2, as acelerações laterais desenvolvidas e, consequentemente, as velocidades foram muito próximas entre os veículos, pois a vantagem aerodinâmica do RS8 foi suprimida pelas baixas velocidades. Houve uma pequena vantagem deste veículo na entrada da curva, dada maior capacidade de desaceleração. Na saída da curva, dentro do limite de tração, o desempenho dos dois carros praticamente se igualou.

Ainda no comparativo de curvas, verificou-se que o RS8 foi mais veloz na entrada e tangência de curvas de média velocidade (algo entre $55 \mathrm{~km} / \mathrm{h}$ e $75 \mathrm{~km} / \mathrm{h}$ ). O RS9, com menores downforce e arrasto aerodinâmico, apenas levou vantagem em curvas de raio maior que 36 metros, onde maiores velocidades foram desenvolvidas.

Nas sequências de curvas de baixa velocidade (item 5.4.3), o RS8 mostrou-se mais rápido, desenvolvendo maiores acelerações laterais e, consequentemente, maiores 
velocidades. O desempenho do RS9 se aproximou do desempenho do RS8 nos trechos de inversão de lado da curva, mas só atingiu velocidade equiparável na saída da última curva, mostrando sua superioridade em retomadas.

A sequência de curvas de média velocidade, também abordada no item 5.4.3, produziu resultados similares às sequências de baixa, exceto pelas maiores acelerações laterais, proporcionadas pelo maior downforce, por sua vez consequência das maiores velocidades.

O RS8 venceu a sequência de curvas de alta velocidade (item 5.4.3) com pequenas frenagens, enquanto que o RS9, mais veloz e com menor capacidade de curva, precisou de desacelerações maiores. Mesmo assim, este foi 2,4\% mais rápido no trecho.

Comparando o desempenho dos dois veículos em todos os trechos (tabela 18) da pista de autocross, percebe-se uma tendência do RS8 ser mais rápido em curvas de baixa e média velocidade, sejam isoladas ou em sequência, enquanto que o RS9 o supera em trechos de alta velocidade, sejam curvas ou retas. Essa diferença é consequência da redução do aerofólio traseiro, conferindo menores downforce e arrasto aerodinâmico ao RS9.

Como resultado da alteração do aerofólio traseiro, no cenário de Michigan 2014, obteve-se a melhora dos tempos nas provas de aceleração, autocross e enduro, com prejuízo na prova de skid-pad, como indicado na tabela 19. Os resultados de skid-pad, porém, devem ser tratados com cautela, dada a imprecisão da simulação dessa prova.

Tabela 19 - Comparação dos tempos de volta simulados para as provas de Michigan 2014

\begin{tabular}{l|c|c|c}
\hline Prova & $\begin{array}{c}\text { Tempo RS8 } \\
\text { [s] }\end{array}$ & $\begin{array}{c}\text { Tempo RS9 } \\
{[\mathbf{s}]}\end{array}$ & $\begin{array}{c}\text { Diferença } \\
{[\%]}\end{array}$ \\
\hline Aceleração $75 \mathrm{~m}$ & 4,520 & 4,410 & $-2,4$ \\
Skid-pad & 4,390 & 4,440 & 1,1 \\
Autocross / Enduro & 57,010 & 56,740 & $-0,5$ \\
\hline \multicolumn{3}{|c}{ Fonte: autor } \\
Nota: RS8 como referência
\end{tabular}




\section{REFERÊNCIAS}

BARRETO, Marco A. Zanussi. Sistemas de embreagem. [mensagem pessoal]. Mensagem recebida por $<$ rodrigopcosta@hotmail.com>em 2011.

BECKMAN, Brian. The physics of racing series. Burbank: [s.n.] [2002?].

BINO. Bino Garagem. [2015?]. Disponível em: <http://www.binogaragem.com.br/>. Acesso em 24 abr. 2015.

CAMBIAGHI, Danilo et al. A tool for lap time simulation. 1996. Disponível em: $<\mathrm{http}$ :/www.researchgate.net/publication/245118899_A_tool_for_lap_time_simulation>. Acesso em 03 mar. 2015.

CASANOVA, D.; SHARP, R. S.; SYMONDS, P. Minimum time manoeuvring: the significance of yaw inertia. Vehicle System Dynamics: International Journal of Vehicle Mechanics and Mobility, v.34, n. 2, p. 77-115, 2000. Disponível em:

$<$ http://dx.doi.org/10.1076/0042-3114(200008)34:2;1-G;FT077>. Acesso em 12 mar. 2015.

CORVAIR center forum. 2014. Disponível em:

$<$ http://corvaircenter.com/phorum/read.php?1,706970,717546>. Acesso em 03 mar 2015.

COSTIN, Michael; PHIPPS, David. Racing and sports car chassis design. Londres: B. T. Batsford, 1965.

FEI. Fórmula FEI. [2015?]. Disponível em: <http://portal.fei.edu.br/pt$\mathrm{BR} /$ pesquisas_projetos/projetos_institucionais/formula_FEI/Paginas/formula_FEI.aspx $>$. Acesso em 29 jun. 2015.

FENTON, John. Advances in vehicle design. Suffolk: Professional Engineering, 1999.

GILLESPIE, Thomas D. Fundamental of vehicle dynamics. Warrendale: Society of Automotive Engineers, 1992.

HAPPIAN-SMITH, Julian. An introduction to modern vehicle design. Oxford: Butterworth-Heinemann, 2002.

LOTTO, Renato Storti. Dinâmica lateral: construção e validação de um modelo de simulação multicorpos de um veículo FSAE usando modelo semi-empírico de pneu. 2014. Dissertação (Mestrado em Engenharia Mecânica) - Centro Universitário da FEI, São Bernardo do Campo, 2014.

MATLAB \& Simulink. [S.1.: s.n.] 1994. Apostila.

MILLIKEN, W. F. Maurice Olley. 2000. Disponível em:

$<$ http://www.millikenresearch.com/MauriceOlleybyWFMilliken.pdf $>$. Acesso em: 28 fev. 2015.

MILLIKEN, W. F.; MILLIKEN, D.L. Race car vehicle dynamics. Warrendale: Society of Automotive Engineers, 1995. 
OPTIMUMG. Clients. [2015?a]. Disponível em:

$<$ http://www.optimumg.com/company/clients/>, acesso em 8 mar 2015.

OPTIMUMG. OptimumLap: design, simulate, analyze, understand. [2015?b]. Disponível em: <http://www.optimumg.com/software/optimumlap/>. Acesso em 02 ago. 2015.

OPTIMUMG. OptimumLap: track database. [2015?c]. Disponível em:

$<$ http://share.optimumg.com/tracks/?page=5>. Acesso em 09 jun. 2015.

OPTIMUMG. OptimumLap v1.4: vehicle dynamics simulation. [S.1.: s.n.] [2015?d].

PUHN, Fred. How to make your car handle. Tucson: H. P. Books, 1976.

REIMPEL, Jörnsen; STOLL, Helmut; BETZLER, Jürgen W. The automotive chassis: engineering principles. Oxford: Butterworth-Heinemann, 2001.

RILL, Georg. Vehicle dynamics: lecture notes. Regensburg: Hochschule, 2009.

SAE INTERNATIONAL. 2015 Formula SAE® rules. 2015a. Disponível em:

$<$ http://www.fsaeonline.com/content/2015-

16\%20FSAE\%20Rules\%20revision\%2091714\%20kz.pdf>. Acesso em 18 abr. 2015.

SAE INTERNATIONAL. Results and awards. 2015b. Disponível em:

$<$ http://students.sae.org/cds/formulaseries/results/>. Acesso em 09 jun. 2015.

SAGAN, Carl. Opinião central: frases de Carl Sagan. [2015?]. Disponível em:

$<$ https://opiniaocentral.wordpress.com/2013/07/14/frases-de-carl-sagan/>. Acesso em: 26 fev. 2015.

SANDLER, Paulo Cesar. Porsche: O homem, o mito, o carro. São Paulo: Alaúde, 2011.

SIEGLER, Blake. Lap time simulation for racing car design. 2002. Tese ( $\mathrm{PhD} \mathrm{em}$ Engenharia Mecânica) - The University of Leeds, Leeds, 2002.

SILVA, Daniel L. Ferreira da. Controle de impedância aplicado a uma suspensão ativa. 2014. Dissertação (Mestrado em Engenharia Mecânica) - Centro Universitário da FEI, São Bernardo do Campo, 2014.

SMITH, Carroll. Tune to win. Fallbrook: Aero Publishers, 1978. 
APÊNDICE A - BIBLIOGRAFIA CONSULTADA 
ACKERMANN, Marko. Dinâmica de Sistemas Veiculares. 22 set. 2014, 8 dez. 2014. 45 p. Notas de Aula.

BARRETO, Marco A. Zanussi. Dinâmica longitudinal: efeitos da geometria de suspensão nas mudanças de atitude da massa suspensa e os esforços nos elementos da suspensão. 2005. Dissertação (Mestrado em Engenharia Mecânica) - Universidade de São Paulo, São Carlos, 2005. Disponível em:

$<$ http://www.teses.usp.br/index.php?option=com_jumi\&fileid=20\&Itemid=96\&lang=ptbr\&cx $=011662445380875560067 \% 3$ Acack5lsxley\&cof=FORID $\% 3 \mathrm{~A} 11 \& \mathrm{hl}=\mathrm{pt}-\mathrm{br} \& \mathrm{q}=$ marco+barreto\&siteurl=www.teses.usp.br\%2Findex.php\%3Foption\%3Dcom_jumi\%26fileid $\% 3 \mathrm{D} 20 \% 26$ Itemid $\% 3 \mathrm{D} 96 \% 26$ lang\%3Dpt-br\&ref $=$ www.teses.usp.br\%2Fteses\&ss $=4098 \mathrm{j} 175$ 3890j16>. Acesso em 26 fev. 2015.

DANIELSSON, Oskar et al. Design of electrical powertrain for Chalmers Formula Student with focus on 4WD versus RWD and regenerative braking. 2013. (Bacharelado em Engenharia Mecânica Aplicada) - Chalmers University of Technology, Göteborg. Disponível em: < http://publications.lib.chalmers.se/records/fulltext/191837/191837.pdf>. Acesso em 09 abr. 2015.

ERICSSON, Luis G. Sigward. Estudo da influência da rigidez do quadro na dirigibilidade de um veículo de competição formula SAE em ambiente multicorpo. 2008. Dissertação (Mestrado em Engenharia Mecânica) - Universidade de São Paulo, São Carlos, 2008. Disponível em: <http://www.teses.usp.br/teses/disponiveis/18/18149/tde-21082009105817/pt-br.php>. Acesso em 26 fev. 2015.

FOURNIER, Ron. Race \& custom car metal fabricator's handbook. Tucson: HPBooks, 1982.

GAROFALO, Franco et al. Optimal tracking for automotive dry clutch engagement. $15^{\text {th }}$ Triennial World Congress. Barcelona: IFAC, 2002. Disponível em:

$<$ http://control.disp.uniroma2.it/ zack/Seminari/0310Vasca/final_584.pdf $>$. Acesso em 10 abr. 2015.

GIRAFFA, Matt. Tech tips: springs \& dampers. [2015?]. Disponível em:

$<$ http://www.optimumg.com/technical/technical-papers/>. Acesso em 9 abr. 2015.

KASPRZAK, Edward M.; GENTZ, David. The formula SAE tire test consortium: tire testing and data handling. Society of Automotive Engineers, 2006. Disponível em: $<$ http://www.millikenresearch.com/TTC_SAE_paper.pdf>. Acesso em: 26 mar. 2015.

KATZ, Joseph. Aerodynamics of Race Cars. The Annual Review of Fluid Mechanics. 2006. p. 27-63. San Diego State University.

OLSSON, Henning. It is all about horsepower... or is it? 2012. Disponível em $<$ http://www.optimumg.com/technical/it-is-all-about-horsepower-or-is-it/>. Acesso em 08 abr. 2015.

PACEJKA, H. B. Tyre and vehicle dynamics. [S.1.: s.n.]. [200?].

PEREIRA, Daniel Ribeiro. Avaliação da dinâmica lateral de veículos comerciais equipados com multieixos esterçantes. 2010. Dissertação (Mestrado em Engenharia Mecânica) - Centro Universitário da FEI, São Bernardo do Campo, 2010. 
RAILTON, Art. Where should a small car's engine be? Popular Mechanics, Hearst Magazines. Set. 1959. 274 p. Disponível em:

$<$ https://books.google.com.br/books?id=jt8DAAAAMBAJ\&pg=PA82\&lpg=PA82\&dq=Wher $\mathrm{e}+$ should $+\mathrm{a}+$ small + car $\%$ E2\%80\%99s + engine + be ++ olley\&source $=$ bl\&ots $=Z 7 d C$ mpT_o\&sig $=$ AjxioESuNzMrzFniIVYadbJ6v7I\&hl=pt-

PT\&sa $=$ X\&ei $=$ hosUVc84qd2wBOfegugB\&ved $=0$ CB0Q6AEwAA\#v $=$ onepage\&q $=$ Where $\% 2$ 0should $\% 20 \mathrm{a} \% 20$ small $\% 20$ car $\%$ E2\%80\%99s\%20engine $\% 20$ be $\% 3 \mathrm{~F} \% 20$ olley $\& \mathrm{f}=$ false $>$. Acesso em 24 mar. 2015.

TREMAYNE, David. The science of formula 1 design: expert analysis of the anatomy of the modern Grand Prix car. 2. ed. Sparkford: Haynes \& Co, 2006.

UHLMANN, Carlos Eduardo. Análise da influência da barra estabilizadora no ângulo de rolagem da suspensão dianteira de ônibus. 2009. Dissertação (Mestrado em Engenharia Mecânica) - Universidade Federal do Rio Grande do Sul, Porto Alegre, 2009.

WHITON, Frank A. Data acquisition. General Motors Proving Ground. 2011. Disponível em: $<$ http://www.sae.org/students/presentations/data_acquisition_by_frank_a_whiton.pdf $>$. Acesso em 10 abr. 2015. 
APÊNDICE B - CÓDIGO DA ACELERAÇÃO NO MATLAB 


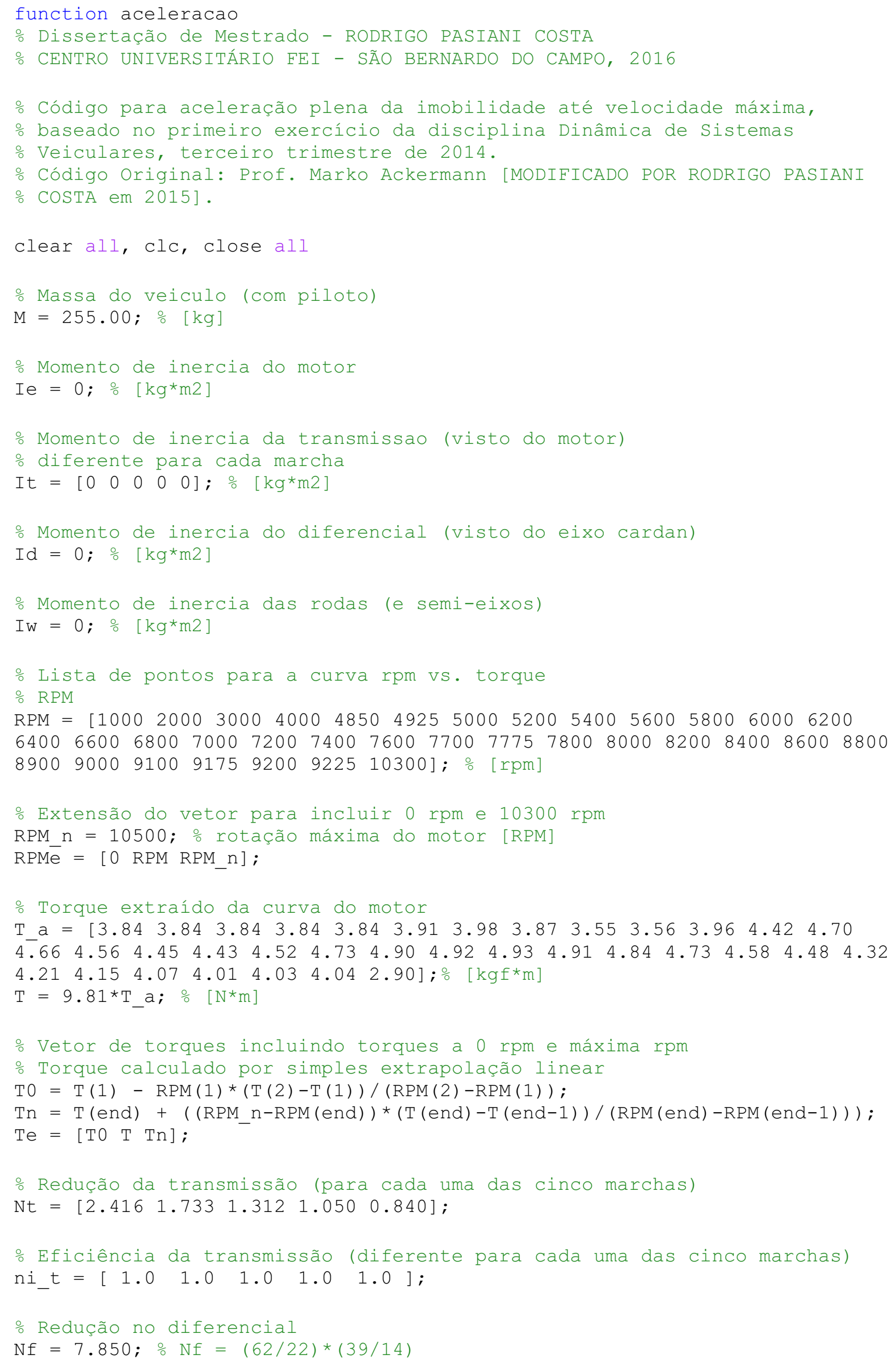




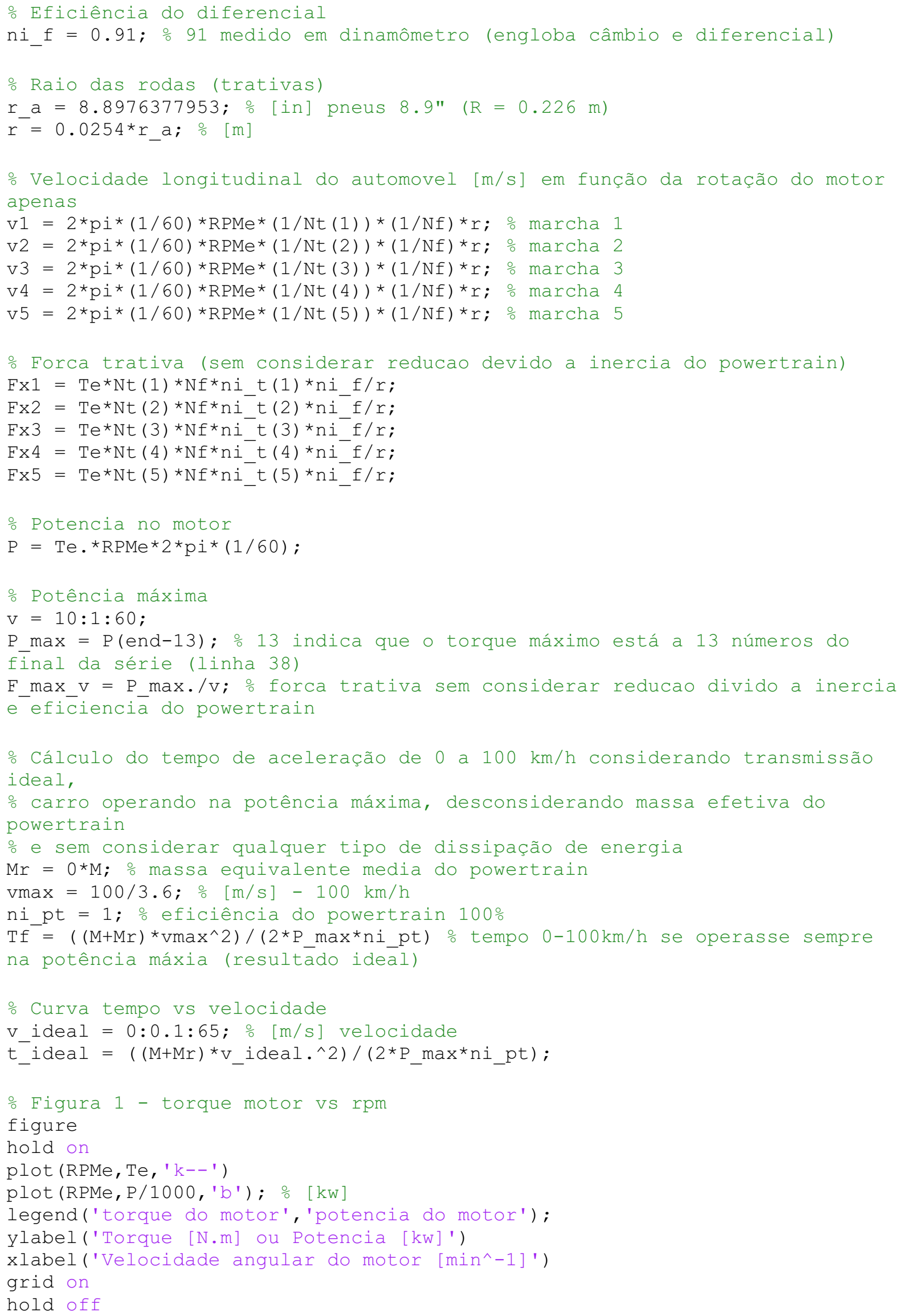




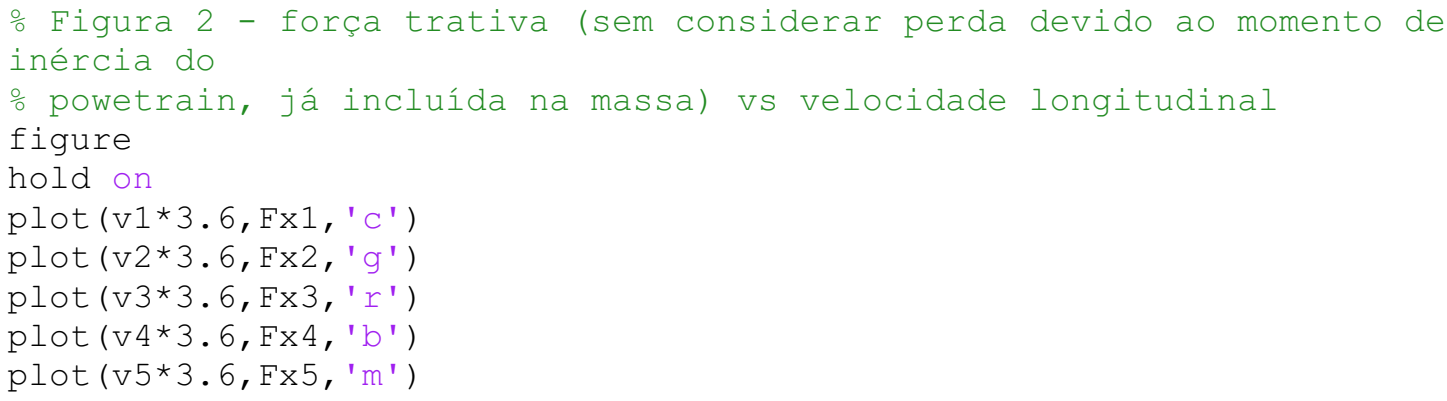




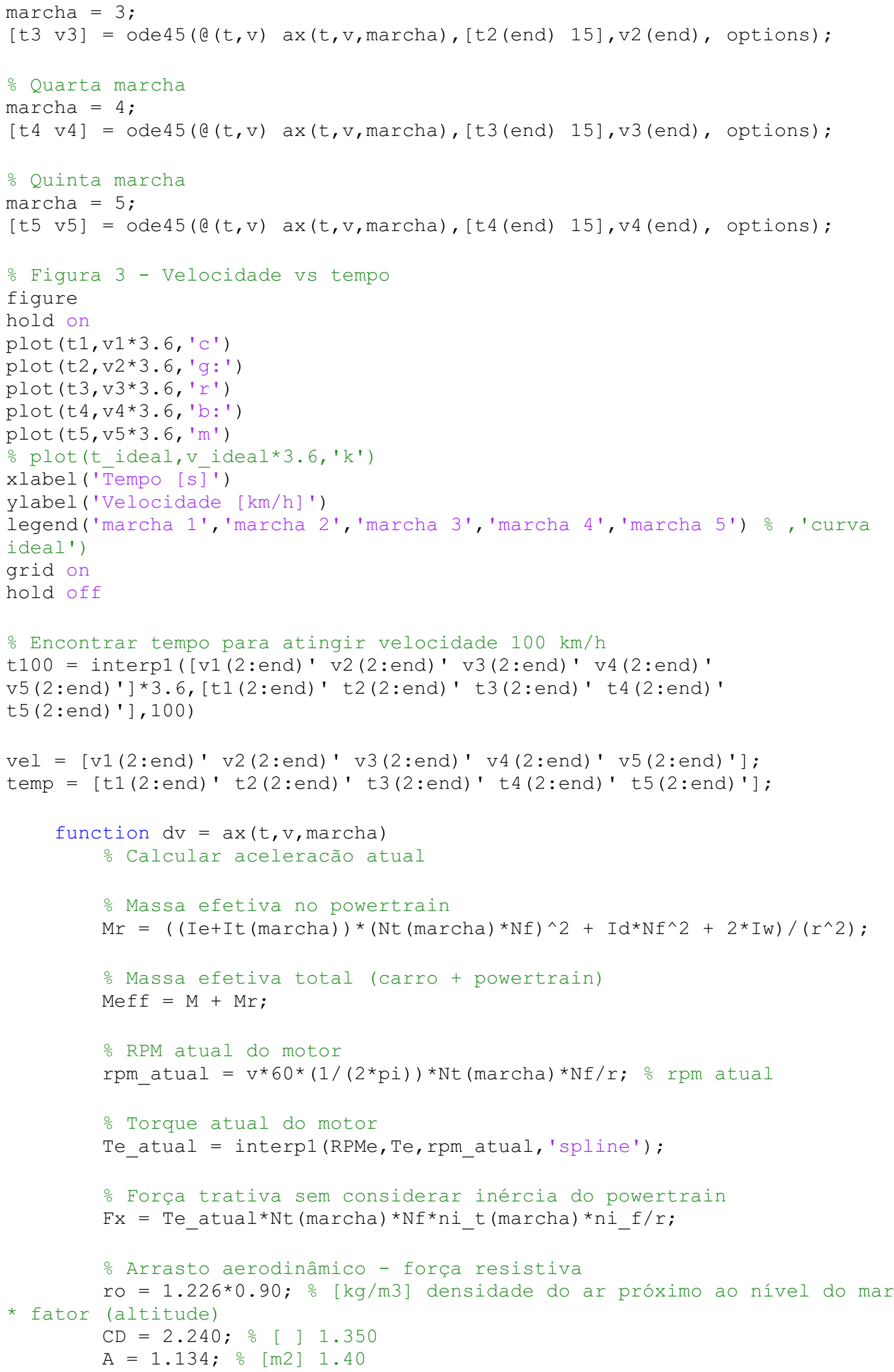


isterminal $=1 ;$ o terminar integracao quando value $(1)=0$ direction $=0$;

end end 
APÊNDICE C - DADOS PARA MODELAGEM DO MOTOR 
Tabela C1 - Rotação e torque do motor em dinamômetro

\section{Engine Speed Engine Torque}

(rpm)

(kgf.m)

\begin{tabular}{c|c}
\hline 802 & 3,84 \\
1000 & 3,84 \\
2000 & 3,84 \\
3000 & 3,84 \\
4000 & 3,84 \\
4850 & 3,84 \\
4925 & 3,91 \\
5000 & 3,98 \\
5200 & 3,87 \\
5400 & 3,55 \\
5600 & 3,56 \\
5800 & 3,96 \\
6000 & 4,42 \\
6200 & 4,70 \\
6400 & 4,66 \\
6600 & 4,56 \\
6800 & 4,45 \\
7000 & 4,43 \\
7200 & 4,52 \\
7400 & 4,73 \\
7600 & 4,90 \\
7700 & 4,92 \\
7775 & 4,93 \\
7800 & 4,91 \\
8000 & 4,84 \\
8200 & 4,73 \\
8400 & 4,58 \\
8600 & 4,48 \\
8800 & 4,32 \\
8900 & 4,21 \\
9000 & 4,15 \\
9100 & 4,07 \\
9175 & 4,01 \\
9200 & 4,03 \\
9225 & 4,04 \\
10300 & $2,90 *$ \\
\hline Fonte: Cortesia Equipe Fórmula FEI, 2015 \\
Nota estimativa \\
\hline
\end{tabular}


APÊNDICE D - TABELA DE RESULTADOS DAS SIMULAÇÕES DO OPTIMUMLAP 
Tabela D1 - Resultados das simulações do OptimumLap para comparação entre veículos RS8 e RS9. (Continua)

\begin{tabular}{|c|c|c|c|c|c|c|}
\hline \multirow{2}{*}{$\begin{array}{l}\text { Track } \\
\text { Vehicle } \\
\end{array}$} & \multicolumn{2}{|c|}{ Reta $75 \mathrm{~m}$} & \multicolumn{2}{|c|}{ Skid-pad (D18,25m) } & \multicolumn{2}{|c|}{ Enduro (Autocross) } \\
\hline & RS8 & RS9 & RS8 & RS9 & RS8 & RS9 \\
\hline Lap time $[\mathrm{s}]$ & 4,52 & 4,41 & 4,39 & 4,44 & 57,01 & 56,74 \\
\hline Percent in Corners $[\%]$ & 0,00 & 0,00 & 100,00 & 100,00 & 98,65 & 98,69 \\
\hline $\begin{array}{l}\text { Percent Accelerating } \\
{[\%]}\end{array}$ & 100,00 & 100,00 & 0,00 & 0,00 & 72,21 & 69,12 \\
\hline Percent Braking [\%] & 0,00 & 0,00 & 100,00 & 100,00 & 27,37 & 30,23 \\
\hline Percent Coasting [\%] & 0,00 & 0,00 & 0,00 & 0,00 & 4,36 & 3,94 \\
\hline $\begin{array}{l}\text { Percent } 100 \% \text { Throttle } \\
{[\%]}\end{array}$ & 100,00 & 100,00 & 0,00 & 0,00 & 1,26 & 1,19 \\
\hline $\begin{array}{l}\text { Percent TCS Enabled } \\
{[\%]}\end{array}$ & 36,12 & 38,01 & 99,83 & 99,83 & 38,20 & 41,81 \\
\hline Lowest Speed $[\mathrm{km} / \mathrm{h}]$ & 3,60 & 3,60 & 47,03 & 46,46 & 35,71 & 35,40 \\
\hline Highest Speed $[\mathrm{km} / \mathrm{h}]$ & 92,34 & 98,70 & 47,03 & 46,46 & 100,50 & 112,73 \\
\hline Average Speed $[\mathrm{km} / \mathrm{h}]$ & 71,75 & 74,69 & 47,03 & 46,46 & 72,29 & 73,63 \\
\hline Energy Spent $[\mathrm{kJ}]$ & 141,29 & 135,65 & 0,00 & 0,00 & 1316,65 & 1192,37 \\
\hline Fuel Consumption [kg] & 0,02 & 0,02 & 0,00 & 0,00 & 0,17 & 0,15 \\
\hline Gear Shifts [-] & 3,00 & 4,00 & 0,00 & 0,00 & 54,00 & 60,00 \\
\hline $\begin{array}{l}\text { Maximum Lateral } \\
\text { Acceleration [G] }\end{array}$ & 0,00 & 0,00 & 1,91 & 1,86 & 2,38 & $-2,27$ \\
\hline $\begin{array}{l}\text { Maximum Longitudinal } \\
\text { Acceleration }[\mathrm{G}]\end{array}$ & 1,15 & 1,16 & 0,00 & 0,00 & 0,85 & 0,86 \\
\hline $\begin{array}{l}\text { Maximum Longitudinal } \\
\text { Deceleration }[\mathrm{G}]\end{array}$ & 0,15 & 0,24 & 0,00 & 0,00 & $-2,79$ & $-2,53$ \\
\hline Time in Sector $1[\mathrm{~s}]$ & 4,52 & 4,41 & 4,39 & 4,44 & 57,01 & 56,74 \\
\hline $\begin{array}{l}\text { Maximum Speed in } \\
\text { Sector } 1[\mathrm{~km} / \mathrm{h}]\end{array}$ & 92,34 & 98,70 & 47,03 & 46,46 & 100,50 & 112,73 \\
\hline $\begin{array}{l}\text { Minimum Speed in } \\
\text { Sector } 1[\mathrm{~km} / \mathrm{h}]\end{array}$ & 3,60 & 3,60 & 47,03 & 46,46 & 35,71 & 35,40 \\
\hline Percent in Gear $1[\%]$ & 12,13 & 12,00 & - & - & 3,71 & 4,04 \\
\hline Percent in Gear $2[\%]$ & 11,47 & 10,80 & 100,00 & 100,00 & 28,55 & 29,11 \\
\hline Percent in Gear $3[\%]$ & 25,07 & 20,93 & 0,00 & 0,00 & 26,45 & 24,95 \\
\hline Percent in Gear $4[\%]$ & 51,33 & 49,60 & 0,00 & 0,00 & 36,36 & 25,98 \\
\hline Percent in Gear $5[\%]$ & 0,00 & 6,67 & 0,00 & 0,00 & 4,93 & 15,91 \\
\hline
\end{tabular}


Tabela D1 - Resultados das simulações do OptimumLap para comparação entre veículos RS8 e RS9. (Continuação)

\begin{tabular}{|c|c|c|c|c|c|c|}
\hline Track & Reta & $75 \mathrm{~m}$ & Skid-pad & $\mathrm{D} 18,25 \mathrm{~m})$ & Enduro $(A$ & utocross) \\
\hline Vehicle & RS8 & RS9 & RS8 & RS9 & RS8 & RS9 \\
\hline Vehicle Mass [kg] & 255,00 & 252,00 & 255,00 & 252,00 & 255,00 & 252,00 \\
\hline Drag Coefficient [-] & 2,24 & 1,50 & 2,24 & 1,50 & 2,24 & 1,50 \\
\hline $\begin{array}{l}\text { Downforce Coefficient } \\
{[-]}\end{array}$ & 3,02 & 2,24 & 3,02 & 2,24 & 3,02 & 2,24 \\
\hline Frontal Area [m^2] & 1,13 & 1,00 & 1,13 & 1,00 & 1,13 & 1,00 \\
\hline $\begin{array}{l}\text { Drivetrain Efficiency } \\
{[\%]}\end{array}$ & 91,00 & 91,00 & 91,00 & 91,00 & 91,00 & 91,00 \\
\hline Tire Rolling Radius [m] & 0,23 & 0,23 & 0,23 & 0,23 & 0,23 & 0,23 \\
\hline Air Density $\left[\mathrm{kg} / \mathrm{m}^{\wedge} 3\right]$ & 1,23 & 1,23 & 1,23 & 1,23 & 1,23 & 1,23 \\
\hline Final Drive Ratio [-] & 7,85 & 7,85 & 7,85 & 7,85 & 7,85 & 7,85 \\
\hline Longitudinal Friction [-] & 1,75 & 1,75 & 1,75 & 1,75 & 1,75 & 1,75 \\
\hline Lateral Friction [-] & 1,75 & 1,75 & 1,75 & 1,75 & 1,75 & 1,75 \\
\hline $\begin{array}{l}\text { Fuel Energy Density } \\
{[\mathrm{J} / \mathrm{kg}]}\end{array}$ & $2,57 \mathrm{E}+07$ & $2,57 \mathrm{E}+07$ & $2,57 \mathrm{E}+07$ & $2,57 \mathrm{E}+07$ & $2,57 \mathrm{E}+07$ & $2,57 \mathrm{E}+07$ \\
\hline $\begin{array}{l}\text { Engine Thermal } \\
\text { Efficiency [\%] }\end{array}$ & 30,00 & 30,00 & 30,00 & 30,00 & 30,00 & 30,00 \\
\hline Tire Rolling Drag [-] & 0,02 & 0,02 & 0,02 & 0,02 & 0,02 & 0,02 \\
\hline $\begin{array}{l}\text { Power Scaling Factor } \\
{[\%]}\end{array}$ & 100,00 & 100,00 & 100,00 & 100,00 & 100,00 & 100,00 \\
\hline $\begin{array}{l}\text { Aero Scaling Factor } \\
{[\%]}\end{array}$ & 90,00 & 90,00 & 90,00 & 90,00 & 90,00 & 90,00 \\
\hline Grip Scaling Factor [\%] & 100,00 & 100,00 & 100,00 & 100,00 & 100,00 & 100,00 \\
\hline $\begin{array}{l}\text { Mass Lateral Friction } \\
{[\mathrm{kg}]}\end{array}$ & 255,00 & 255,00 & 255,00 & 255,00 & 255,00 & 255,00 \\
\hline $\begin{array}{l}\text { Mass Longitudinal } \\
\text { Friction }[\mathrm{kg}]\end{array}$ & 255,00 & 255,00 & 255,00 & 255,00 & 255,00 & 255,00 \\
\hline Aero Efficiency [-] & 1,35 & 1,49 & 1,35 & 1,49 & 1,35 & 1,49 \\
\hline Rev Limit [rpm] & 10300,00 & 10300,00 & 10300,00 & 10300,00 & 10300,00 & 10300,00 \\
\hline Torque Data [kgf.m] & 0,00 & 0,00 & 0,00 & 0,00 & 0,00 & 0,00 \\
\hline RPM Data [rpm] & 0,00 & 0,00 & 0,00 & 0,00 & 0,00 & 0,00 \\
\hline Gear Ratio Data [-] & 0,00 & 0,00 & 0,00 & 0,00 & 0,00 & 0,00 \\
\hline Gear Shift Points [rpm] & 0,00 & 0,00 & 0,00 & 0,00 & 0,00 & 0,00 \\
\hline
\end{tabular}


Tabela D1 - Resultados das simulações do OptimumLap para comparação entre veículos RS8 e RS9. (Conclusão)

\begin{tabular}{l|c|c|c|c|c|c}
\hline Track & \multicolumn{2}{|c|}{ Reta $75 \mathrm{~m}$} & \multicolumn{2}{c|}{ Skid-pad (D18,25m) } & \multicolumn{2}{c}{ Enduro (Autocross) } \\
\hline Vehicle & RS8 & RS9 & RS8 & RS9 & RS8 & RS9 \\
\hline $\begin{array}{l}\text { Shift Point [1 to 2] } \\
\text { [rpm] }\end{array}$ & 9995,76 & 9995,76 & 9995,76 & 9995,76 & 9995,76 & 9995,76 \\
$\begin{array}{l}\text { Shift Point [2 to 3] } \\
\text { [rpm] }\end{array}$ & 9701,03 & 9701,03 & 9701,03 & 9701,03 & 9701,03 & 9701,03 \\
$\begin{array}{l}\text { Shift Point [3 to 4] } \\
\text { [rpm] }\end{array}$ & 9396,79 & 9396,79 & 9396,79 & 9396,79 & 9396,79 & 9396,79 \\
$\begin{array}{l}\text { Shift Speed [1 to 2] } \\
\text { [km/h] }\end{array}$ & 44,90 & 44,90 & 44,90 & 44,90 & 44,90 & 44,90 \\
$\begin{array}{l}\text { Shift Speed [2 to 3] } \\
\text { [km/h] }\end{array}$ & 60,76 & 60,76 & 60,76 & 60,76 & 60,76 & 60,76 \\
$\begin{array}{l}\text { Shift Speed [3 to 4] } \\
\text { [km/h] }\end{array}$ & 77,73 & 77,73 & 77,73 & 77,73 & 77,73 & 77,73 \\
$\begin{array}{l}\text { Top Speed [km/h] } \\
\text { Acceleration Time To }\end{array}$ & 104,67 & 121,56 & 104,67 & 121,56 & 104,67 & 121,56 \\
$\begin{array}{l}\text { Speed [100 km/h] [s] } \\
\text { Acceleration Time For }\end{array}$ & 6,99 & 4,56 & 6,99 & 4,56 & 6,99 & 4,56 \\
$\begin{array}{l}\text { Distance [100 m] [s] } \\
\text { Deceleration Time For }\end{array}$ & 5,48 & 5,30 & 5,48 & 5,30 & 5,48 & 5,30 \\
$\begin{array}{l}\text { Speed [100 km/h] [s] } \\
\text { Deceleration Distance }\end{array}$ & 1,40 & 1,54 & 1,40 & 1,54 & 1,40 & 1,54 \\
$\begin{array}{l}\text { For Speed [100 km/h] } \\
\text { [m] }\end{array}$ & 17,30 & 18,70 & 17,30 & 18,70 & 17,30 & 18,70 \\
$\begin{array}{l}\text { Shift Point [4 to 5] } \\
\text { [rpm] }\end{array}$ & 9396,79 & 9396,79 & 9396,79 & 9396,79 & 9396,79 & 9396,79 \\
$\begin{array}{l}\text { Shift Speed [4 to 5] } \\
\text { [km/h] }\end{array}$ & 97,13 & 97,13 & 97,13 & 97,13 & 97,13 & 97,13 \\
\hline
\end{tabular}


APÊNDICE E - PROPOSTAS PARA TRABALHOS FUTUROS 
A fim de dar continuidade à presente pesquisa, propõe-se refinar o modelo de veículo. Pode-se utilizar uma pista menos complexa que a de autocross, andar com o veículo instrumentado e comparar dados das acelerações lateral e longitudinal coletados com aqueles previstos em simulação.

Propõe-se também avaliar a influência da largura da pista nas simulações. Para isso, pode-se criar um modelo de pista de sua linha média, como feito no presente trabalho, e outro modelo com o traçado percorrido pelo piloto, via aquisição de dados. A aquisição pode ser feita por GPS ou pela combinação de acelerômetro e velocímetro, sendo este último método mais adequado ao programa OptimumLap.

Uma terceira proposta é aprimorar o modelo da prova de skid-pad, única que apresentou erro de tempo de volta acima do esperado. Pode-se avaliar a influência do momento de inércia de guinada, desprezado pelo programa aqui adotado.

Ao aluno integrante da equipe Fórmula FEI interessado em desenvolver o protótipo RS9, ou ainda o próximo veículo, fica a sugestão de avaliar alterações que poderiam melhorar seu tempo de volta. 